Materials Science and Engineering Laboratory

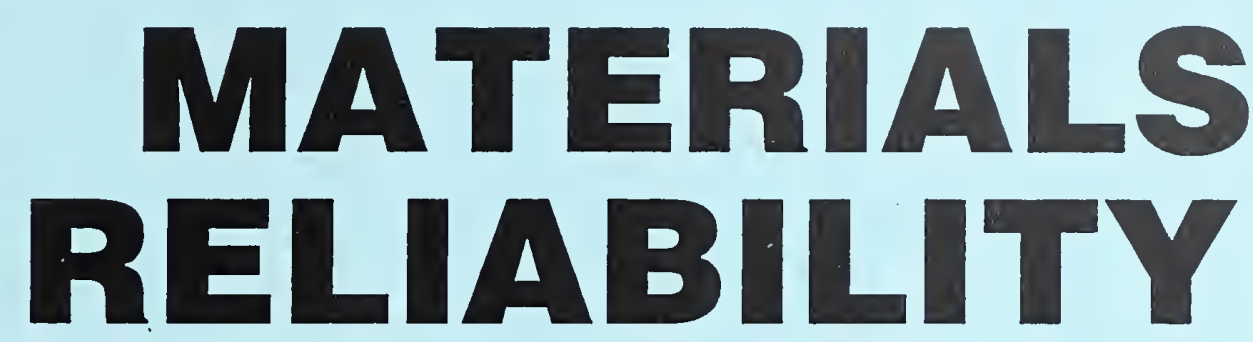

NAS-NRC

Assessment Panel

May 13-14, 1993

NISTIR 4965

U.S. Department of Commerce Technology Administration

National Institute of Standards and Technology
QC

100

.456

\#4965

1993



\title{
Technical Activities 1992
}


Experimental arrangement for using ultrasonic resonance spectroscopy to determine a material's complete elasticstiffness tensor $C_{i j}$ and internal friction $C_{i j}^{*}$ from any simple-shape specimen: sphere, disc, cylinder, cube, parallelepiped, and so on. 


\section{Materials Science and Engineering Laboratory}

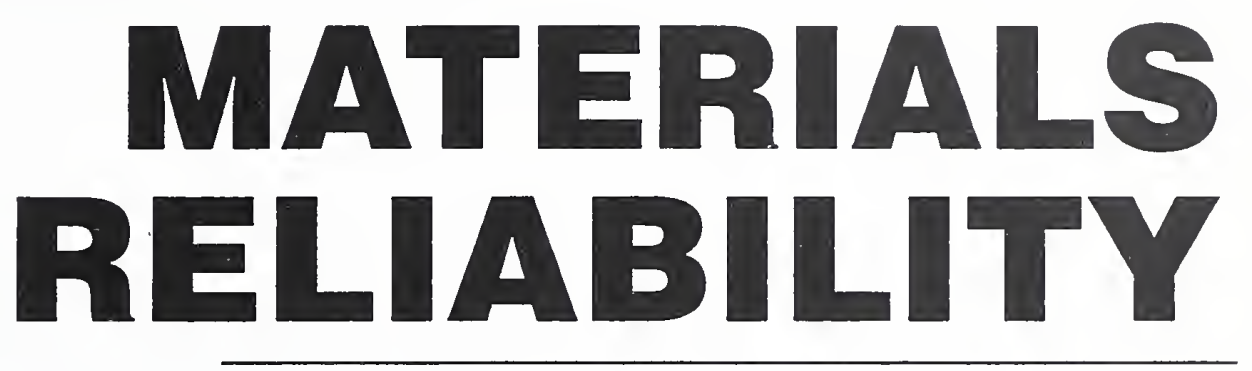

H.I. McHenry, Chief

C.M. Fortunko, Deputy

NAS-NRC

Assessment Panel

May 13-14, 1993

NISTIR 4965

U.S. Department of Commerce

National Institute of Standards

and Technology

\section{Technical Activities 1992}

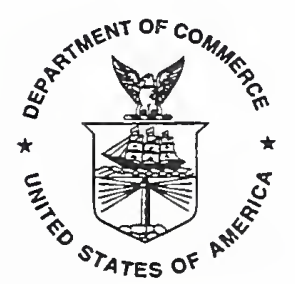



DIVISION ORGANIZATION • . • . . . . . . . . . . . . . . . IV INTRODUCTION • • • • • • • • • • • • • • • . • • • • • • • 1

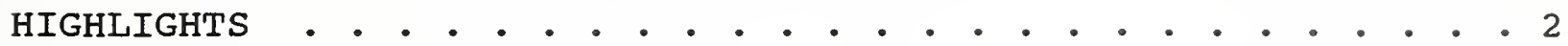

RESEARCH STAFF . . . . . . . . . . . . . . . . . . 3

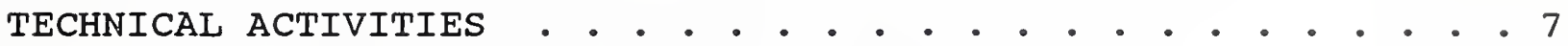

Materials Characterization . . . . . . . . . . . . 8

Ultrasonic Characterization . . . . . . . . . . 8

Physical Properties . . . . . . . . . . . 22

Micromechanical Measurements . . . . . . . . 29

Process Sensing and Modeling . . . . . . . . . . . 34

In-Process Sensing . . . . . . . . . . . . . 34

Nondestructive Evaluation . . . . . . . . . . 38

Thermomechanical Processing . . . . . . . . . 42

Structural Materials . . . . . . . . . . . . . 45

Welding . . . . . . . . . . . . . . . . 45

Standards . . . . . . . . . . . . . . . . 50

Cryogenic Materials. . . . . . . . . . . . 54

OUTPUTS AND INTERACTIONS • . . . . . . . . . . . . . 69

Selected Recent Publications . . . . . . . . . . . 70

Selected Technical and Professional Committee Leadership 82

Awards . . . . . . . . . . . . . . . . . . 83

External Recognition . . . . . . . . . . . . . . 84

Industrial and Academic Interactions . . . . . . . . . . 85

APPENDIX • . . . . . • . . . . . . . . . . . . . 94

Materials Reliability Division . . . . . . . . . . . 95

Materials Science and Engineering Laboratory . . . . . 96

National Institute of Standards and Technology . • . • 97 


\title{
DIVISION ORGANIZATION
}

\author{
Harry I. McHenry, Chief \\ (303) 497-3268 \\ Christopher M. Fortunko, Deputy \\ (303) 497-3062 \\ Kathy S. Sherlock, Administrative officer
}

(303) 497-3288

\author{
GROUP LEADERS \\ Materials Characterization \\ Christopher M. Fortunko \\ (303) 497-3062 \\ Process Sensing and Modeling \\ A. Van Clark, Jr. \\ (303) 497-3159
}

Structural Materials

Thomas A. Siewert

(303) 497-3523 


\title{
INTRODUCTION
}

\author{
MATERIALS RELIABILITY DIVISION \\ Harry I. McHenry, Chief \\ Christopher M. Fortunko, Deputy
}

\begin{abstract}
The Materials Reliability Division conducts materials research to improve the quality, reliability, and safety of industrial products and the nation's infrastructure. Our research fosters the use of advanced materials in commercial products by improving confidence in their service performance. We do this by developing measurement technology for:
\end{abstract}

1. process control which improves the quality, consistency and producibility of materials,

2. nondestructive evaluation (NDE) which assures the quality of finished materials and products,

3. fitness-for-purpose standards which relate material quality to reliability and safety, and

4. materials evaluation for severe applications, particularly for service at cryogenic temperatures.

Early in FY92, we reorganized the Division to build a stronger group structure. This report summarizes the Division programs, and it is organized according to the three groups:

\section{Materials Characterization \\ Process Sensing and Modeling \\ structural Materials}

No sooner had we reorganized than eight new staff members were transferred into the Division from the Chemical Engineering Division. The new staff have strengthened our expertise in cryogenic materials and have added new capabilities in thermal properties, oxygen compatibility, and friction and wear studies. The new staff were assigned to the structural Materials Group.

In support of the long-range plan of the Materials science and Engineering Laboratory, our programs focus on advanced materials with high commercial potential and on automated processing, which is the key to improved productivity in the materials industry. We also conduct materials research for other government agencies and provide technical services to industries, universities, and other scientific laboratories. 


\section{SELECTED HIGHLIGHTS}

Flexible Acoustic Array: A flexible array of ultrasonic transducers was used to detect defects in composite materials. Adaptive signal processing was used to overcome the effects of inhomogeneity.

Gas-coupled Acoustic Microscope: A high-pressure, gas-coupled acoustic microscope was completed and used to demonstrate the detection of internal anomalies in a complex electronic package.

Elastic Wave Propagation Modeling: A three-dimensional, wavelet representation for the elastodynamic Green's function was used to model elastic wave propagation in an anisotropic plate. The new theory facilitates computationally efficient, model-based interpretations of ultrasonic measurements.

Oxide Superconductors: We extended our $T_{c}-\theta_{D}$ relationship, found for La-O materials, to other systems: $\mathrm{Y}-\mathrm{O}, \mathrm{Bi}-\mathrm{O}$, and $\mathrm{Tl} \longrightarrow \mathrm{O}$. contrary to the BCS model, $T_{c}$ increases with increasing $\theta_{D}$ as increasing elastic stiffness.

Thin Film Testing: Electronic microfabrication techniques were developed to make multiple tensile specimens simultaneously. TiAl-Ti thin films were found to have low ductility and reduced fatigue life relative to bulk material.

Electron Beam Moiré: Electron beam lithography was used to write moiré grids with pitches down to $100 \mathrm{~mm}$. The specimens were loaded in a scanning electron microscope (SEM), and the SEM raster scan served as the reference grid. The E-beam moire has $5 x$ the resolution of optical moiré.

Residual stress Measurements: In cooperation with the American Association of Railroads (AAR), a comparison of destructive (by $A A R$ ) and nondestructive (by NIST) measurements of stresses in railroad wheels revealed excellent agreement in hoop stress values.

Intelligent Welding: our arc sensing system for monitoring weld quality from electrical signals was evaluated by the AC Rochester Division of General Motors under a CRDA. Based on positive results, $A C R$ is implementing the NIST technology in their production operations.

Radioscopy standard: An X-ray stage calibration board, Standard Reference Material (SRM) 1842, was developed and made available for checking the accuracy of $X$ and $Y$ translation stage encoders or the uniformity of the field of view of automated X-ray systems.

Composite Materials: The mechanical behavior in compression of glass-epoxy composite materials was investigated in a program to evaluate tubular composite struts for use in the superconducting magnetic energy storage (SMES) system. 


\title{
RESEARCH STAFF
}

\author{
Austin, Mark W. \\ - Radioscopy \\ - Elastic properties \\ - x-ray diffraction

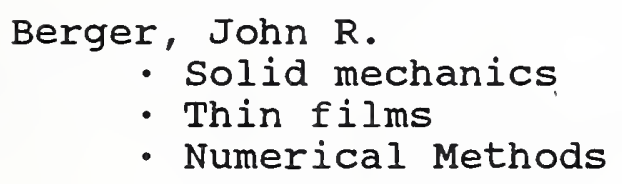

Drexler, Elizabeth S.

- Materials properties at low temperatures

- Database management

- Micromechanical property measurement

Dubé, William P.

- Thermal conductivity

- Ultrasonics

- Electromechanical instruments

Filla, James B.

- Thermal conductivity

- High temperature measurements

- oxidation of metals 
Fitting, Dale W.

- Sensor arrays for NDE

- Ultrasonic and radiographic NDE

- NDE of composites

Fortunko, Christopher M.

- Ultrasonic transducers and instrumentation

- Nondestructive evaluation

- Analog measurements

Kim, sudook

- Elastic properties

- Low-temperature physical properties

- Ultrasonics

Ledbetter, Hassel $\mathrm{M}$.

- Physical properties of solids

- Theory and measurement of elastic constants

- Martensite-transformation theory

Lin, Ing-Hour

- Electronic materials

- Physics of fracture

- Dislocation theory

Madigan, R. Bruce

- Welding engineering

- Welding process sensors

- Process control

McColskey, J. David

- Cryogenic materials

- Composite materials

- Mechanical testing

McCowan, Chris N.

- Welding metallurgy

- Mechanical properties at low temperatures

- Metallography and fractography

McHenry, Harry I.

- Fracture mechanics

- Low-temperature materials

- Fracture control

Purtscher, Patrick T.

- Fracture properties of metals

- Metallography and fractography

- Mechanical properties at low temperatures 


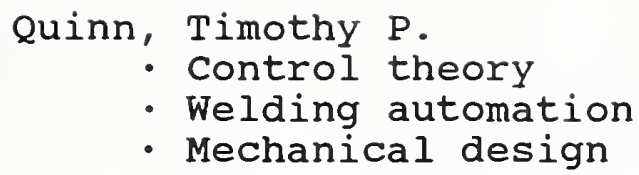

Read, David T.

- Electronic packaging

- Elastic-plastic fracture mechanics

- Mechanical properties of metals

Rule, Dennis L.

- Thermal conductivity

- Mechanical testing

- Composite materials evaluation

Schaps, Stephen R.

- Electrical design

- Nondestructive evaluation

- Capacitance sensors

Schramm, Raymond E.

- Ultrasonic NDE of welds

- Ultrasonic measurement of residual stress

- Electromagnetic acoustic transducers

Shepherd, Dominique A.

- Charpy impact testing

- Metallography and fractography

- Thermomechanical processing

Siewert, Thomas A.

- Welding metallurgy of steel

- Gas-metal interactions during welding

- Welding database management

Simon, Nancy $\mathrm{J}$.

- Material properties at low temperatures

- Database management of material properties

- Handbook of material properties

Slifka, Andrew J.

- Friction and wear

- Tribological coatings

- Surface characterization

Smith, David R.

- Thermal conductivity

- Thermal expansion

- Low-temperature physics 
Sparks, Larry L.

- Cryogenic materials

- Thermophysical properties

- Materials evaluation

Tobler, Ralph L.

- Fracture mechanics

- Material properties at low temperatures

- Low-temperature test standards

Vigliotti, Daniel P.

- Charpy impact testing

- Standard reference materials

- Fabrication technology

Walsh, Robert $\mathrm{P}$.

- Mechanical properties at low temperatures

- Mechanical test equipment

- Large scale testing

Yukawa, sumio

- Fracture mechanics

- Codes and standards

- structural safety 
TECHNICAL ACTIVITIES 


\section{MATERIALS CHARACTERIZATION}

Christopher M. Fortunko, Group Leader

The Materials Characterization Group develops experimental methods for measuring the properties and characterizing the quality of materials, particularly complex materials such as composites, thin films and superconductors. The Group has three program areas.

1. Theory, modeling and measurement technology for the ultrasonic characterization of materials,

2. Measurements and modeling of elastic constants and related physical properties, and

3. Micromechanical measurements of material behavior in electronic packaging.

\section{ULTRASONIC CHARACTERIZATION OF MATERIALS}

C.M. Fortunko, D.W. Fitting, V.K. Tewary*, M.A. Hamstad**, W. Dubé, E. Boltz, and M. Renken

our research in ultrasonic characterization of materials is aimed at developing quantitative methods for determining material properties and flaw detection and sizing. Our current emphasis is on polymer-matrix composite materials. Because composite materials are typically inhomogeneous and elastically anisotropic, ultrasonic methods developed for characterization of metals are often inapplicable. To overcome this problem, we are pursuing a multidisciplinary approach that directly addresses the complexities of ultrasonic signal propagation, transduction, and data interpretation. To extend the effort, we are engaged in a range of collaborative efforts involving universities, government agencies, and selected industrial organizations.

\section{Significant Accomplishments}

A flexible array of "point-source, point-receiver" ultrasonic transducers was completed and tested to demonstrate detection of simulated defects in a thick polymer-composite plate. Adaptive signal processing was used to overcome the effects of material elastic anisotropy and inhomogeneity.

- A high-pressure, gas-coupled acoustic microscope was completed and used to demonstrate the detection of internal anomalies in a complex electronic package.

* Visiting Scientist from ohio state University.

** Visiting Professor from University of Denver. 
- A three-dimensional, wavelet representation for the elastodynamic Green's function was used to model elastic wave propagation in an anisotropic plate. The new theory facilitates computationally efficient, model-based interpretations of experimental data.

Considerable progress was made towards the development of broad band, waveform-based instrumentation for waveform-based acoustic emission ( $\mathrm{AE}$ ) studies in polymer composites.

\section{Adaptive Array Imaging in Inhomogeneous Media}

Conventional ultrasonic array imaging is based on the ability to compensate for the differential delays of a spherical wavefront detected over the transducer array. Thus, when the received ultrasonic signals are coherently added, they add constructively. Such coherent delay-and-sum imaging performs satisfactorily if the scatterers are embedded in a medium of constant sound velocity. In inhomogeneous or anisotropic composites, the time delays may not be proportional to path lengths. To overcome this effect, an adaptive algorithm has been formulated which compensates for random signal time shift variations.

To demonstrate the performance of the algorithm, a laboratory prototype array has been developed. "Point-source" transmitters broadcast broad-directivity ultrasonic fields into the composite. Backscattering from features in the interior of the material is sensed by a 32-element array of broadband, wide-field-of-view receivers. Tests of the adaptive algorithm on simulated scattering data and on the experimental data gathered with the new array show an improved ability to detect scatterers in the composite over conventional delay-and-sum imaging.

A block diagram of the "point-source" array and signal acquisition system is shown in Figure 1. The array uses a flexible, drycoupled approach that facilitates data collection in specimens of different shape and surface condition. Currently, 1 mm-diameter elements, spaced in $2.54 \mathrm{~mm}$ intervals, are used. Through careful design and fabrication, a high degree (less than $3 \mathrm{~dB}$ ) of arrayelement response uniformity was achieved in the $200 \mathrm{kHz}-2 \mathrm{MHz}$ frequency region. Waveform data from each element is digitized to 8-bit resolution with a $100 \mathrm{MSample} / \mathrm{s}$ instrument. A $20 \mathrm{MSample} / \mathrm{s}$, 12-bit instrument is also available.

To evaluate the performance characteristics of the array, simulated ultrasonic data were generated in an inhomogeneous medium. Figure 2 shows reconstructions performed using the new adaptive algorithms and conventional delay-and-sum algorithms. 


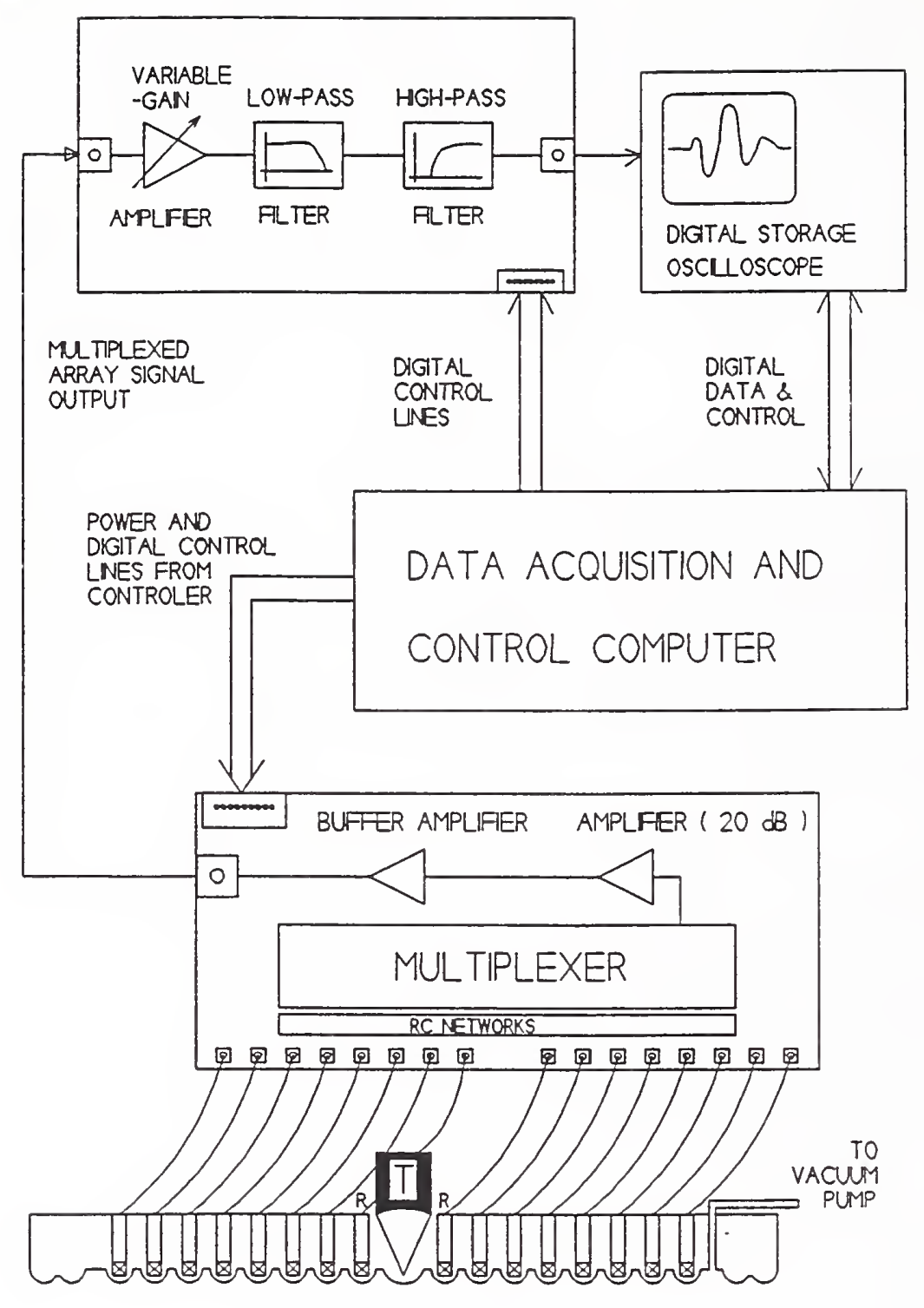

Figure 1. Block diagram of NIST flexible, dry-coupled ultrasonic array for composite-material characterization. 

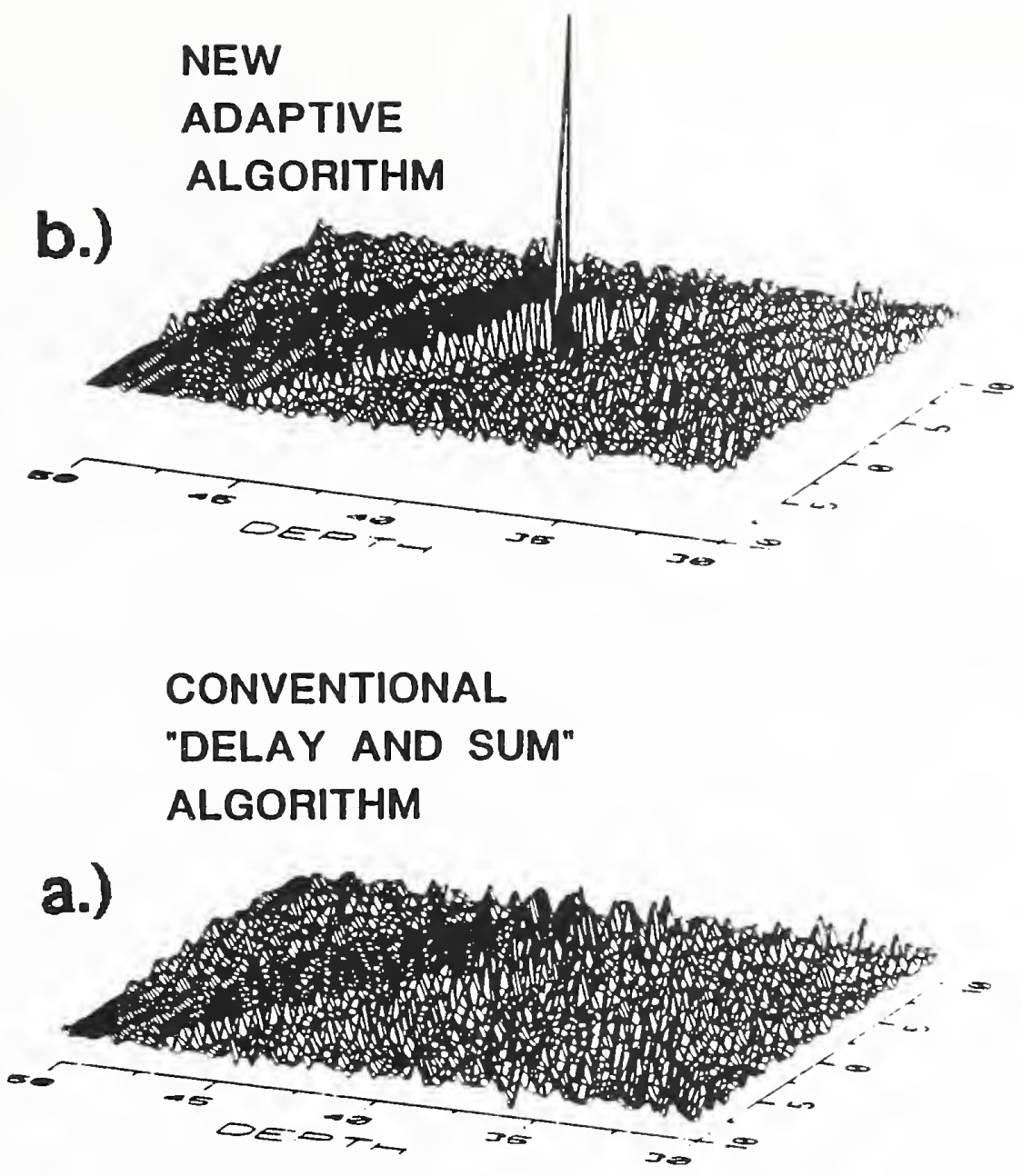

Figure 2.

Completed array performance (point defect) using the new adaptive algorithm and conventional delayand-sum algorithm.

Figure 3 shows reconstructions of experimental array data acquired in a glass/thermoplastic composite test block containing artificial defects. The defects were $2 \mathrm{~mm}$-diameter side-drilled holes. Figure $3 a$ is a cross-sectional diagram of the test block. Figure $3 \mathrm{~b}$ shows images reconstructed using the adaptive algorithm described earlier. The vertical scale for the reconstructions has been exaggerated. The adaptively reconstructed images clearly show the defects, whereas conventionally-processed images were obscured by background clutter.

The experimental results depicted in Figure 3 demonstrate the power of the "point-source" array, adaptive algorithm approach. It is believed that this approach will find important applications in the characterization of thick composite structures. Other applications are also likely. For example, the approach may be inherently compatible with concrete structures. 


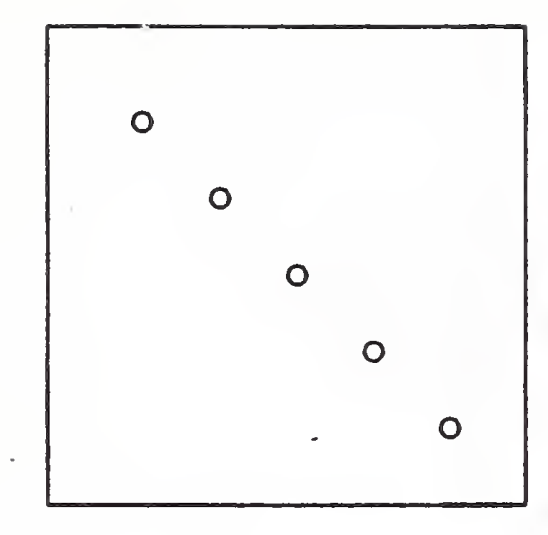

3a. BLOCR

Z-SECTIONS

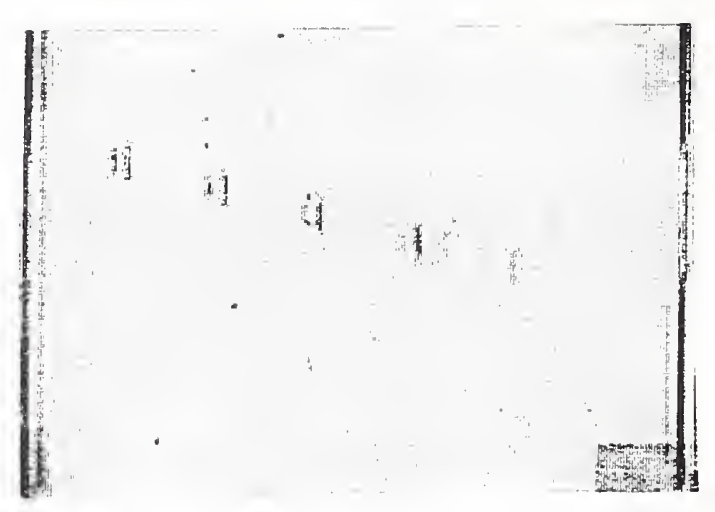

3b. ADAPTIVE

RECONSTRUCTIONS

Figure 3. Results of adaptive and correctional
reconstructions performed using data from a thick
glass/thermoplastic plate containing artificial
defects. High-Fidelity Sensor/Preamplifier Subsystems

Since the middle of the 1970's, a considerable quantity of theoretical work has been carried out to lay the scientific basis for quantitative interpretation of acoustic-emission (AE) measurements. Work by Pao et al. (J. Acoust. Soc. Am. 65 [1], 1979) brought attention to other important aspects of quantitative $\mathrm{AE}$. The experimental studies designed to validate the early $\mathrm{AE}$ theoretical work relied on artificial sources of $\mathrm{AE}$ waveforms (e.g., pencil-lead or glass-capillary breaks) and, in a few cases, on near-field monitoring of naturally-occurring $A E$ events. The results of the early theoretical and experimental studies clearly demonstrated that accurate $\mathrm{AE}$ source location and characterization requires the use of broadband, "point-contact" AE sensors in conjunction with an appropriate wave-propagation theory.

In the majority of practical applications, the amplitudes of naturally-occurring $A E$ events are considerably smaller than those produced by artificial $A E$ sources. In recognition of this fact, a recently-introduced, commercial $A E$ preamplifier offers a $45 \mathrm{~dB}$ gain-reduction option for pencil-break calibrations. Furthermore, "resonant" AE sensors are commonly used to increase the sensitivity. Unfortunately, most $A E$ measurements made using such sensors are not useful for accurate AE source location and material characterization purposes. To make waveform-based AE source 
location and characterization practical, sensitive and broadband $A E$ sensors are needed.

The purpose of our work was to maximize the sensitivity and bandwidth capabilities of high-fidelity ultrasonic sensors intended to operate in the $10 \mathrm{kHz}-2 \mathrm{MHz}$ region. As a part of the study, we also investigated those aspects of sensor design that would cause distortions of the received $\mathrm{AE}$ signals.

A computer model has been used to evaluate the suitability of five piezoelectric materials for use in broadband (10 $\mathrm{kHz}-2 \mathrm{MHz}$ ) $\mathrm{AE}$ "point" sensors. The computer model accounts for the effects of the electrical loading of the piezoelectric material by the input impedance of the preamplifier and the mechanical loading by the specimen and backing materials. We compare the model predictions with results of measurements which are normalized using the NIST Standard Reference Material (SRM) "conical" transducer. The effects of selecting different piezoelectric materials (PZT-5A, lead metaniobate, $\mathrm{X}$-cut quartz, $36^{\circ} \mathrm{Y}$-cut $\mathrm{LiNbO}_{3}$, and PVDF) and transducer configurations ("pinducer" vs. "conical") are evaluated experimentally and analytically.

Figure 4 shows the experimental configuration used in our studies to determine the time-domain response characteristics of the pinducer containing different piezoelectric materials. A large $(1.2$ by $1.5 \mathrm{~m})$ aluminum plate, $3.175 \mathrm{~mm}$ in thickness, was used as the propagation medium. In the configuration of Figure 4, the acoustic test signals were generated using a simulated AE source $(0.3 \mathrm{~mm}$ dia., $2 \mathrm{H}$ pencil lead). The test signals were received simultaneously using the pinducer and a "reference" broadband AE surface displacement sensor.

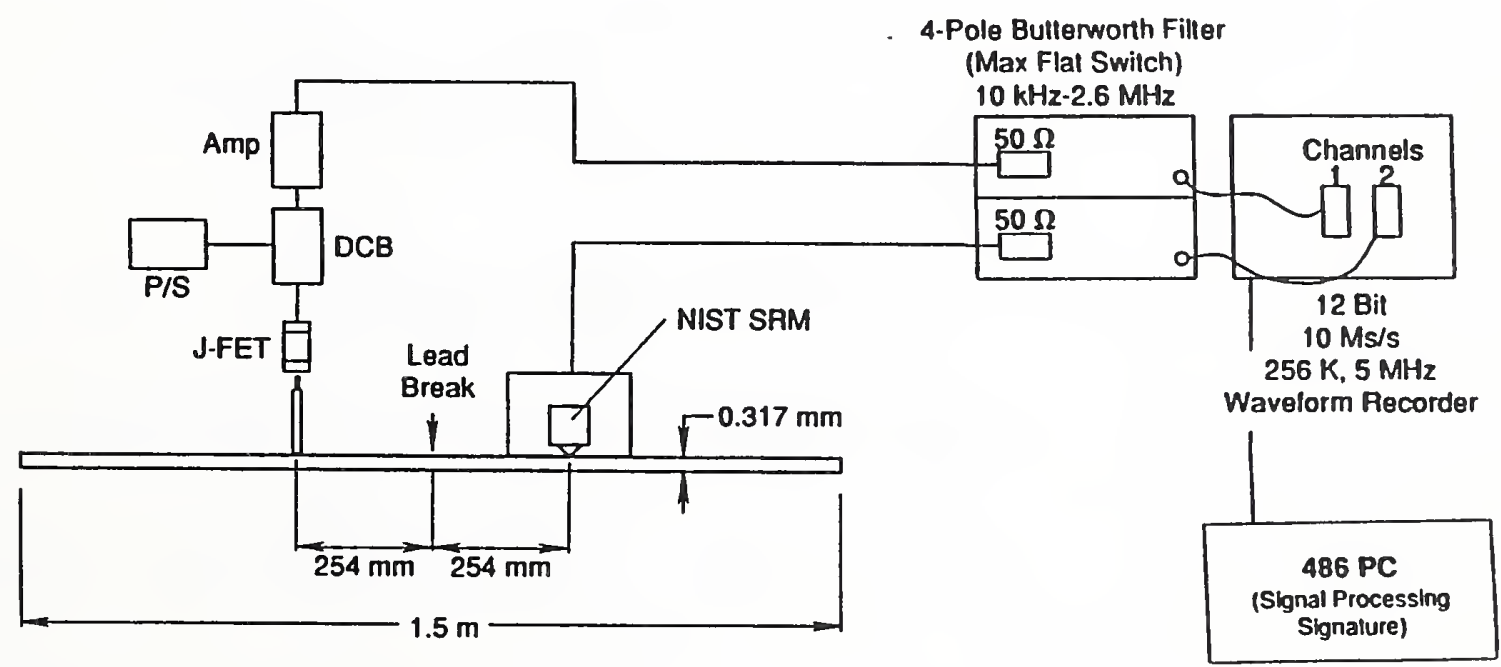

Figure 4 .

Experimental configuration used to evaluate performance of various $A E$ "point" sensors. 
Figure 5 shows typical waveforms obtained with pinducers using the five different piezoelectric materials and the NIST SRM sensor, using the measurement configuration of Figure 4. It is interesting to note that the waveform obtained using the NIST SRM sensor closely resembles that calculated from the theory by spicer et al. on the other hand, the waveforms obtained using the five pinducers appear to exhibit various distortions. The waveform obtained with the PVDF pinducer most clearly resembles that obtained using the NIST SRM sensor.

\section{Normalized Pinducer Responses}

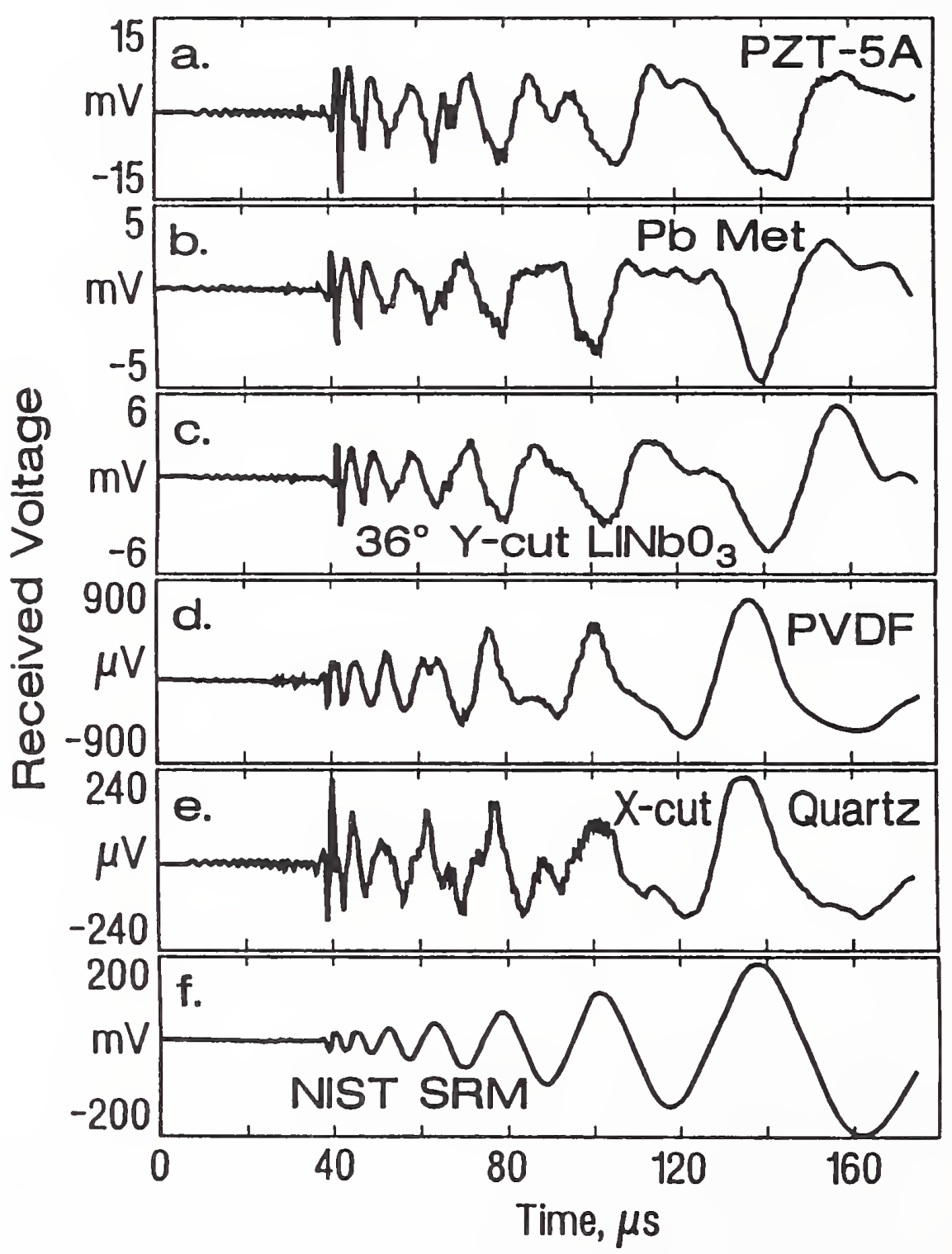

Figure 5. Time-domain responses of five pinducer designs and NIST SRM "conical" sensor. 
Figure 6 shows the results of a calculation designed to estimate the absolute sensitivity of four different pinducers: (1) PZT-5A, (2) lead metaniobate, (3) $36^{\circ} \mathrm{Y}$-cut $\mathrm{LiNbO}_{3}$, and (4) X-cut quartz. In this case, the smallest detectable harmonic particle velocity, "noise equivalent velocity," is plotted as a function of the frequency, assuming that the instantaneous bandwidth of the sensor is $20 \mathrm{kHz}$. It is seen that the PZT-5A pinducer exhibits the highest sensitivity. In fact, the sensitivity of the PZT-5A pinducer approaches the fundamental limit (set by thermal fluctuation within the specimen) in the $100 \mathrm{kHz}$ region.

\section{Pinducer Response Sensitivities (Reception)}

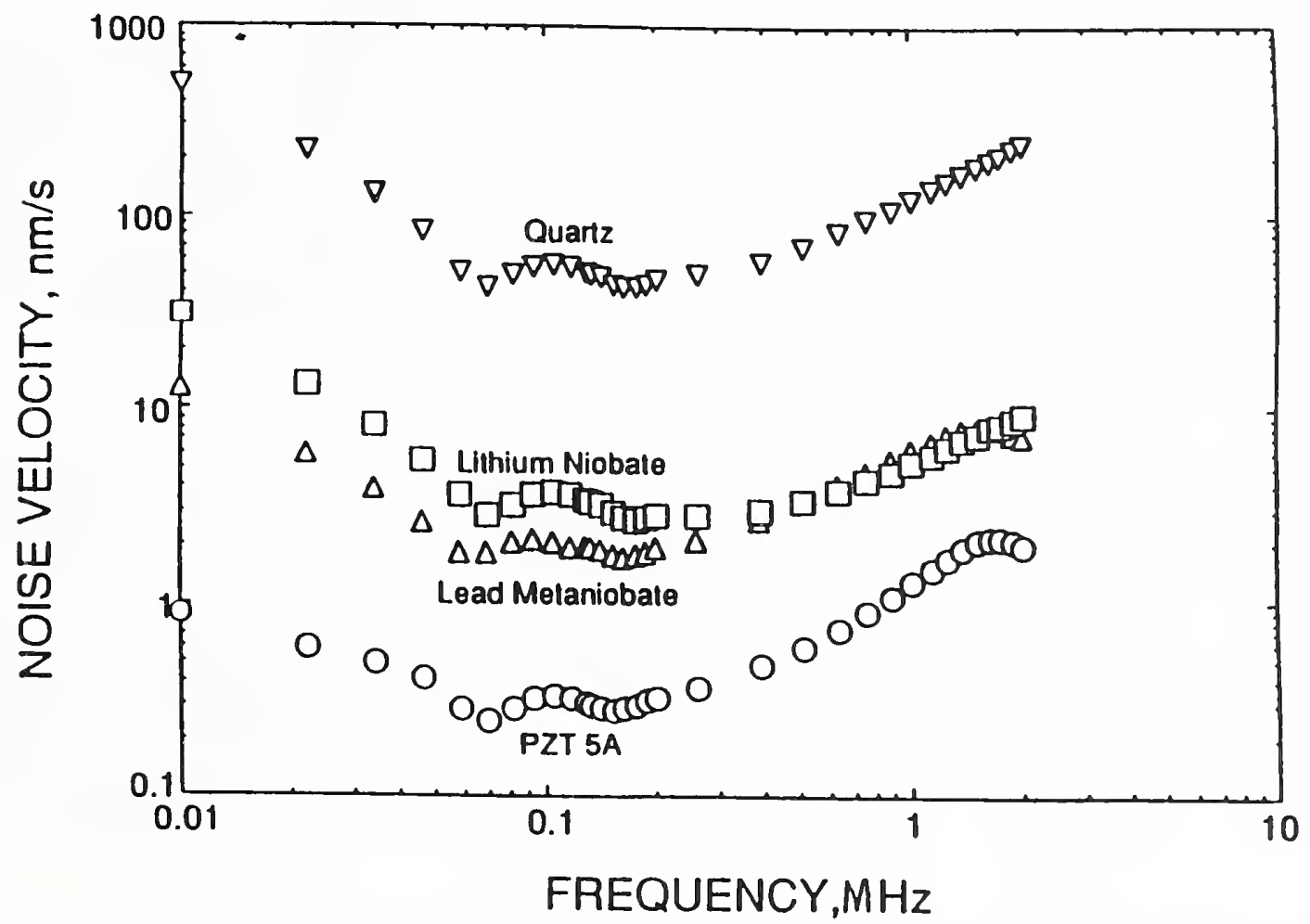

Figure 6. Calculated "noise equivalent velocities" of four different pinducer designs.

It is expected that our new wideband sensor/preamplifier subsystems will play a critical role in our future material characterization work.

Through Transmission Gas-Coupled Ultrasonics in Electronic Packaging and Composite Materials

Quality control for electronic packaging requires high resolution imaging of internal flaws, in particular the detection of delaminations and cracks. It has been shown that liquid coupled scanning acoustic microscopy can give high resolution images in 
electronic materials. These images enable internal flaws to be detected. The problem is then that current acoustic microscopes employ a liquid couplant and some electronic packages cannot be immersed in a liquid.

The use of gas coupling eliminates the need for immersion in a liquid and this also gives improvements in resolution, because the velocity in a gas such as argon is one fifth of that for water (about $330 \mathrm{~m} / \mathrm{s}$ vs. $1500 \mathrm{~m} / \mathrm{s}$ ). The operation of the system at high pressures then reduces the attenuation in the gas to a level where it is comparable with that for many liquids. For $20 \mathrm{MHz}$ ultrasound in air, the attenuation is $65 \mathrm{~dB} / \mathrm{mm}$ at standard temperature and pressure, and this is reduced to $0.22 \mathrm{~dB} / \mathrm{mm}$ at $10 \mathrm{MPa}$.

The enabling technologies which made the success of the current project possible were: higher power ultrasonics, including new transducers, new materials (lithium niobate) and novel designs; higher power transmitters, operating in a tone burst mode at higher frequencies; impedance matching for both the electrical and acoustic parts of the system, and low noise electronics, including a custom preamplifier. In addition, the technology is combined with the observation that the attenuation for ultrasonic waves in gases is a strong function of pressure and it is reduced as the pressure is increased.

The acoustic microscope was designed and built at NIST. The heart of the microscope is a measurement stage which fits inside a pressure vessel. The various motions were purchased and combined in custom mounts set onto the measurement stage.

The measurement stage (Figure 7) has two transducers mounts and a sample mount. The transmitter mount is a five degree-of-freedom unit with has manual $X, Y, Z$ and pitch and yaw. The sample mount is also a five degree-of-freedom unit which has XYZ and pitch and yaw, all under computer control. The receiver mount has manual XY motions and $\mathrm{Z}$ motion under computer control.

To demonstrate the feasibility of gas-coupled ultrasonic microscopy at $40 \mathrm{MHz}$ and higher, we selected a commercial "flip-chip" that had been previously imaged using a state-of-the-art water-coupled ultrasonic microscope. The package was also radiographed. The "flip-chip" was known to contain specific anomalies, such as "popcorn" cracks and delaminations. The presence and locations of all of the known anomalies were positively confirmed using the new gas-coupled microscope. A portion of an ultrasonic scan, showing a delaminated area, is shown in Figure 8 . 


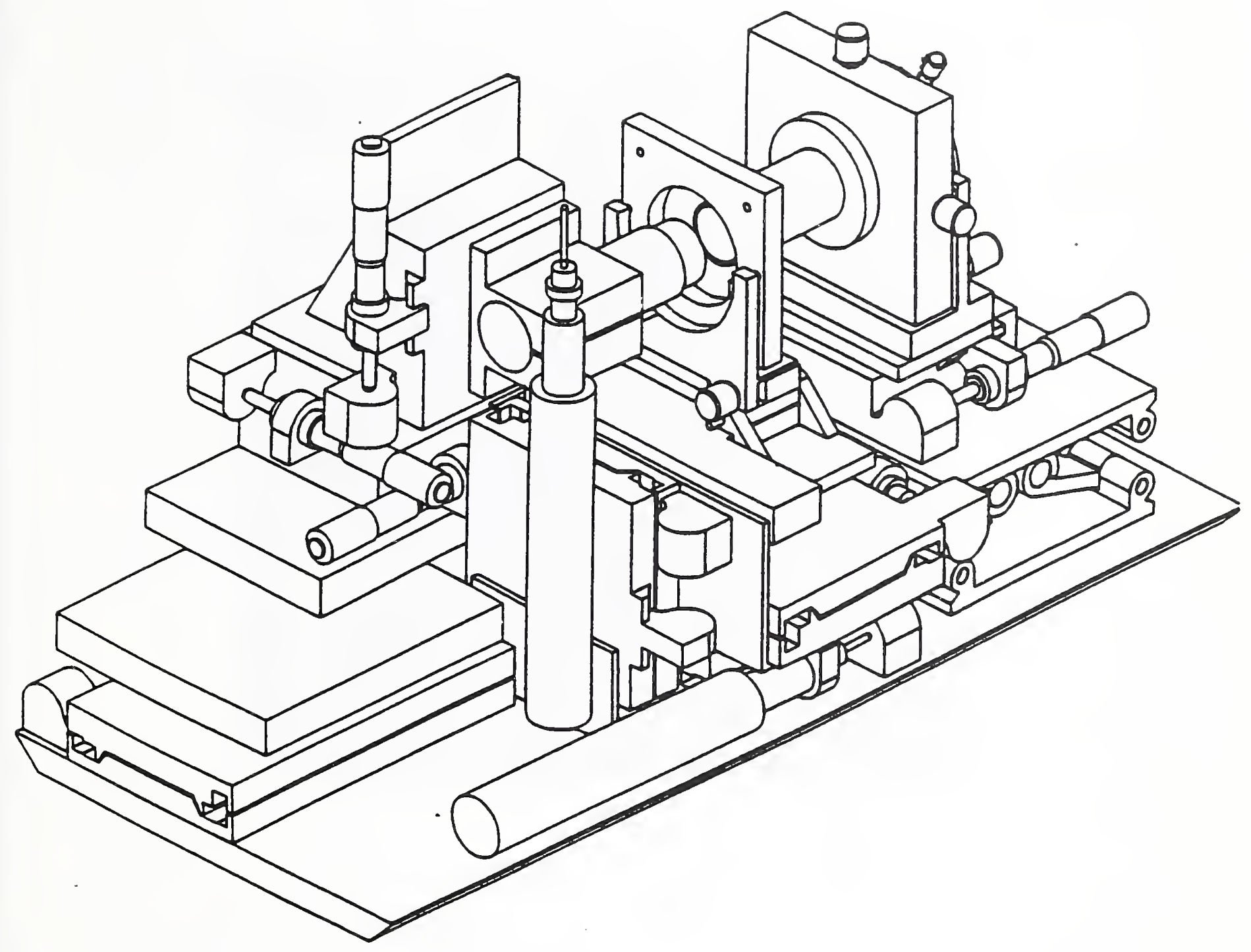

Figure 7. Measurement stage for gas-coupled transmission acoustic microscope. 


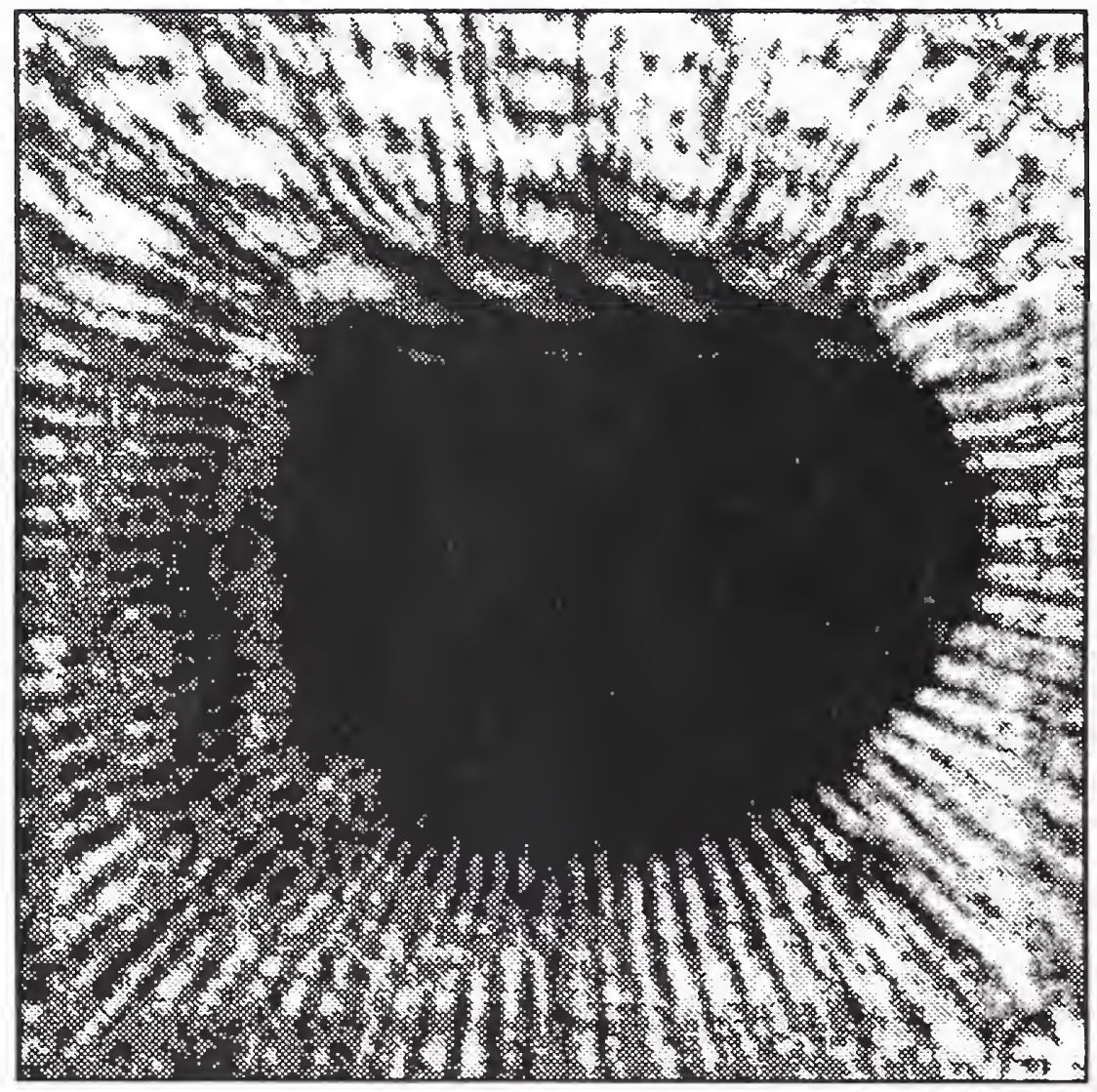

Figure 8 . Gas-coupled transmission microscope image of a portion of a "flip-chip," showing areas of delamination between the silicon die and the ceramic substrate. 
Gas-coupled acoustic microscopy clearly has many possible applications. When operating at $20 \mathrm{MHz}$, the system has the same resolution as a water-coupled system operating at $100 \mathrm{MHz}$. Microscopy at this frequency has a 15 micron wavelength which makes it useful in a number of electronic packaging applications. The current system could be modified to operate up to 40 or $45 \mathrm{MHz}$, which yields a $7.5 \mathrm{micron}$ wavelength. These frequencies give an instrument which is suited to inspection for electronic packaging applications. We are currently investigating other applications of the new instrument. These include characterization of films, magnetic storage media, and possibly, functionally-gradient materials.

\section{Wavelet Representation for Elastodynamic Green's Function}

We have developed a wavelet representation for the elastodynamic Green's function in an anisotropic solid. We have already applied this representation to calculate the elastic wave propagation characteristics of an anisotropic half-space solid (see J. Acoust. Soc. Amer. vol 91, p. 1888, 1992). Presently, we are applying it to an anisotropic 3-dimensional plate. With this representation we can now do detailed and precise calculations of ultrasonic waveforms in anisotropic materials.

We write the space-time dependent Green's function in terms of wavelets $1 /(q \cdot x+t+i \epsilon)$ in the form

$$
G(x, t)=1 /(2 \pi)^{3} \operatorname{Lim}_{\epsilon \rightarrow+0} \int \hat{G}(q)[1 /(q \cdot x+t+i \epsilon)] d q
$$

where $\mathrm{n}$ is an integer, $\mathrm{x}$ and $\mathrm{t}$ are the space and time coordinates and $\mathrm{q}$ is a slowness vector. The mathematical advantage of the wavelet representation is that it gives the time dependence of the Green's function directly, unlike the Fourier representation which requires a numerical integration over frequencies. In the conventional Fourier transform method, one has to evaluate numerically a 4-D integral--over 3 wave vectors and frequency. In the wavelet representation, only a 3-D integral (over 3 components of slowness vectors) needs to be evaluated. Even out of these 3 , integration over only one variable can be done analytically. Thus, only a 2-D integral needs to be done numerically. This reduces the computation time by an order of magnitude.

For a half-space solid or a plate, we include secondary sources of wavelets to satisfy the surface boundary conditions. When a wavelet strikes a discontinuity, such as a surface, it induces secondary sources of wavelets. The strength of these sources determine the waveforms in the solid. Our preliminary results are given in Figure 9. Although our formulation is for general 


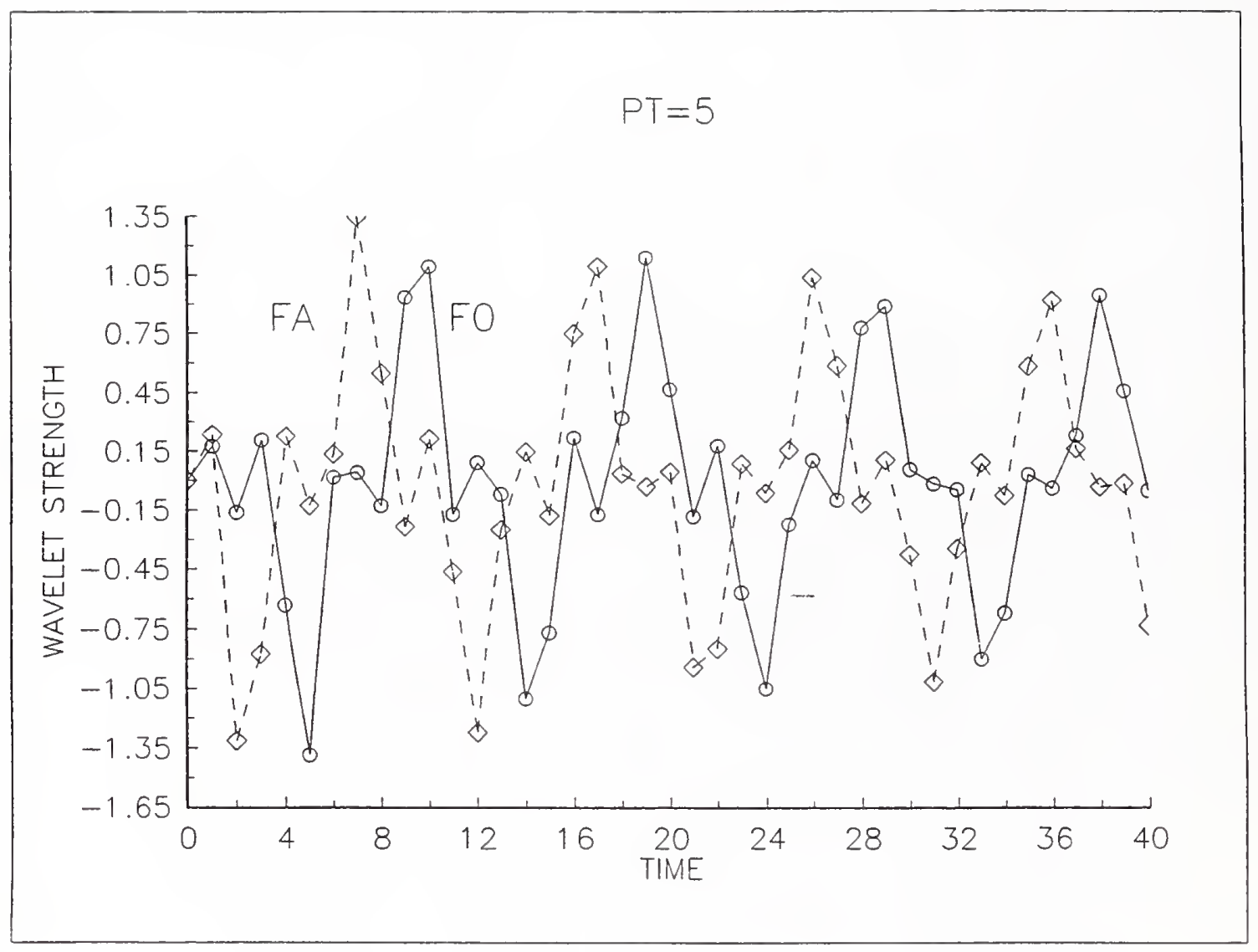

Figure 9.

Wavelet strength as a function of time calculated for delta-function excitation of an isotropic plate. $\left(F_{O}\right.$ and $F_{A}$ represent the wavelets generated at, respectively, the front and rear surfaces of the plate.) 
anisotropic plates, the results given here are for a model isotropic plate. The units are chosen such that the transverse wave velocity is unity and the longitudinal wave velocity is about 2. A delta function pulse is applied at the front surface $(x=0)$ of the plate at $t=0$.

When a wavelet generated from the applied source reaches the back surface, it induces a source of wavelets of strength $F_{A}$ at the back surface. When, after reflection, the wavelet comes back to the front surface, it induces another source of strength $F_{0}$. The temporal variations of these source-strengths are shown in Figure 9 for a plate of thickness $\mathrm{P}_{\mathrm{T}}=5$.

Multiple peaks in the induced source-strength curves show multiple reflections. The shape of the induced peaks is similar to the source peak. After each reflection, the peaks broaden showing dispersion. The peaks in $F_{A}$ occur at $t=2.5,7.5,12.5 \ldots$, whereas the peaks in $F_{0}$ occur at $t=5,10,15 \ldots$ The position of each peak is consistent with the fact that the wave takes 2.5 units of time to travel from one surface to the other.

We are now applying this representation to calculate the detailed waveforms in anisotropic plates which will be measured in our laboratory. The wavelet representation, combined with our Green's function formulation, will enable us to build analytical models of wave propagation in anisotropic homogeneous materials as well as inhomogeneous materials containing interfaces such as plates with coatings and multilayer materials. 


\section{PHYSICAI PROPERTIES}

H. Ledbetter, D. Balzar*, M. Földeáki**, S. Kim

our research emphasizes measurements and modeling of elastic constants and related physical properties of metals, alloys, composites, ceramics, and the new high- $\mathrm{T}_{\mathrm{c}}$ oxide superconductors. For many studies, the temperatures range between 295 and $4 \mathrm{~K}$. The elastic constants, which relate deformation to stress, sustain our interest because they relate to fundamental solid-state phenomena: interatomic potentials, equations of state, and phonon spectra. Furthermore, thermodynamics links elastic constants with specific heat, thermal expansivity, atomic volume, and the Debye temperature.

In recent years, our research efforts fell into four categories:

1. austenitic steels,

2. composite materials,

3. high-T oxide superconductors,

4. other materials, studies.

\section{significant Accomplishments}

- For a 316LN austenitic stainless steel, we showed the equivalence of dynamic and static Young moduli.

Among eighteen resinous polymers, we found a nearly constant Poisson ratio: $\nu=0.385 \pm 0.008$.

For cast iron, for the first time, we explained quantitatively the strong dependence of elastic constants on graphiteparticle aspect ratio.

In $\mathrm{Y}_{1} \mathrm{Ba}_{2} \mathrm{Cu}_{3} \mathrm{O}_{7}$, we found an unusually large (factor of two) change in bulk modulus with temperature. We hypothesized that this reflects a change in oxygen-atom order, which affects superconducting properties.

We gave a theoretical basis for an observed relationship between volume change and the thermal-expansivity tensor's value.

* Visiting scientist from Physics Department, Faculty of Metallurgy, University of Zagreb, Croatia.

* Visiting scientist from Institute for Materials Testing and Quality Control, Budapest. Now at Physics Department,

University of Colorado. 


\section{Austenitic steels}

1. Dynamic-static Young modulus: A case study.

For one material, a 316LN austenitic steel, we compared critically the Young modulus measured statically in usual commercial equipment with that measured dynamically at megahertz frequencies. The first gives a $\pm 6 \%$ uncertainty; the second a $\pm 0.5 \%$ uncertainty. The two Young moduli, 207 (static) and $202 \mathrm{GPa}$ (dynamic), agree within the statistical bounds of the static measurement, 195 and $219 \mathrm{GPa}$, the extreme static values being 178 and $229 \mathrm{GPa}$. We summarized the simple thermodynamics that shows the difference between staticdynamic elastic constants. We hope this study serves to dispel the common view that dynamic and static Young moduli differ and that dynamic values always exceed static. Figure 10 shows the difference expected from simple thermodynamics.

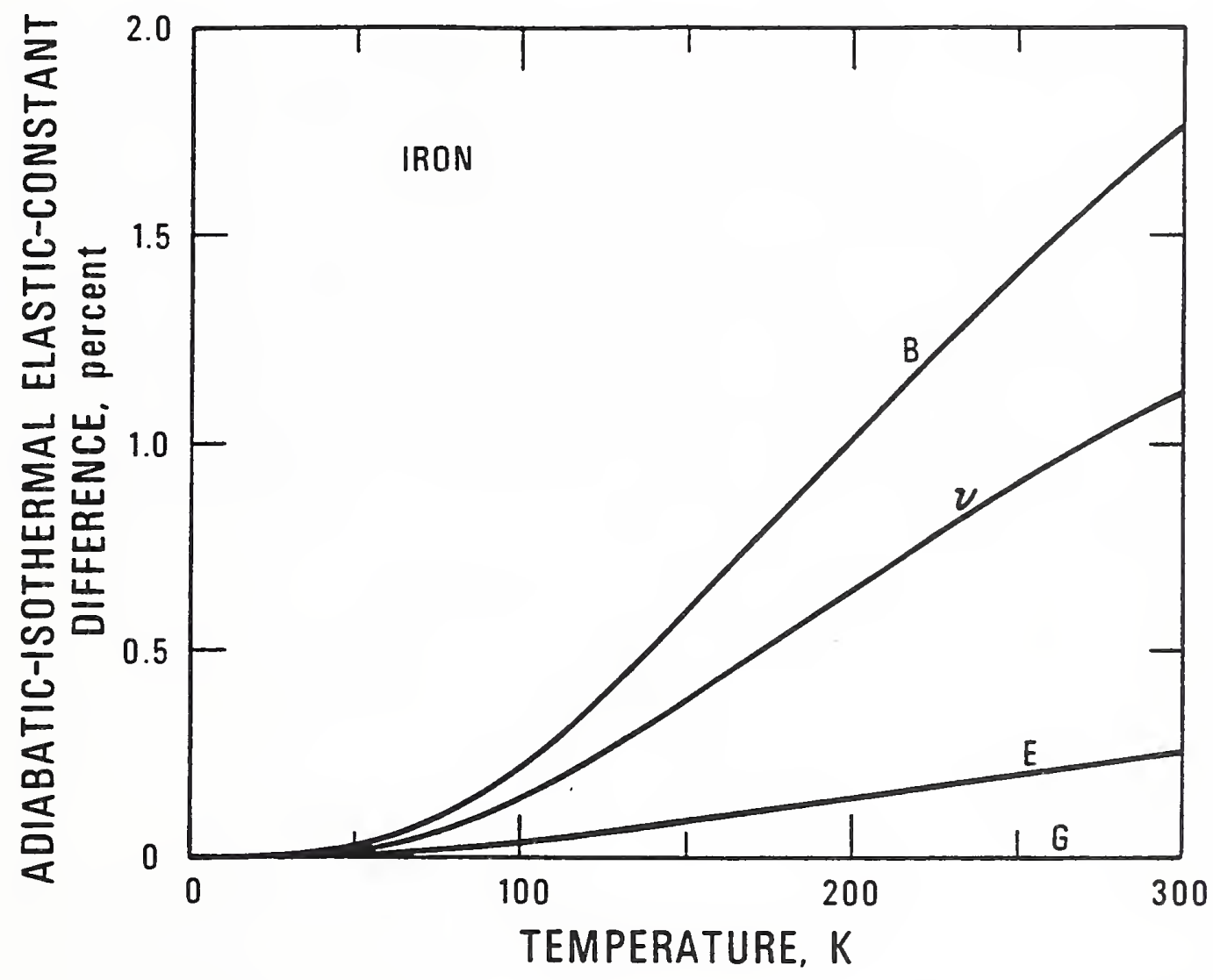

Figure 10. For iron, difference between adiabatic and isothermal elastic constants as a function of temperature. For dispersionless materials, this represents the expected difference between dynamic and static elastic constants. B denotes bulk modulus, $\nu$ Poisson ratio, E Young modulus, G shear modulus. 


\section{Composite materials}

1. Dynamic elastic properties of eighteen resinous polymers.

2. Elastic constants of a $\gamma-\mathrm{Al}_{2} \mathrm{O}_{3}-\mathrm{SiO}_{2}$ (fiber)/PEEK composite.

3. Elastic constants of $\mathrm{SiC}_{\mathrm{w}} / \mathrm{Al}_{2} \mathrm{O}_{3}$ composites.

4. Temperature-dependent Young modulus of a $\mathrm{SiC}_{\mathrm{w}} / \mathrm{Al}_{2} \mathrm{O}_{3}$ composite.

5. Elastic properties of uniaxial-fiber reinforced composites: General features.

6. Residual stresses in aluminum/mullite( $\alpha$-alumina) composites.

7. Cast-iron elastic constants: Effect of aspect ratio.

In the sixth case we studied particle-reinforced 6061-aluminumalloy composites with particle volume fractions ranging from 0 to 0.25 . The mullite particles are approximately spherical and contain embedded $\alpha$-alumina phase. We obtained lattice parameters of all three phases in the composites and starting materials by using Rietveld refinement of $x$-ray diffraction patterns. In all three phases, stresses are tensile and approximately of the same magnitude. They increase both with the increase of particle size and volume fraction. Measurements of extracted-from-composites particles showed no evidence of a possible chemical reaction at the matrix-particle interface. The matrix is [111] and [100] textured, but measurements of elastic constants revealed only small anisotropy. A principal finding is that the composite fails to satisfy the usual basic requirement of mechanical equilibrium:

$$
f\langle\sigma\rangle_{P}+(1-f)\langle\sigma\rangle_{m}=0 \text {. }
$$

Here f denotes particle volume fraction, $\sigma$ stress, p particle, $m$ matrix. Figure 11 shows some of our results. 

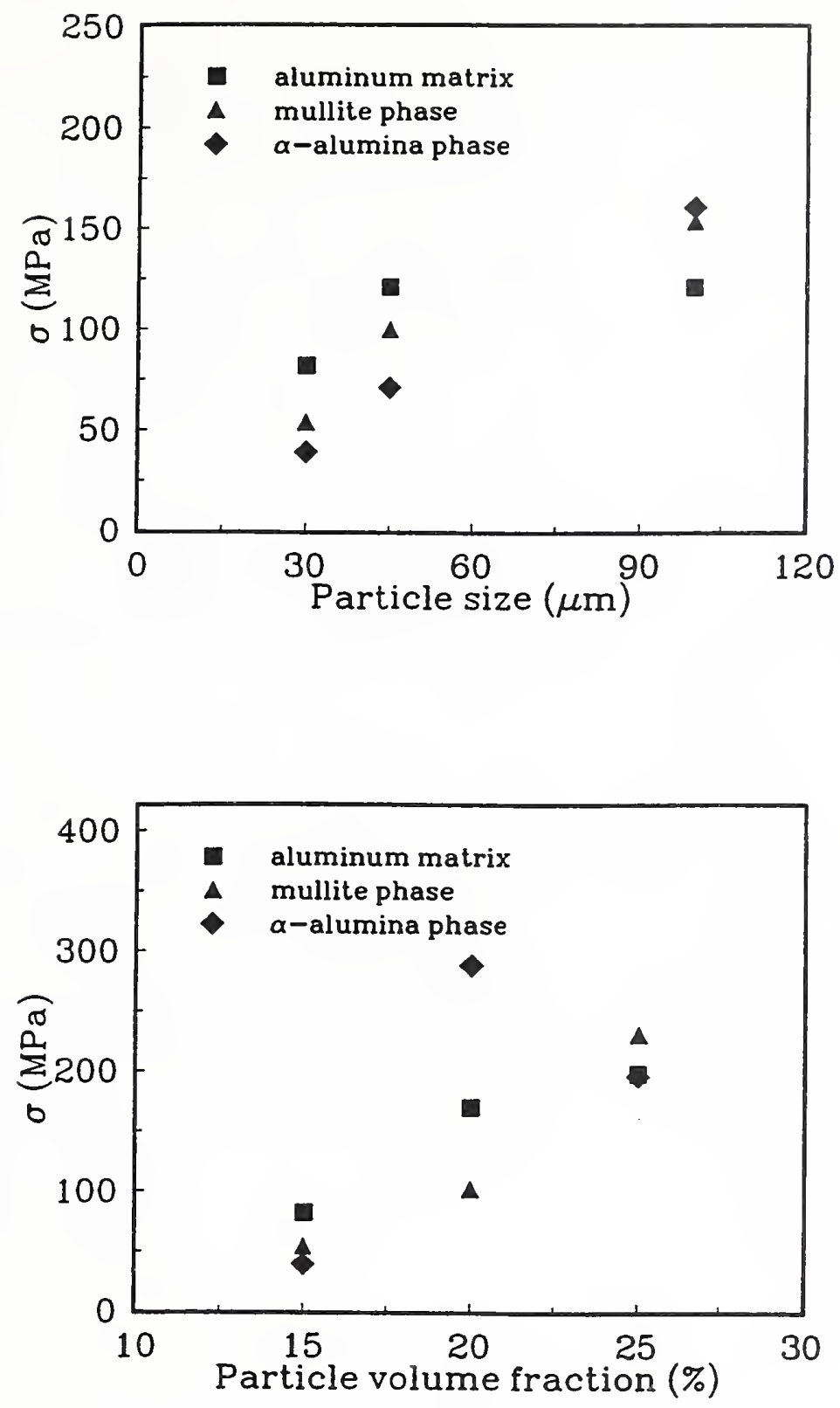

Figure 11. Residual stresses in all three phases as a function of particle volume fraction and particle size.

In the seventh case, using a scattered-plane-wave ensemble-average model developed for composite materials, we calculated the effective elastic constants of cast iron. We focused on the effect of graphite-particle aspect ratio on the Young modulus. Between model and observation, we found good agreement. Oblate-spheroidal graphite flakes lower the elastic stiffness much more than do spheres. To obtain good model-measurement agreement, one must use graphite's lower third-order-bound (Kröner-bound) elastic constants. Besides the Young modulus, we give calculated results for all the other usual quasi-isotropic elastic constants: shear modulus, Poisson ratio, and bulk modulus. We believe this study 
represents the first quantitative explanation of cast iron's unusual elastic behavior. Figure 12 compares calculation and observation for the Young modulus.

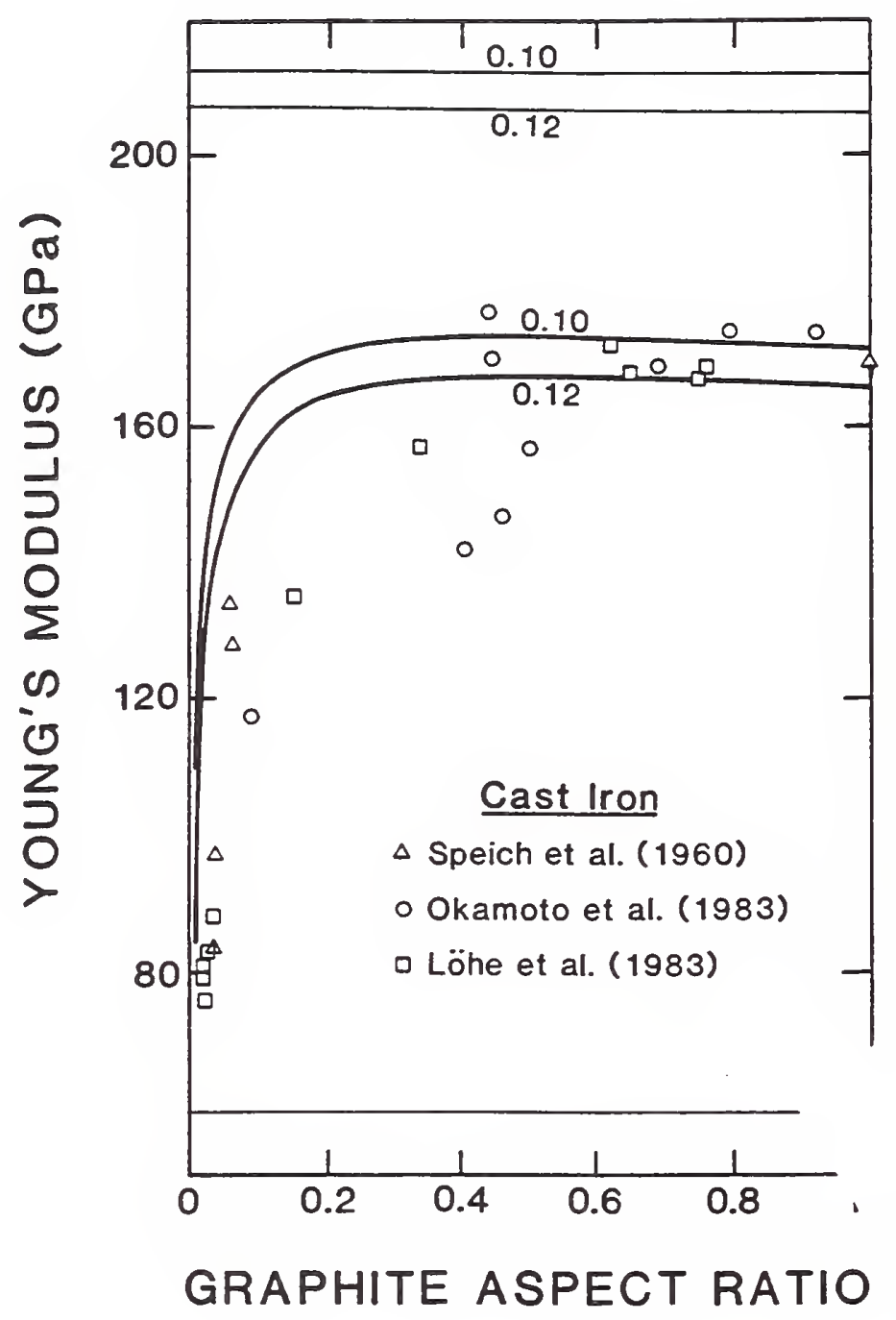

Figure 12 .

Young modulus versus graphite-particle aspect ratio. Symbols represent measurements. Curves represent model-calculation results for two volume fractions: 0.10 and 0.12 . Upper, nearly horizontal, curves represent graphite's upper third-order-bound (Kröner-bound) elastic constants. Lower curves represent graphite's lower third-order bond.

\section{oxide superconductors}

1. Enhanced flux pinning via selective chemical substitution in bulk superconducting $\mathrm{Tl}-2212$. 
2. Microstrains and domain sizes in Bi-Cu-O superconductors.

3. X-ray diffraction peak-broadening analysis of ( $\mathrm{La}-\mathrm{M})_{2} \mathrm{CuO}_{4}$ high- $T_{c}$ superconductors.

4. Asymmetry between flux penetration and flux expulsion in T1-2212 superconductors.

5. Orientation dependence of flux pinning in a layered $\mathrm{Bi}_{2} \mathrm{Sr}_{2} \mathrm{Ca}_{1} \mathrm{Cu}_{2} \mathrm{O}_{8}+10 \% \mathrm{Ag}$ composite.

6. Pinning force and time-dependent response in a grain-oriented yttrium 1:2:3 superconductor.

7. Metal-oxide Debye temperatures and elastic constants: Estimation from interionic spacing.

8. Low-temperature elastic constants of $\mathrm{Y}_{1} \mathrm{Ba}_{2} \mathrm{Cu}_{3} \mathrm{O}_{7}$.

In the last case, using ultrasonic methods, we studied the 4-295-K elastic constants of a "good" $\mathrm{Y}_{1} \mathrm{Ba}_{2} \mathrm{Cu}_{3} \mathrm{O}_{7}$ polycrystal. We reported the bulk, shear, Young moduli and the Poisson ratio. Except for the Poisson ratio, all elastic constants show smooth temperature behavior. Near $T_{c}$, during cooling, the Poisson ratio decreases irregularly. Focusing on the bulk modulus $B$, we used simple thermodynamics to show that the harmonic-observed decrement at $\mathrm{T}=$ 0 corresponds to expectation, but the temperature effect $\mathrm{dB} / \mathrm{dT}$ is too large by about a two factor. We attributed the irregular slope to oxygen-atom reordering. Against many reports, our bulk-modulus value is approximately that found in monocrystals or that predicted by an ionic-crystal-model calculation. Figure 13 shows the principal measurement results.

\section{other Materials, studies}

1. Profile fitting of $\mathrm{x}$-ray diffraction lines.

2. Voigt-function modeling in Fourier analysis of size- and strain-broadened $x$-ray diffraction peaks.

3. Elastic constants of isotropic cylinders using resonant ultrasound.

4. A thermal-expansion/thermal-expansivity relationship.

In the last study, we give a theoretical basis for an existing empirical observation relating volume change between temperatures 0 and $\mathrm{T}$ to the thermal-expansivity tensor $\beta$ at temperature $\mathrm{T}$. That is, for all materials, $(\Delta V / V) / \beta$ depends only on the Debye characteristic temperature $\theta_{D}$. 


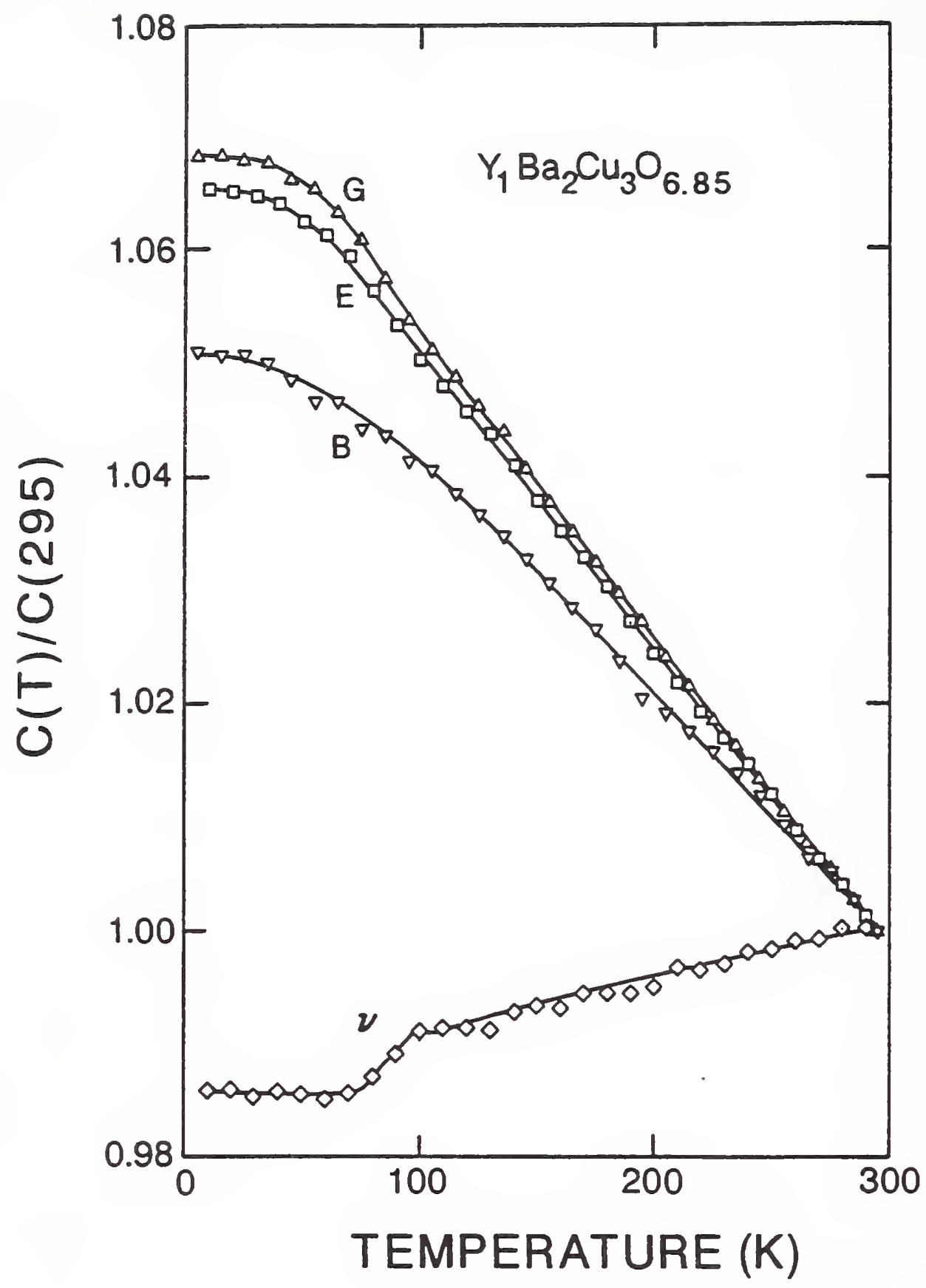

Figure 13. Temperature variation of the polycrystalline elastic constants. $G$ denotes shear modulus, E Young modulus, B bulk modulus, $\nu$ Poisson ratio. Except for the dip in $\nu$ below $100 \mathrm{~K}$, all constants show essentially regular temperature behavior. 


\section{MICROMECHANICAL MEASUREMENTS}

D.T. Read, E.S. Drexler, J.W. Dally*, J.R. Berger

We are developing measurement methods to characterize the mechanical properties and behavior of materials used in advanced microelectronic devices. These measurements are intended to contribute to device reliability by allowing quantitative analysis of mechanical failure modes. We are developing four types of measurements: mechanical properties of thin films, electron beam moiré measurements of local strain, acoustic microscopy, and infrared microscopy.

The common technical objective of these projects is to measure the mechanical behavior of materials as they exist within microelectronic devices. These materials differ from bulk materials with the same nominal chemical composition in two fundamental ways: fabrication method and size scale. For example, thin metal films produced by vapor deposition are expected to have microstructures considerably different from bulk materials. And, the thickness of evaporated films is a $2 \mu \mathrm{m}$ or less, so they cannot be handled directly. This makes it impossible to use conventional techniques to prepare thin-film specimens or to measure their mechanical properties.

Our general approach to this problem is to develop specimen designs, preparation techniques, and test methods that are compatible with microelectronics manufacturing practices and that operate in the microscopic size scale.

\section{significant Accomplishments}

Ti-Al-Ti thin films were prepared using electronic microfabrication techniques to deposit the film and etch away the substrate in the test section. Tensile tests of the freestanding films were conducted in a loading stage with a resolution of $\pm 67 \mathrm{MN}$ and $2.5 \mathrm{~mm}$ in displacement. The $2.2 \mu \mathrm{m}-$ thick films were found to have low ductility and reduced fatigue life, relative to bulk material.

An electron-beam moiré technique was developed which can map displacement fields with $5 x$ the resolution of optical moiré. Electron beam lithography is used to write the lines on the test section with pitches down to $100 \mathrm{~nm}$. The specimen is loaded with a scanning electron microscope, and the SEM raster scan serves as the reference grid. Strain measurements are made at $1900 x$ over gage lengths of 10 to $30 \mu \mathrm{m}$.

* Visiting Professor from University of Maryland. 


\section{Mechanical Properties of Thin Films}

We have developed a new method for fabricating and testing tensile specimens of thin metal films. This uses fabrication techniques adapted from the lithography tools used in microelectronics. We prepare miniature arrays of four tensile specimens, each $0.25 \mathrm{~mm}$ wide, $1 \mathrm{~mm}$ long, and $2.2 \mu \mathrm{m}$ thick, using deposition, patterning and etching processes common to the semiconductor industry. Each array of four specimens is carried on and protected by a rectangular silicon frame. Thirty-six such specimen arrays are produced on a single silicon wafer. After a specimen frame is mounted, its vertical sides are severed without damaging the specimens. The load is applied by micrometers through a calibrated tension spring.

Tensile properties of a $2.2 \mu \mathrm{m}$ thick Ti-Al-Ti film were determined. Figure 14 shows force-elongation results for a tensile test. Table 1 lists strength and ductility results for seven tests. The general behavior and strength properties indicated by these results are consistent with the behavior of bulk aluminum specimens, with one important difference: the elongation to failure for these specimens is much less than that of bulk specimens of any normal aluminum alloy.

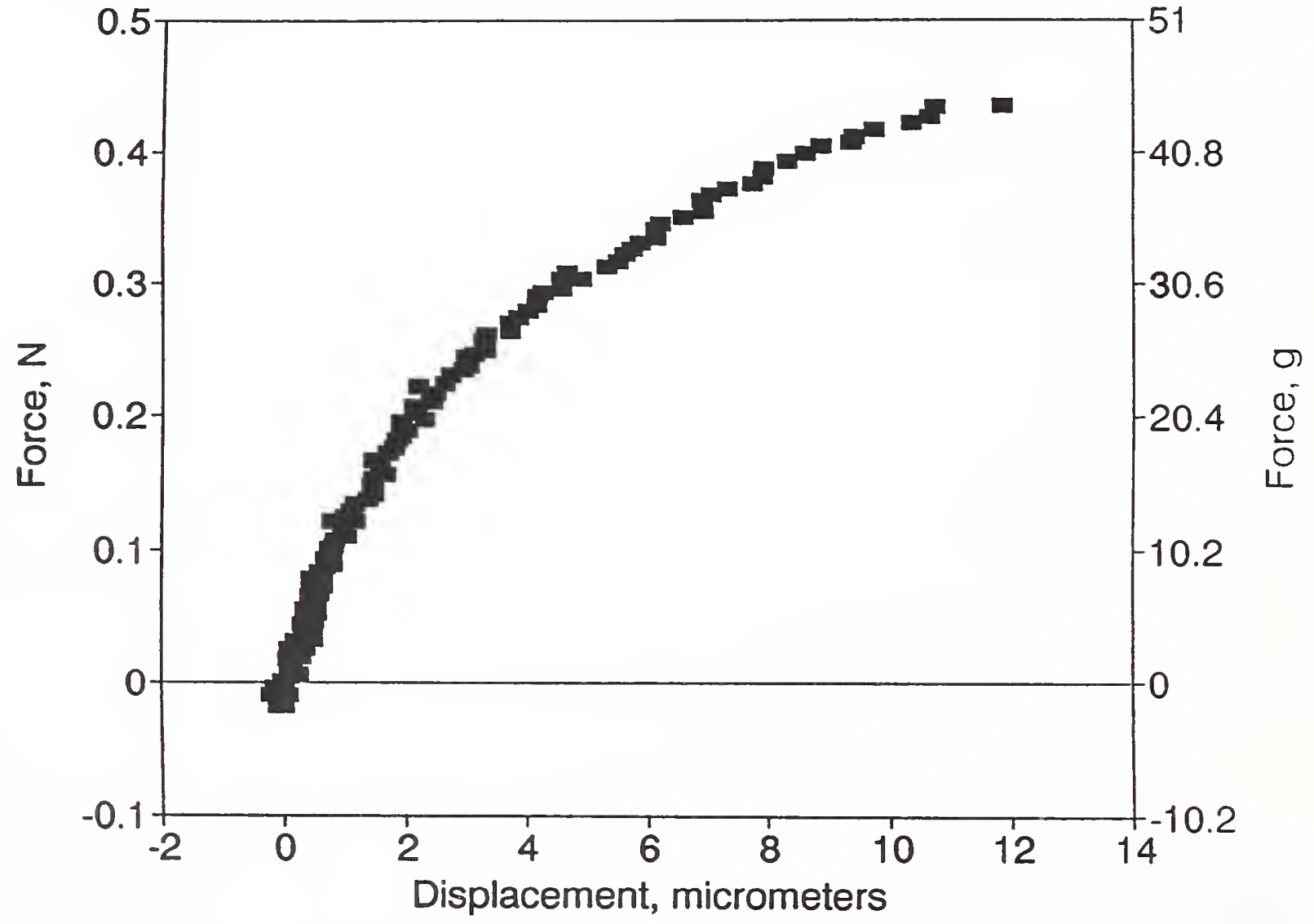

Figure 14. A typical force-elongation record for $\mathrm{TI}-\mathrm{Al}-\mathrm{TI}$ $(0.1-2.0-0.1 \mu \mathrm{m})$ films. 
Table 1. Mechanical Properties of Thin Ti-Al-Ti Films

\begin{tabular}{||c|c|c|c||}
\hline $\begin{array}{c}\text { Specimen } \\
\text { Identity }\end{array}$ & $\begin{array}{c}\text { Yield Strength } \\
\text { MPa }\end{array}$ & $\begin{array}{c}\text { Ultimate Strength } \\
\text { MPa }\end{array}$ & $\begin{array}{c}\text { Strain at Failure } \\
\%\end{array}$ \\
\hline 0 & $*$ & 172 & $*$ \\
\hline A & 121 & 199 & 1.18 \\
\hline$\theta$ & 115 & 199 & 1.15 \\
\hline C & 96.4 & 191 & 1.81 \\
\hline$D$ & 71.5 & 199 & 1.28 \\
\hline$E * *$ & 120 & 144 & 0.54 \\
\hline F & 91.0 & 146 & 0.85 \\
\hline
\end{tabular}

* Not measured.

** Single specimen rather than an array of four specimens.

Fatigue life as a function of number of stress cycles has been determined for three-layer $\mathrm{Ti}-\mathrm{Al}-\mathrm{Ti}$ thin film specimens. The fatigue strength of the thin films, shown in Figure 15, is substantially lower than expected based on the properties of bulk aluminum. For nominal stresses ranging from 50 to 90 percent of the upper-bound ultimate strength, the fatigue lives ranged up to 76 cycles. The failure mode was dominated by crack propagation; active cracks were observed after a few load cycles.

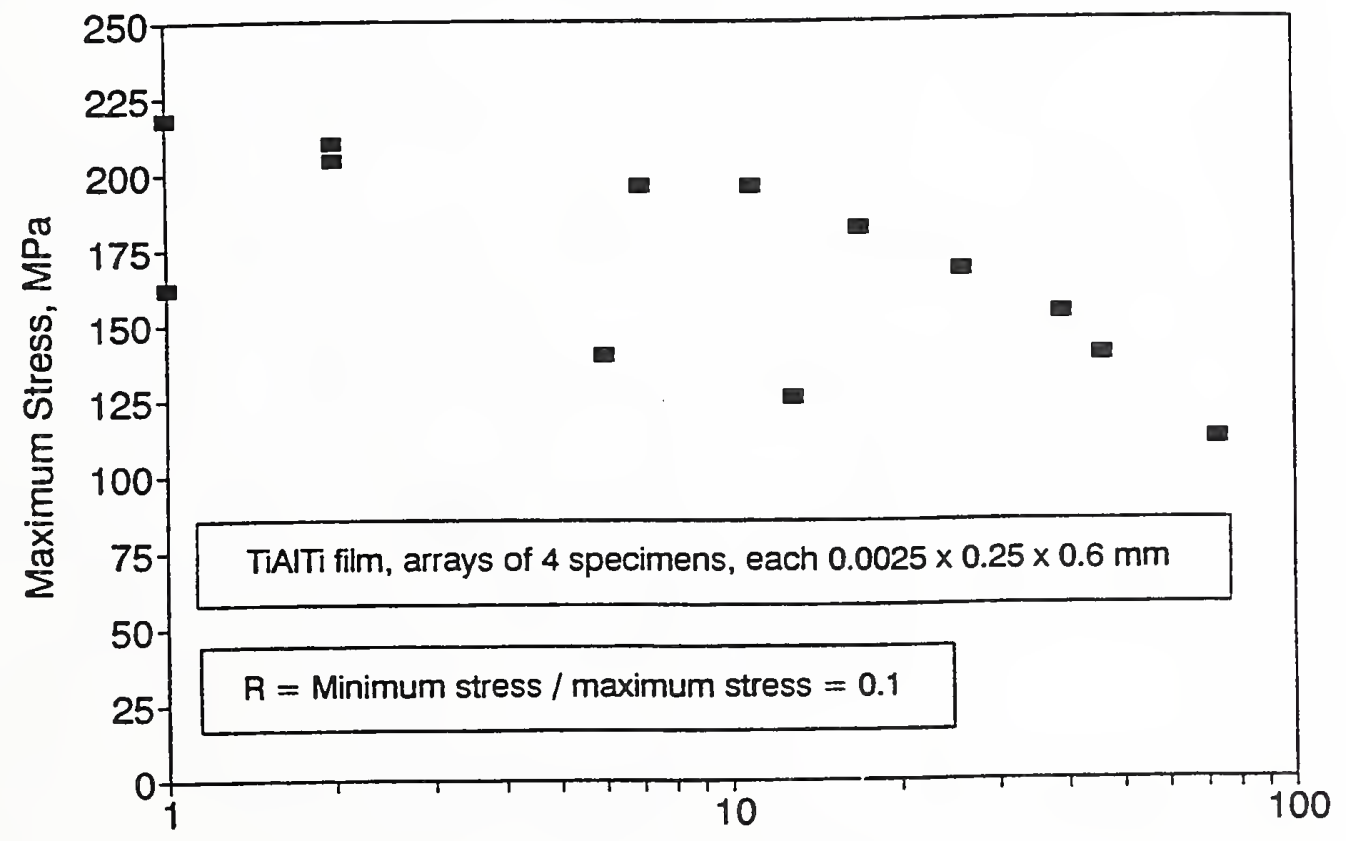

Cycles to failure

Figure 15. Fatigue curve showing the maximum cyclic stress as a function of number of cycles to failure. 


\section{Electron-Beam Moiré Measurements of strain}

We have developed an electron-beam moiré technique for measuring local strains with very high spatial resolution. As in optical moiré, a method of writing dense grating and grid patterns is needed. We have used e-beam lithography to write patterns in excess of 10,000 lines/mm on mechanical test specimens. A specialpurpose resist, consisting of polymethyl methacrylate dissolved in solvent, is spun onto the polished specimen surface. The electron beam of a scanning electron microscope (SEM), which has a diameter of 10 to $20 \mathrm{~nm}$, sensitizes the $100 \mathrm{~nm}$ thick layer of resist. The line and dot patterns are produced by dissolving the sensitized regions of resist in a solvent.

In optical moiré, a reference grating is commonly placed over the specimen surface. Then the spatial frequency of the reference grating differs from the frequency of the grating on the specimen surface, a moiré fringe pattern appears. The fringe pattern has a spatial frequency equal to the difference between the frequencies of the specimen and reference gratings. Moiré fringe patterns occur when the line arrays are observed in the SEM. The raster scan of the SEM serves as a virtual reference grating, replacing the reference grating. Moiré fringes with excellent contrast have been produced at magnifications as high as 1900x. This capability permits the e-beam moiré to be employed in micromechanics. Examples of line arrays, dot arrays and moiré fringe patterns on a brass disk and on a tensile specimen fabricated from glass fiber reinforced plastic (GFRP) were demonstrated to introduce the possibilities for micromechanics applications.

Using the method of electron beam moiré, we examined a small region at an interface of a $\left[\mathrm{O}_{2} / 90\right]_{8}$ glass-fiber-reinforced plastic composite during tensile testing. The tensile test was conducted inside the SEM, with a high spatial frequency line grating $(10,000$ lines/mm) at the interface between a longitudinal ply and a transverse ply. During the test, we observed this region at a magnification of 1900x. Local strain measurements were made by interpreting the moiré fringe patterns over gage lengths from 10 to $30 \mu \mathrm{m}$. The magnitude and distribution of the local strains depended on the damage that occurred as load increased. Load shedding by the transverse ply was evident from the fringe patterns. Extremely high local strains were observed: longitudinal fiber strains up to 3 percent; normal strains in the epoxy matrix up to 40 percent; and shear strains in the epoxy matrix up to 40 percent. Figure 16 shows a moiré fringe pattern on the surface of the tensile specimen. The large differences in strain between the longitudinal and transverse plies, smaller strain differences within the plies, and shear deformations indicative of load shedding are evident in the image. 


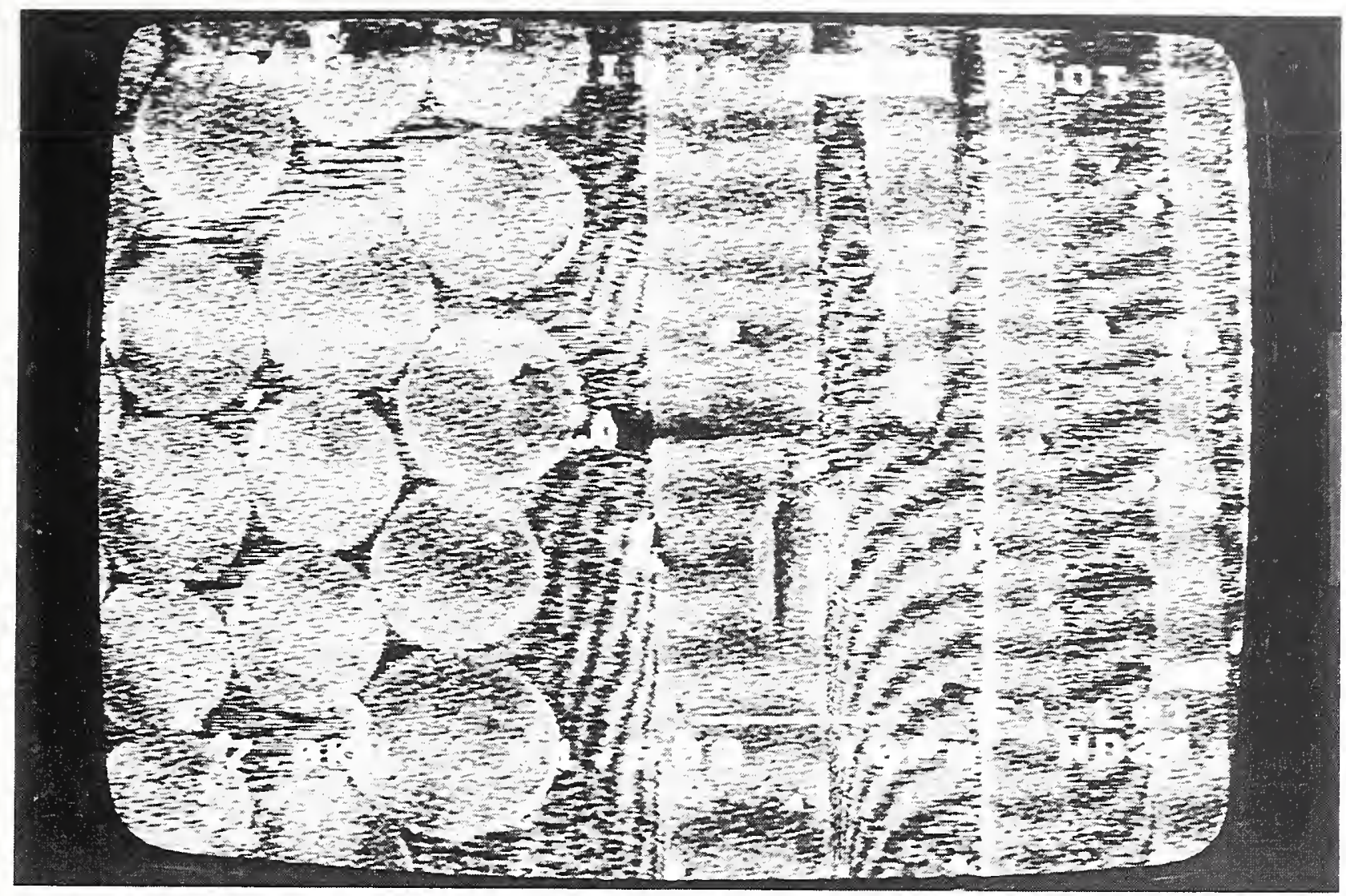

Figure 16. Moiré fringe pattern prior to longitudinal-ply cracking at the location marked, at a stress of 933 $\mathrm{MPa}$.

A mathematical model of e-beam moiré was developed that gives the spatial dependence of the SEM image brightness as a product of the local intensity of the scanning beam and the local scattering function from the specimen grating. Equations were derived that give the spatial frequency of the moire fringes as functions of the microscope settings and the spatial frequency of the specimen grating. The model also describes the contrast of different magnifications. We analyzed the formation of these different fringe patterns and divide them into different categories including: natural fringes, fringes of multiplication, fringes of division, and fringes of rotation.

\section{Infrared Microscopy}

We have reviewed the commercially available infrared microscopes and have purchased a unit with spatial resolution and temperature sensitivity that approach the theoretical limits. We plan to use it to develop new techniques for measurement of thermal properties of materials used in microelectronics, especially thin films. 


\section{PROCESS SENSING AND MODELING}

\section{A. Van Clark, Jr., Group Leader}

The Process Sensing and Modeling Group develops sensors for inprocess measurements of material condition and models relating these measurements to microstructure and properties. In addition, the Group develops nondestructive evaluation techniques to characterize material quality for process control, quality assurance and in-service inspection. The Group has three program areas:

1. In-process sensing of material condition, particularly the measurement of crystalline orientation in sheet steel.

2. Measurements and modeling of the microstructure and property changes that occur during the thermomechanical processing of steel.

3. The development of nondestructive evaluation systems to detect cracks and residual stresses in railroad wheels.

\section{IN-PROCESS SENSING}

A.V. Clark, Jr., M. Lozev*, S.R. Schaps

The Group is developing sensors for on-line monitoring of the preferred crystalline orientation in steel sheet. Mathematical models predict that the velocity of sound waves in the steel sheet is affected by the preferred crystalline orientation (texture) in the sheet. Physical metallurgy models also predict that the formability of the sheet is affected by texture, and, in fact, velocity measurements can be used to determine the formability index of steel. This index is known as the plastic strain ratio, $r$.

\section{Significant Accomplishments}

A single transducer has been designed and built to replace the ultrasonic sensor array, which consisted of nine transducers. The device measures the resonant frequencies of acoustic waves in steel sheet. Preliminary studies reveal a good correlation with the plastic strain ratio, $\bar{r}$, a measure of formability.

NIST and Iowa State University shared an Award of Merit from the Federal Laboratory Consortium for technology transfer of their joint work on ultrasonic measurement of steel sheet formability.

* Guest Researcher from Sofia University of Technology, Sofia, Bulgaria. 
In previous years, this concept was demonstrated by developing an array of non-contact transducers which were designed for making online measurements of $r$-value. Sound waves were propagated in the plane of the sheet at different angles to the sheet rolling direction and the arrival times were measured. The transducers were attached to a "bridge" which spanned over a track down which the sheet metal was propelled at speeds typical of those in a continuous annealing line ( 3 meters per second). By measuring the distance, $d$, between transmitting and receiving transducers as well as the propagation time, $t$, the velocity, $v$, was determined from the relation $V=d / t$. Experiments showed little difference between the velocities measured on static and moving sheet provided the out-of-plane motion of the sheet was constrained.

The American Iron and steel Institute (AISI) expressed interest in this technology to monitor the formability of sheet steel. It set resolution requirements for the measurements to be useful for industry. Error analyses showed that to meet the resolution goals of AISI the velocity must be measured to approximately \pm 2 parts in $10^{3}$. In the measurements described above, the waves were propagated in the plane of the sheet; the actual distance traveled can change if out-of-plane motion is allowed. The degree of constraint required may present obstacles to technology transfer. The measurement of the velocity with the array requires constraint of the sheet over a large area bounded by the outline of waves propagating at $0^{\circ}, 45^{\circ}$ and $90^{\circ}$ to the sheet rolling direction. Furthermore, the array technology requires electronics to drive three transmitting transducers and electronics to amplify signals from up to six receiving transducers.

To circumvent these problems a new transducer was designed and evaluated. This device is shown in Figure 17. It consists of an electromagnet which generates a large magnetic induction, $\underline{B}$. Underneath the pole piece is a coil which has current flowing through it at $\mathrm{MHz}$ frequencies. When the coil is placed a few $\mathrm{mm}$ from the sheet it generates an eddy current, $\underline{J}$, which is the image of current in the coil. The force, $\underline{F}$, generated by the reaction of the $\underline{B}$ field with the eddy current is given by $\underline{F}=\underline{J} \mathrm{x} \underline{B}$. This transducer is therefore capable of generating compressional waves, and shear waves polarized parallel and perpendicular to the sheet rolling direction. These waves propagate through the thickness of the sheet. The measurement "gage length" is just the area under the transducer. The single transducer generates and receives all three wave types. 


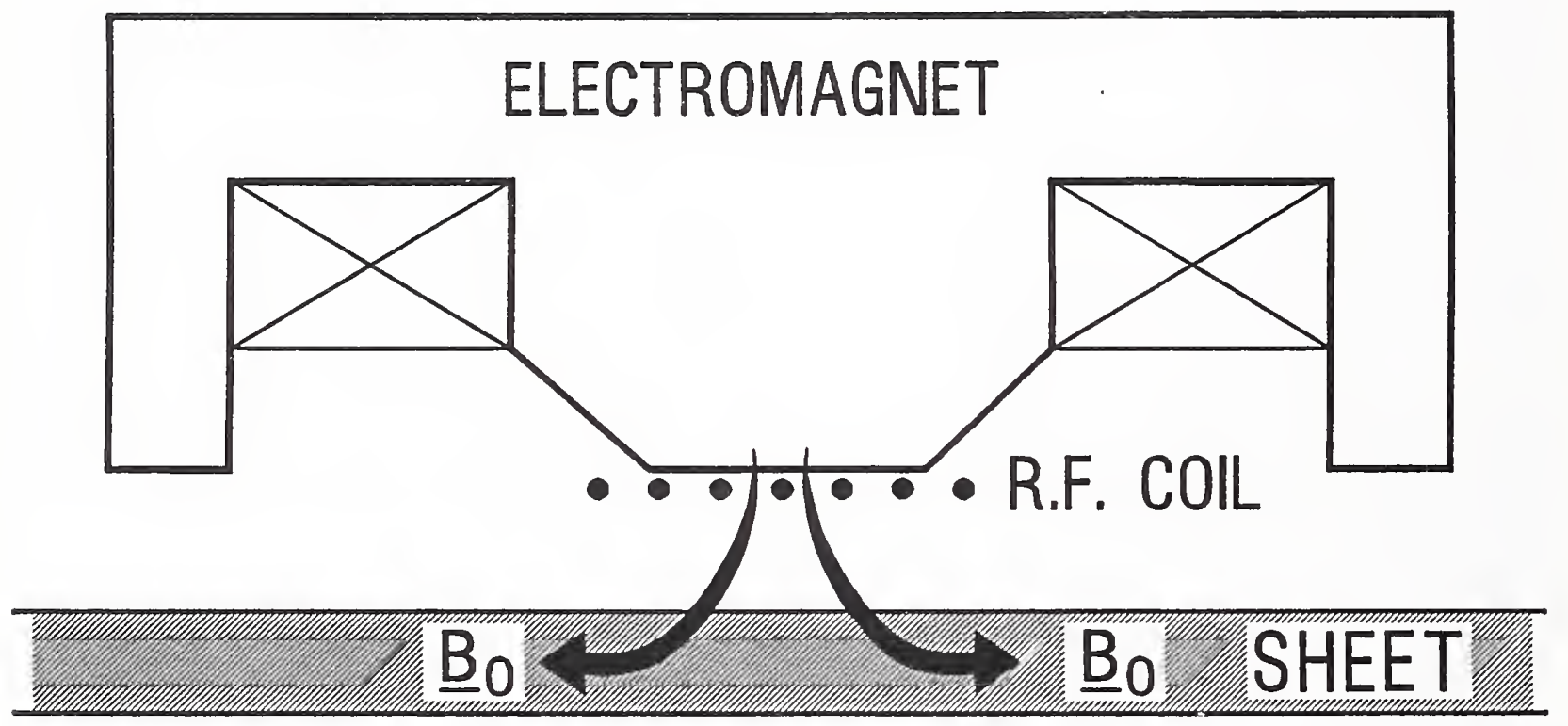

Figure 17. Schematic of transducer for ultrasonic measurement of formability.

Theory shows that the average $\bar{r}$-value can be correlated with the ultrasonic parameter, $\mathrm{K} ; \mathrm{K}=\left(\mathrm{V}_{\mathrm{rd}}^{2}+\mathrm{V}_{\mathrm{rd}}^{2}\right) /\left(\mathrm{V}_{\mathrm{rd}}^{2}+\mathrm{V}_{\mathrm{td}}^{2}+\mathrm{V}_{\mathrm{l}}{ }_{\mathrm{l}}\right)$. Here $\mathrm{V}_{\mathrm{rd}}$ and $V_{t d}$ are the velocities of shear waves polarized parallel and perpendicular to the sheet rolling direction; $V_{1}$ is the velocity of the compressional wave. Because the velocities are all measured over the same pathlength (the thickness of the sheet) the thickness cancels out and the ultrasonic parameter, $\mathrm{K}$, can be determined from ratios of resonant frequencies; $K=\left(f_{r d}^{2}+f^{2}{ }_{t d}\right) /\left(f_{r d}^{2}+f^{2}{ }_{t d}+f^{2}{ }_{1}\right)$. Thus, the only requirement for sheet constraint is that it be held in proximity to the transducer (2-3 mm of clearance). Furthermore, only one set of electronics is required for the measurements.

To prove this measurement concept, the transducer was integrated with a swept frequency phase-sensitive measurement system. The principle of measurement is as follows. A long tone burst of many cycles at frequency $\Omega_{d}$ is generated by a gated amplifier in the instrument. This drives the transducer; in the vicinity of a resonance of the sheet the amplitude of the sound traveling back 
and forth in the thickness direction of the sheet builds up. After the toneburst ends, the waveform "rings down" at a rate governed by the attenuation in the sheet and at the frequency $\Omega_{r}$ of the resonance. The waveform during ringdown is gated out and mixed with the signal having the toneburst frequency $\Omega_{\mathrm{d}}$. This generates a "beat" waveform given by $\cos \left(\Omega_{\mathrm{r}}-\Omega_{\mathrm{d}}\right) \mathrm{t}$ which is integrated and stored in a computer. The measurements are done under control of a computer which sweeps the frequency $\Omega_{d}$. The result is displayed on a screen. Peaks in the output occur when $\Omega_{\mathrm{r}}=\Omega_{\mathrm{d}}$.

Measurements were made on a data set of sheets representative of those used to produce automobile body parts. The results are shown in Figure 18, where a good correlation is evident between $\bar{r}$ and $k$. This indicates that the technology has good potential for measurement of formability in on-line applications.

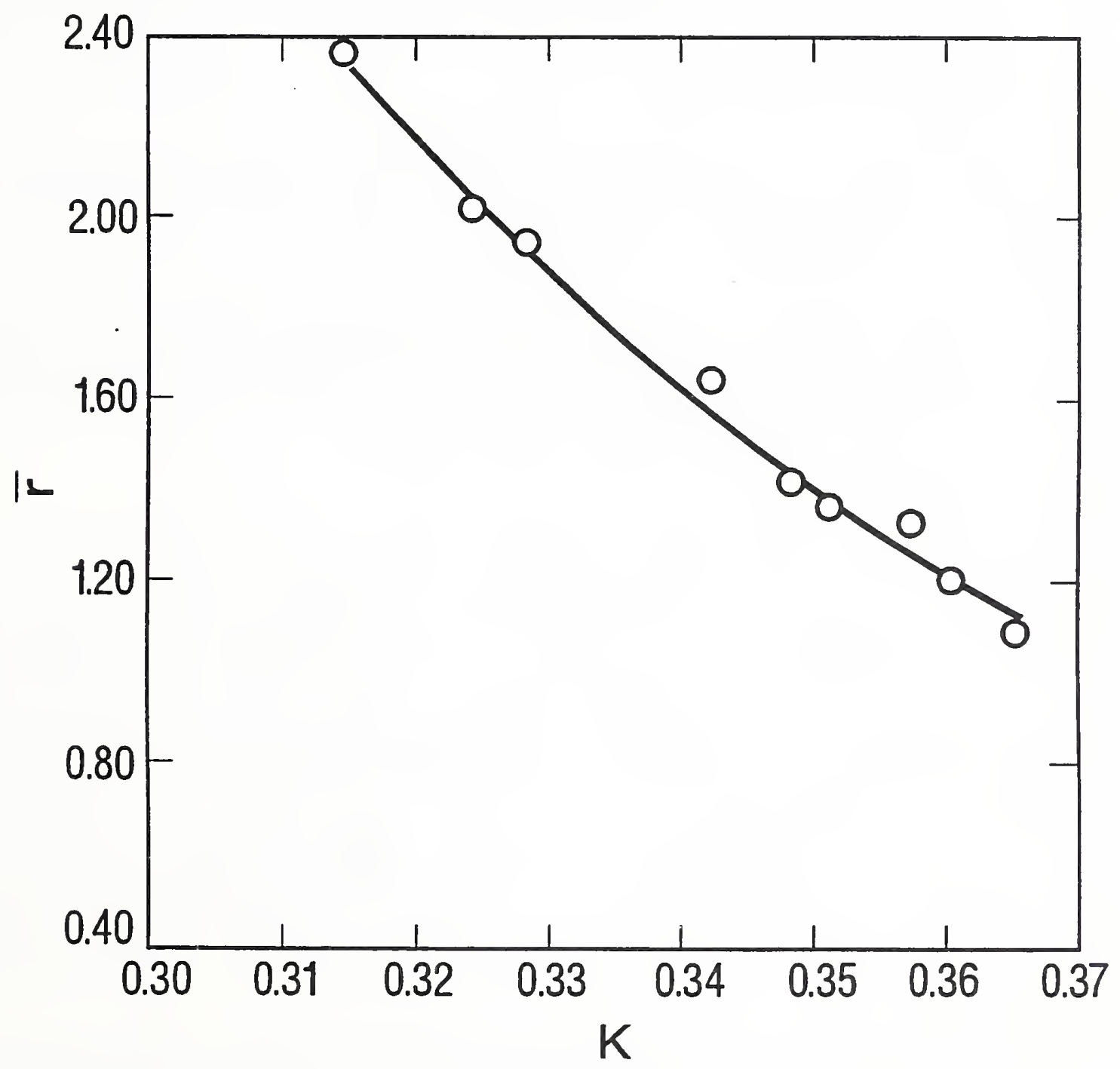

Figure 18. Correlation of ultrasonic parameter, $K$, and $\bar{r}$. 


\section{NONDESTRUCTIVE EVALOATION}

R.E. Schramm, S. R. Schaps, A.V. Clark, Jr., and D.V. Mitrakovic*

For several years, the Federal Railroad Administration has funded research to improve railroad wheel safety. On average, there are 33 derailments annually in the U.S., with annual economic loss estimated at $\$ 7$ million. In addition, there is a significant safety hazard posed by toxic materials being transported by rail.

There are two primary causes of wheel failure leading to derailments: (1) cracks in the wheels, especially those originating in the wheel treads; (2) tensile stresses, which cause growth of cracks and subsequent failure. The Process sensing and Modeling Group is developing two separate systems which will detect defective wheels (with tread cracks) and measure the state of stress in the wheels.

\section{Significant Accomplishments}

- In cooperation with the American Association of Railroads (AAR), a comparison of destructive (by $A A R$ ) and nondestructive (by NIST) measurements of stresses in railroad wheels revealed excellent agreement in hoop stress values.

- For roll-by detection of tread cracks in freight-car wheels, a "rocking shoe" fixture and an inductive trigger have been integrated into a prototype facility. Laboratory evaluations indicate that the reliability problems encountered in previous field tests may be solved.

\section{Residual stress}

The Group has worked with AAR researchers in an initial comparison of destructive and nondestructive evaluation of residual stress in cast steel wheels. Wheels were drag-braked by AAR (at the Transportation Test Center in Pueblo, CO) by using a dynamometer with varying levels of braking horsepower. We measured the residual stress in the wheels using a technique illustrated in Figure 19a. Here orthogonally polarized shear waves propagate through the thickness of the rim and a difference in time of propagation (the acoustic birefringence, $B$ ) is measured. Birefringence is related to the hoop stress, $\sigma$, in the wheel by the relation $\mathrm{B}=\mathrm{B}_{0}+\mathrm{C}_{\mathrm{a}} \sigma_{\theta}$ where $\mathrm{C}_{\mathrm{a}}$ is the "stress acoustic constant" and $B_{0}$ is the birefringence due to texture in the wheels. The latter effect arises due to preferred orientation of grains during

* Guest Researcher from the University of Belgrade, Belgrade, Yugoslavia. 
the cooling and the casting process. In most applications the terms $\mathrm{B}_{0}$ and $\mathrm{C}_{\mathrm{a}} \sigma_{\theta}$ are of comparable magnitude. Hence, a significant materials evaluation problem is separation of texture and stress.

After measurement of the birefringence in the drag-braked condition, destruction evaluation was done by the Transportation Test center and the thickness average value of the hoop stress $\sigma_{\theta}$ was calculated. Wheels then were cut to produce rim blocks; these are short segments of the rim cut out from the wheel and nominally in a stress free condition. The unstressed birefringence was measured on the rim blocks and the hoop stress predicted from the ultrasonic measurements.

A comparison between destructive and ultrasonic methods is presented in Figure 20. Overall, good agreement exists. Furthermore, it may be that the net rim force (the integral of the hoop stress over the area of the rim) controls the wheel safety. If a crack grows into an area of net compressive force it will likely be arrested.

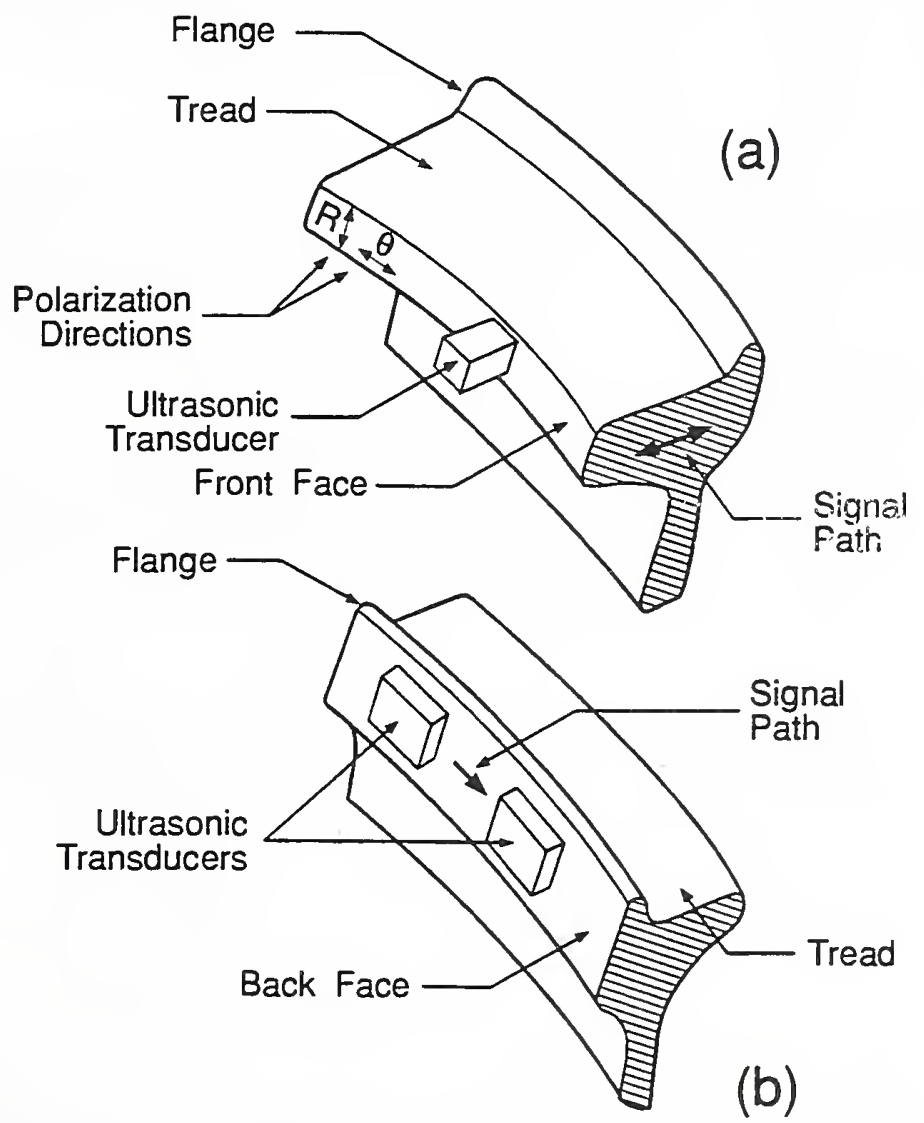

Figure 19a. Method of making birefringence measurements of thickness-averaged stress in railroad wheel rims.

Figure 19b. Method of measurement of surface stress in railroad wheel rims. 


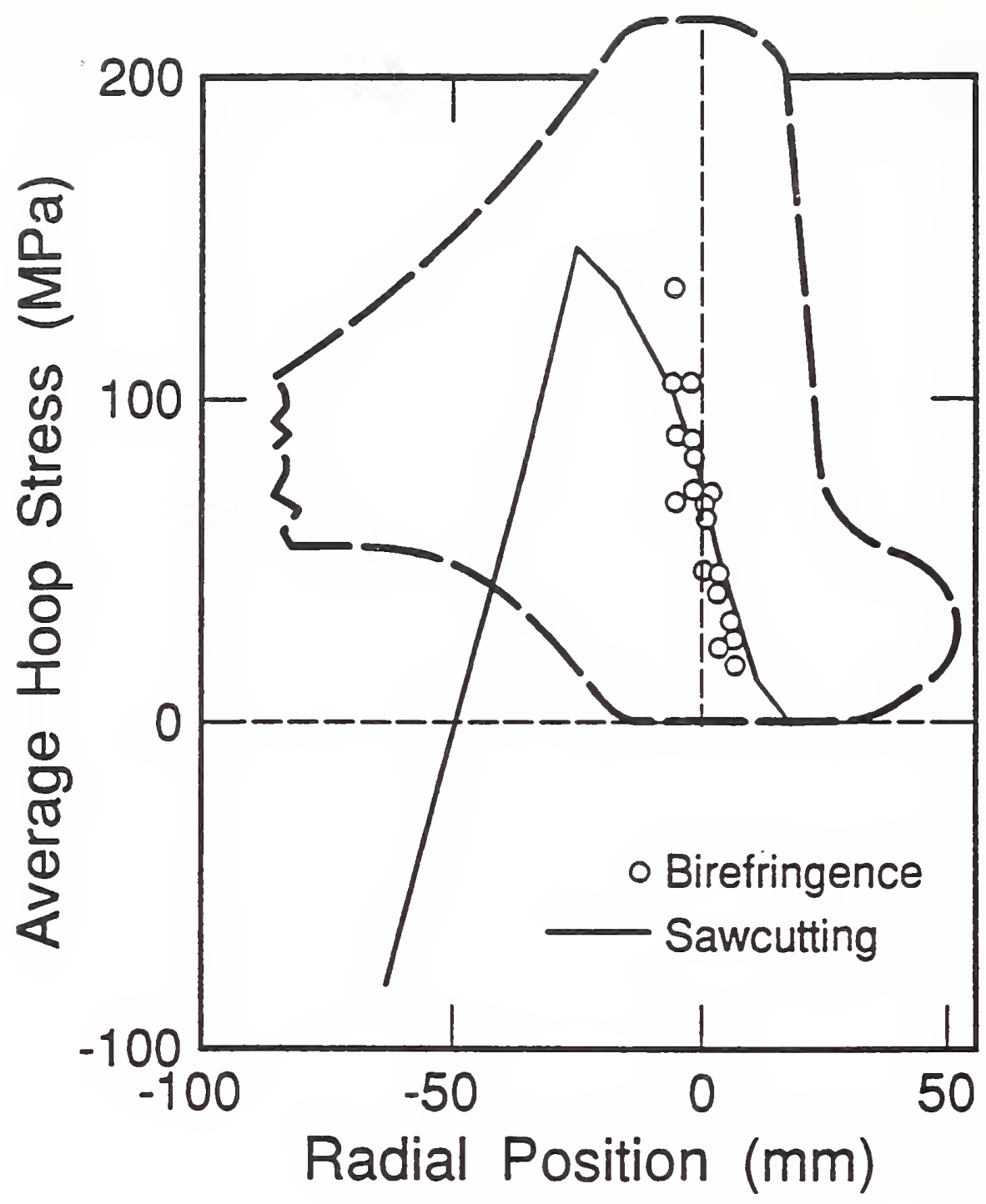

Figure 20. Comparison of stress in railroad wheel rims as measured with birefringence and destructive (sawcutting) techniques.

In practice, cutting wheels into rim blocks would be impractical. However, our previous research indicated that the unstressed birefringence is relatively constant for cast wheels of U.S. manufacture. The uncertainty resulting in the hoop stress measurements due to this "metallurgical scatter" is estimated to be $\pm 50 \mathrm{MPa}$ ( $\pm 7 \mathrm{ksi}$ ) at most. Since no completely reliable nondestructive method yet exists to determine whether wheels are in compression or tension this uncertainty is quite acceptable.

Finite element modeling and destructive analyses performed by AAR indicated that peak stress occurred on the "back face" of the rim (the side of the rim on the inside of the track). We developed 
transducers to send compressional waves along the surface of the rim. This is illustrated in Figure 19b. By measuring the velocity in the stressed and unstressed specimens it may be possible to determine the surface stress provided that the texture effect can be suppressed.

\section{Rol1-by Inspection of Wheels}

A second component of nondestructive evaluation of wheels is detection of tread cracks in freight car wheels in a roll-by mode. Here a sensor is embedded on the non-weightbearing part of the rail and sends sound waves around the tread as the wheel rolls over the sensor. The presence of defect causes echoes; these are detected by the sensor and analyzed by a microprocessor to evaluate the state of wheel safety.

This system had previously been subjected to 3 field tests at the Transportation Test center. It had good short-term reliability for train speeds up to $25 \mathrm{~km} / \mathrm{h}(15 \mathrm{mph})$. However, the sensor "package" was found to degrade after several hundred wheels had passed over it.

To rectify this, the sensor is now mounted in a "rocking shoe" device. The device is mounted on springs which allow it to rock from side to side to better position the sensor for good ultrasonic coupling to the wheel as the wheel rolls by. It also reduces the stress on the sensor package.

When the wheel is centered over the sensor package it is necessary to trigger the sensor electronics. Previously this was done by switches embedded in the sensor package; this required some load to act on them. The present design uses a totally noncontacting trigger consisting of coils which sense the presence of the wheel. These coils are part of an electric bridge circuit, balanced to give peak output when the wheel is centered on the sensors. The combination of "rocking shoe" fixture and inductive trigger circuit has been integrated in a lab facility consisting of a short test track. The system has proven reliable for slow roll-by speeds. Plans call for future field tests at the Transportation Test Center in $\mathrm{FY}-93$. 


\title{
THERMOMECHANICAI PROCESSING
}

\author{
Y. W. Cheng, P.T. Purtscher
}

Research in thermomechanical processing (TMP) uses a deformationprocessing simulator built at NIST. We measure the metallurgical changes that occur in steels during processing, such as forging and hot rolling. With experimental data, we develop, improve or validate process models that are needed in microstructural engineering of steels. We study microalloyed bar steels, hot-strip steels and high-strength low-alloy steels.

\section{Significant Accomplishments}

Equations have been developed to generalize the effects of temperature and strain rate on flow behavior of a microalloyed bar steel.

- With the large-scale TMP simulator, we have produced different microstructures in a microalloyed bar steel with different TMP schedules to validate the structure-property relations of ferrite-pearlite steels.

\section{Stress-strain Curves at High Temperature and High strain Rate}

For a Nb-treated microalloyed steel, stress-strain curves have been determined under different temperatures and different strain rates. Cylindrical specimens were compressed at temperatures of 900, 1000, 1100, and $1200^{\circ} \mathrm{C}$ and at constant strain rates of $0.1,1$, and $10 \mathrm{~s}^{-}$ 1. The results show that the flow stress decreases with increasing test temperature. The flow stress also decreases with decreasing strain rate, except in the case when precipitation occurred at 900 ${ }^{\circ} \mathrm{C}$ with the strain rate of $0.1 \mathrm{~s}^{-1}$. In the latter case, the flow stress is higher than that of testing at the strain rate of $1 \mathrm{~s}^{-1}$. The stress-strain data have been fitted into the physically based equation $\sigma=\sigma_{s}[1-\exp (-B \epsilon)]^{\mathrm{n}}$. In the equation, $\sigma_{s}$ is the saturation stress, $B$ is related to characteristics of strain hardening and dynamic recovery, and $\mathrm{n}$ is the functional relationship between stress and dislocation density. The combined effects of temperature and strain rate are described by the equation, $\left[\sinh \left(\alpha \sigma_{s}\right)\right]^{\mathrm{m}}=A^{\prime} \dot{\epsilon} \exp [\Delta \mathrm{H} /(\mathrm{RT})]$, where $\alpha, \mathrm{m}$, and $A^{\prime}$ are constants, $\dot{\epsilon}$ is strain rate, and $\Delta \mathrm{H}$ is the activation energy of deformation. A computer program has been written to predict the stress-strain behavior with inputs of temperature and strain rate. without microstructural changes during deformation, such as dynamic precipitation and recrystallization, predictions of the computer program agree well with the experimental data. However, discrepancies exist between predictions and experimental data when precipitation occurred during deformation. Figure 21 shows the comparison between computer predictions and experimental results. 


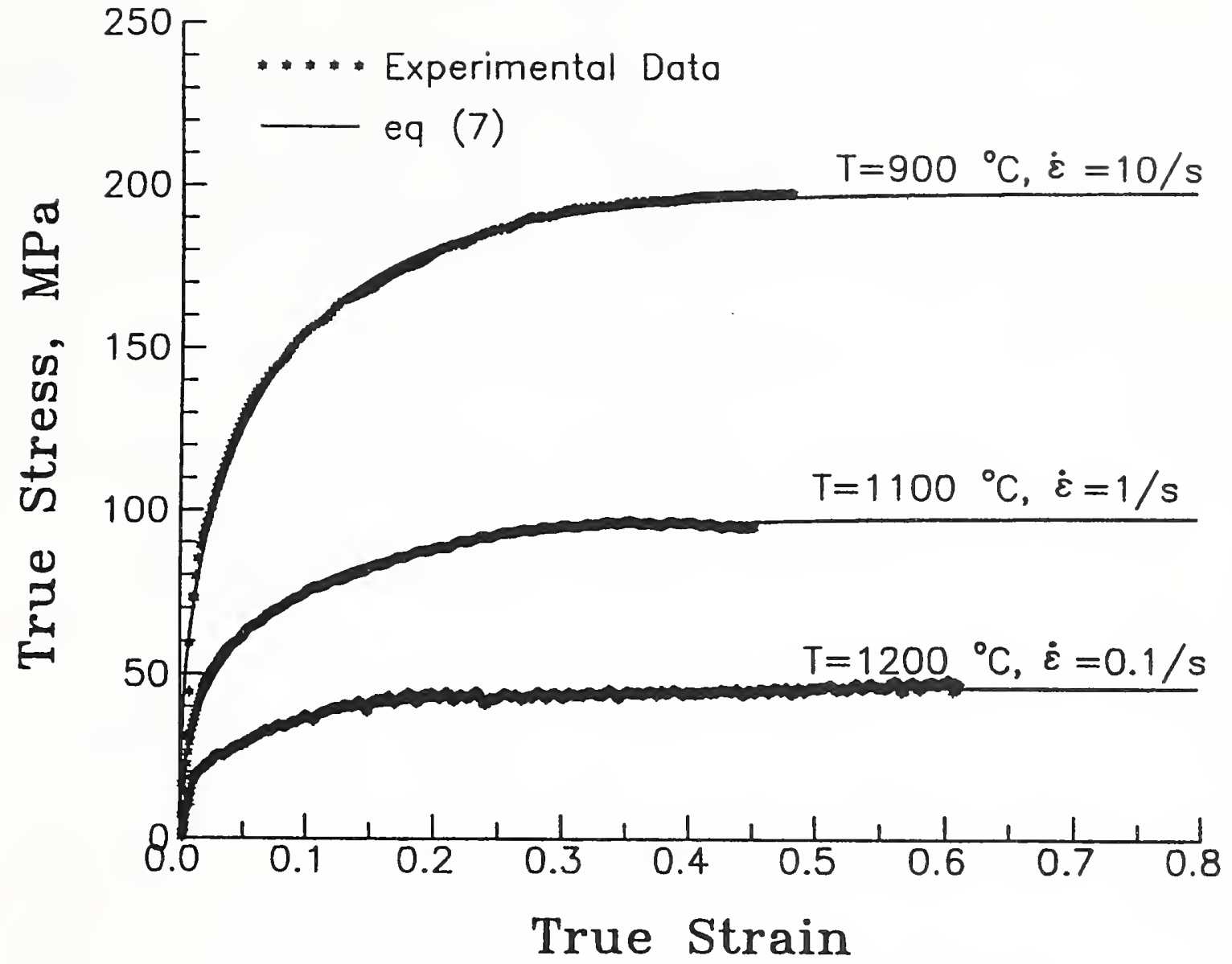

Figure 21. Comparison between computer predictions and experimental results.

\section{structure-property relations of ferrite-pearlite steels}

In the study of structure-property relationships, the Nb-treated microalloyed steel was processed with different TMP schedules with a newly upgraded 500-kN TMP simulator to produce different microstructures. Tensile and impact (Charpy V-notch specimens) properties were measured on the specimens extracted from the TMP processed steels. Preliminary results indicated that the equations of Gladman and Pickering predict the tensile properties well when the ferrite content is less than 15\% of the structure: the predicted and the measured yield strength were 464 and $471 \mathrm{MPa}$, respectively, and the predicted and the measured ultimate tensile strength were 795 and $754 \mathrm{MPa}$, respectively. However, for a ferrite content of $40 \%$, the equations underpredicted the measured values: $20 \%$ in yield strength and $11 \%$ in ultimate tensile strength. 


\section{Evaluation of directly quenched steel plates}

We have assisted Lukens steel company and United states steel corporation in evaluating the directly quenched steel plates, which are to be used for naval shipbuilding applications. These steels have strength requirements of 450,560 , and $700 \mathrm{MPa}$ with excellent impact toughness at low temperatures. Our evaluation tasks include microstructural characterization, tensile properties evaluation, charpy impact testing, and dynamic tear assessment. 
Thomas A. Siewert, Group Leader

The structural Materials Group conducts materials research to improve the quality and safety of structural materials and weldments. The Group develops measurement methods, standards and property databases to evaluate the thermal and mechanical behavior of materials, particularly at cryogenic temperatures. The Group has three program areas:

1. Measurement methods and process models for the control of arc welding processes.

2. Measurement methods, standards, and data compilations to evaluate materials for cryogenic service.

3. Standards and standard reference materials for radioscopy and Charpy impact testing.

\section{WELDING}

T.A. Siewert, T.P. Quinn, R.B. Madigan, B.R. Danley*, and P. Jonsson**

The integrity of welded joints is a primary concern in the fabrication and repair of engineering structures. Rising expectations of system safety and longevity can only be met with improved production techniques. Yet, recent improvements in automated welding equipment have not been accompanied by a corresponding increase in intelligent control systems. Researchers at NIST are addressing these control concerns by developing new weld sensors to detect changes in the arc, models that predict the behavior of the arc, and control systems that will permit automatic detection and correction of welding problems. Of equal importance to detection and correction is the integration of these systems in a practical design, one that can be easily implemented at low cost.

\section{significant Accomplishments}

An arc sensing system for monitoring weld quality from electrical signals has been developed and delivered to the U.S. Navy for use in a multisensor weld controller.

- Under a CRDA, the AC Rochester Division of General Motors evaluated the NIST arc sensing technology for the materials and processes used in production of catalytic converters. Based on positive results, ACR is implementing the NIST technology in their production operations.

* Research Associate from General Motors.

** Graduate student from MIT. 


\section{Monitoring weld quality from the Electrical signals}

The NIST research is based on through-the-arc sensing, which is a practical sensing strategy that relies on simple measurements of the current and voltage in the circuit. This sensing strategy keeps the weld head free of devices that restrict movement. To keep the cost low, the systems run on a personal computer. A typical system comprises a PC, a Hall-effect transducer, a digitalto-analog converter, signal conditioners, and software.

For calibration purposes, we use a high-speed video system with a laser back lighting system to image the welding arc and relate it to the electrical signals. Figure 22 shows the laser vision system used to calibrate the sensor and assure that the electrical signals are correlated to the physical reality. Process models were also developed and confirmed with experimental measurements, permitting the behavior in this region to be deduced.

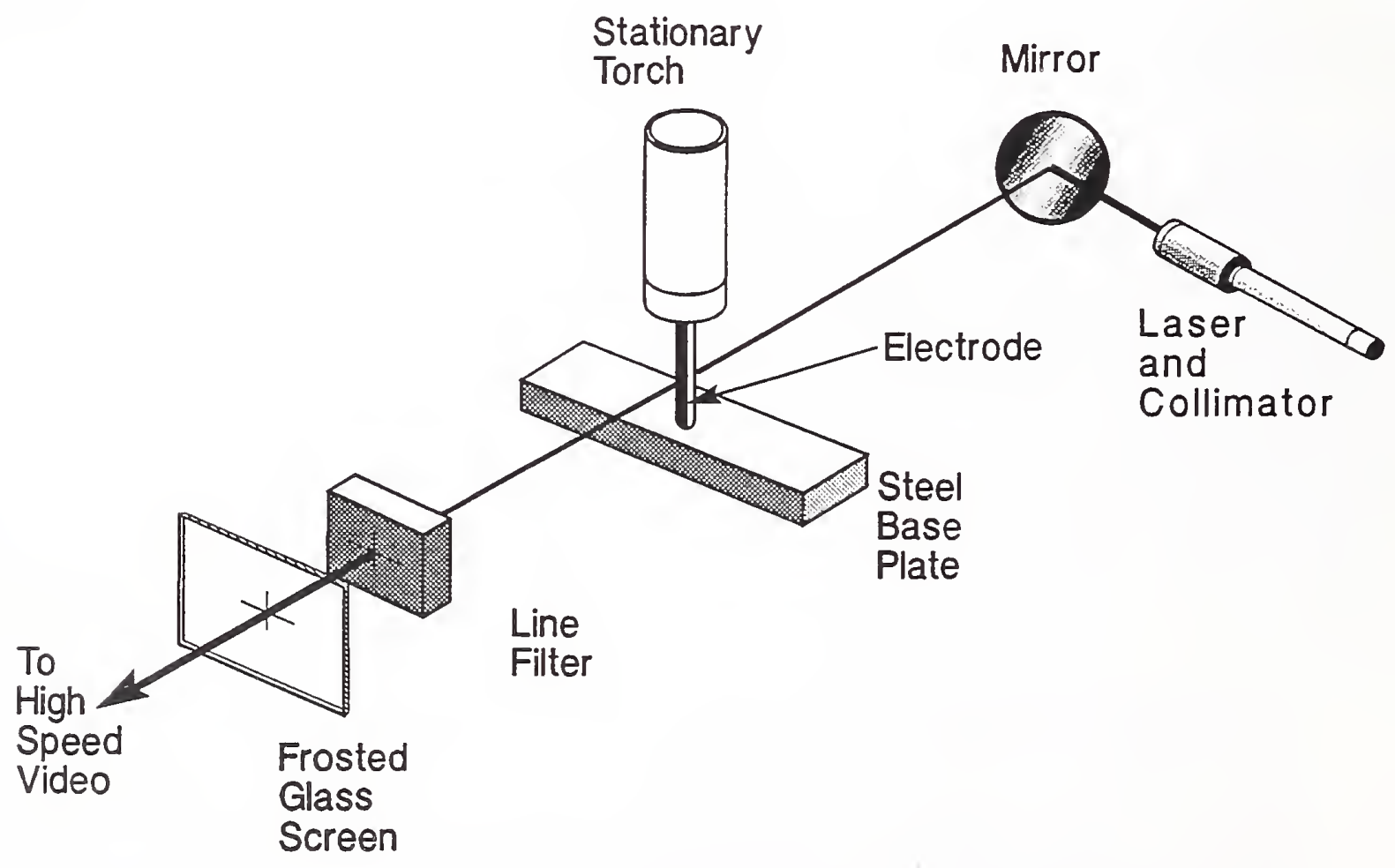

Figure 22. Schematic diagram of laser imaging system. 
Based on these data, we were able to select appropriate sensing strategies and control systems to improve the quality of welds produced with automated GMAW systems. We have developed automated systems for gas metal arc and flux cored arc welding that can detect contact tube wear, degradation of the gas shielding, mode of droplet transfer, and intermittent changes in the droplet transfer. These systems, originally designed for specific government applications, are now being packaged in generic versions that can be easily used by industry.

Future improvements to the system will require parallel improvements in our models. For this reason, a steady state model of the arc during gas metal arc welding was developed under an NIST contract by $\mathrm{P}$. Jonsson and $\mathrm{J}$. Szekely at the Massachusetts Institute of Technology. The fundamental transport equations for the radial and axial velocities, pressure, enthalpy and electric potential have been solved accounting for the temperature dependent physical properties of the shielding gas (argon). The geometries of the electrode and weld pool as well as the overall process variables (current, electrode feed speed, etc.) used in the model were measured in experiments carried out in the NIST welding laboratory, using our welding test bed. Figure 23 shows the gas velocity predicted for a steady state GMAW argon welding arc. Future work will include (1) calculations with a tapered anode (the tip of the melting electrode) using the dimensions measured in the experiments and (2) calculations of the geometry of the fluid film at the end of the electrode to predict droplet detachment.

The weld quality improvements possible with these advances in sensing, modeling, and control have important industrial applications and have generated significant interest. This year we completed a six-month Cooperative Research and Development Agreement (CRDA) with the AC-Rochester Division of General Motors. During this time, a Research Associate from AC worked in our laboratory to learn our technology and assess its utility for their applications. This CRDA has now been extended for another three years, during which we will advise them on software modifications and in interpretation of the data. Other industries are expressing interest in this technology and several more CRDAs are expected in the near future.

\section{Arc Length and Droplet Detachment sensor system for Gas Metal Arc welding}

Some aspects of weld quality can not be determined from the electrical signals alone. To supplement the data from the electrical signals, an arc light intensity sensor system is being developed. This system has shown that it is capable of detecting droplet detachment and arc length for gas-metal-arc welding (GMAW) under drop and streaming spray transfer welding conditions. 


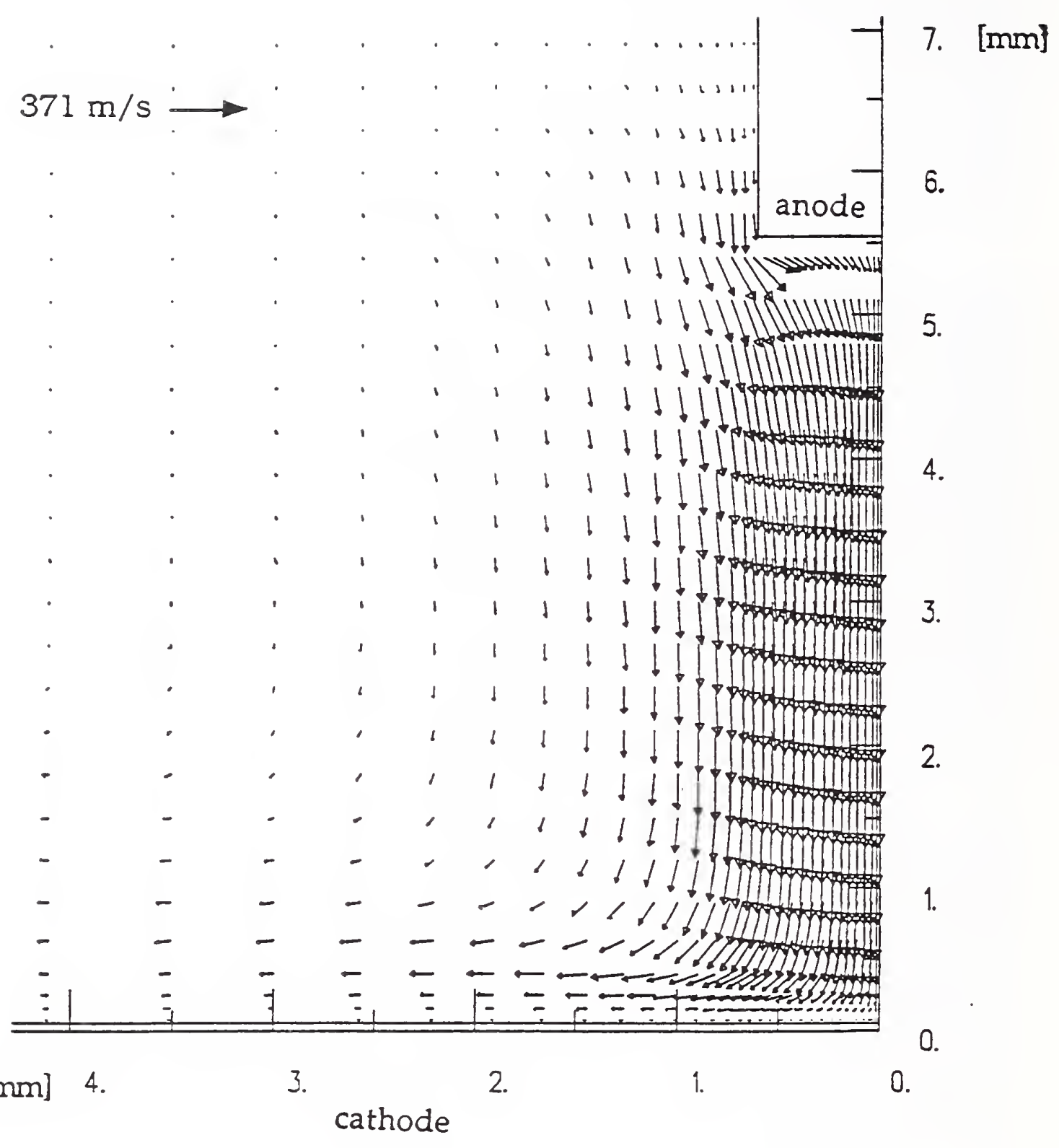

Figure 23. The gas velocity in an argon arc during GMAW for a current of $250 \mathrm{~A}$ and a cathode spot size of $2.5 \mathrm{~mm}$. 
Electrode extension can be obtained if contact-tube-to-work distance (CTWD) is known. Short circuiting can be detected during short circuiting transfer welding conditions.

The ability to monitor and control arc length during arc welding allows consistent weld characteristics to be maintained and therefore improves weld quality. The need for arc length control is demonstrated by the large installed base of automatic voltage control (AVC) units for gas-tungsten-arc welding (GTAW). There, the arc length is maintained by measuring the voltage drop across the arc. While voltage sensing is sufficient for controlling GTAW arc length, it is not sufficient to control the arc length in GMAW as voltage sensing provides only the composite voltage drop across the contact tip/wire interface, the electrode extension, and the arc. The light sensor discussed here is capable of determining arc length from arc light intensity and arc current.

This system also relies on a dynamic model of the melting electrode during GMAW. This model supplements the information provided by the light sensor, and helps to separate the composite voltage drop into its components. The model considers the heat sources of Joule heat in the electrode and heat directly applied to the end of the electrode by the condensing electrons, and heat loss by conduction along the electrode. The thermal conductivity, the thermal diffusivity, and the electrical resistivity of the electrode material were allowed to vary with temperature. The model was verified with experiments. The steady state electrode extension can be predicted within $1.9 \mathrm{~mm}$. The model is a transient version of the steady state model proposed by Kim et al. (Welding J., 70 [1], 1991) and has allowed for the development of quasi-linear transfer functions relating electrode extension to electrode feed speed and current. The melting electrode model together with the model of the arc allows for a thorough theoretical description of the process current-voltage characteristics. These models provide valuable support for our development of new weld sensing strategies.

Research has indicated that the ability to sense and control droplet detachment also assists in maintaining weld quality. Variations in arc light due to droplet detachment have been detected and droplet frequency measured.

The system consists of an arc light intensity sensor, a Hall-effect current sensor, a personal computer and software implementing a data interpretation algorithm. Although we developed the system with GMAW, the sensing technique could be used for arc length measurement and droplet detachment detection during flux cored arc welding (FCAW) and for arc length measurement during GTAW. 


\section{STANDARDS}

T.A. Siewert, M.W. Austin, D.L. Fitting, D.A. Shepherd, D.P. Vigliotti, and C.N. McCowan

The Division has a wide range of standards activities associated with its mission to develop measurement technology to improve the quality, reliability and safety of advanced materials. However, only two programs are specifically directed toward the development and distribution of standards and standard reference materials. The radioscopy program develops measurement standards to facilitate industry's shift from film-based radioscopy to imaging screen systems. The charpy v-notch calibration program annually certifies about 1000 impact test machines from all over the world.

\section{significant Accomplishments}

An X-ray stage calibration board, standard Reference Material (SRM) 1842, was developed and made available for checking the accuracy of $X$ and $Y$ translation stage encoders or the uniformity of the field of view of automated X-ray systems.

A new higher energy reference specimen, SRM 2098, was developed and made available for certifying charpy impact test machines with energy levels greater than $200 \mathrm{~J}$.

\section{Real-time Radioscopy}

The objectives of this investigation are to develop, for radioscopy systems, measurement standards that are based on fundamental units and to develop the corresponding test methods. These developments have become increasingly important because the high cost of film and the delay in evaluating the images are causing many users to switch to imaging screen (radioscopy) systems. Unfortunately, these systems have slightly different capabilities from film, so that conventional image quality indicators and control procedures are not able to fully characterize the images from these systems.

Our approach has been to learn of standardization needs from radioscopy systems users through participation in American society for Testing and Materials (ASTM) Subcommittee E07.01 on Radiology and through discussions with system users groups. For example, users of laminography systems (a special subset of radioscopy that can focus on a single plane) for circuit board inspection identified a need for several calibration devices. In a joint program with the U.S. Army Harry Diamond Laboratory, we satisfied one of these needs by developing a calibration board for the $X-Y$ stages of automated radioscopy systems. The board, shown in Figure 24, is designed to directly measure the positioning accuracy and geometrical magnification of the system by the use of calibrated holes. The first stocking order of this standard material (SRM 1842 ) has been produced and verified. It is available for purchase from the NIST Office of Standard Reference Materials. 


\section{X-RAY LAMINOGRAPHY CALIBRATION PLATE}

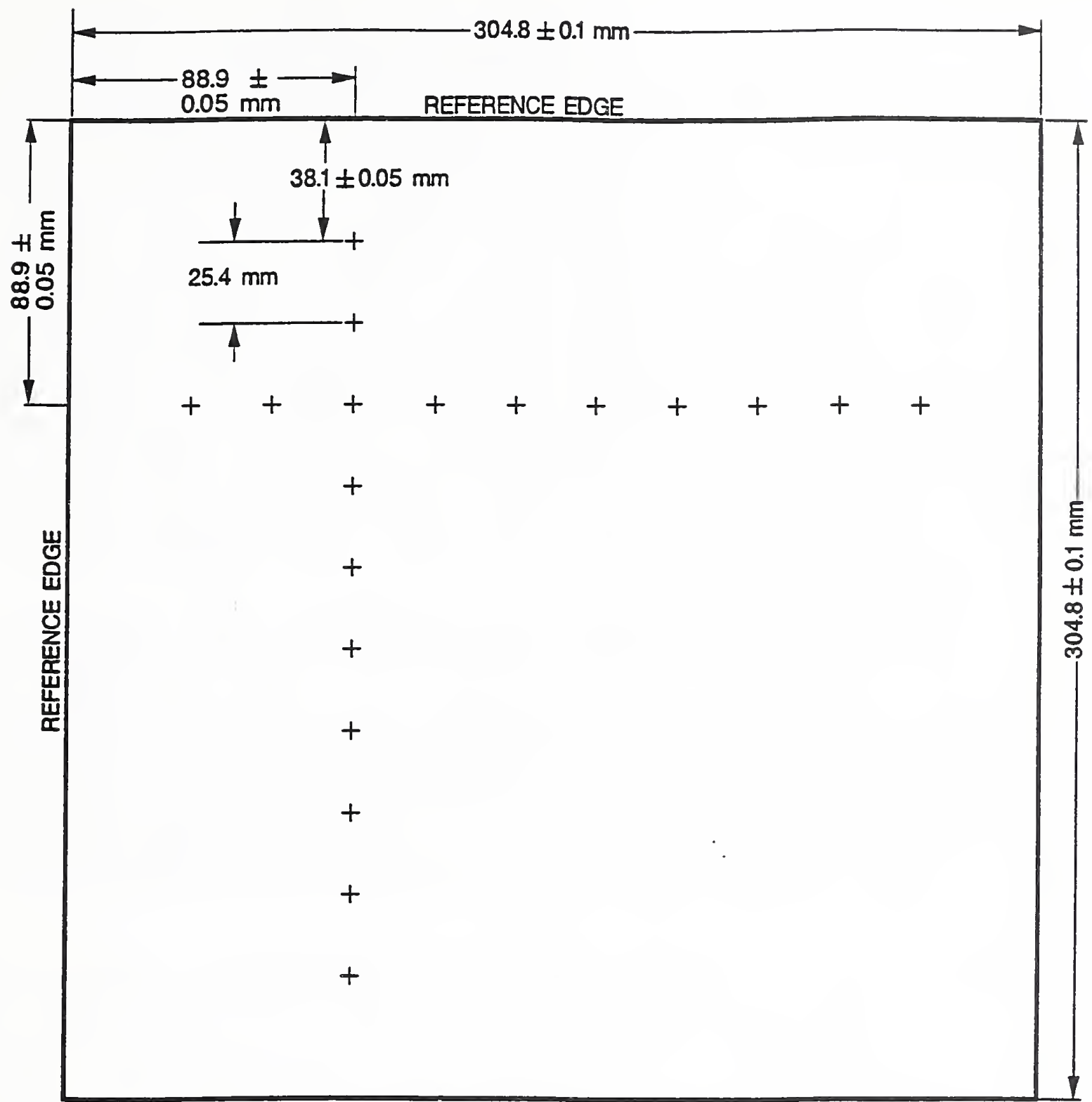

Each hole should be $\pm 0.05 \mathrm{~mm}$ from the appropriate reference edge.
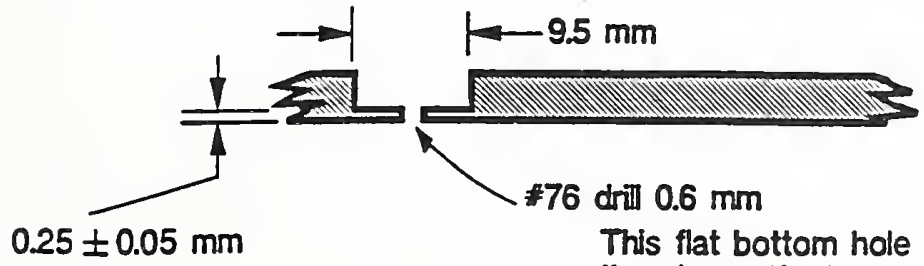

This flat bottom hole should be centered in the above 19 places on the plate. The plate is $3.2 \mathrm{~mm}$ thick 304 S.S.

Figure 24 .

Calibration board for confirming the $X-Y$ stage positioning accuracy and magnification of an automated $\mathrm{x}$-ray radioscopy system. 
The cooperative radioscopy standards development program with the Harry Diamond Laboratory is continuing. This next year we will complete the development of a second standard material, one to measure the depth of focus and the $\mathrm{z}$-dimension resolution of laminography systems. This device is a series of alternate layers of high- and low-density material. As the plane of focus is moved up or down, the high-density layers move in and out of focus. optical calibration of the layer positions (furnished with the device) allows users to calibrate the z-dimension of their system.

In test method development, we have been working closely with ASTM subcommittee E07.01 on Nondestructive Testing. This committee contains representatives of the industrial developers and users of this technology, and is responsible for maintaining a wide variety of $x$-ray testing procedures and standards. We have been assisting in the preparation of new standards for radioscopy, that parallel the older standards for film-based radiography. We have just drafted a proposed standard for the use of British Standard 3971 duplex wire gages for use with radiologic imaging applications. This document will be balloted in the next few months.

NIST has also been working with the General Electric Company, the Naval Air Engineering Center, and the U.S. Army Materials Technology Laboratory in developing an ASTM standard for radioscopic inspection of military components. In accordance with a Department of Defense desire to avoid the preparation of separate military standards, the standard will be a supplement to a general ASTM standard (E1255) on radioscopic inspection. The sixth draft of this standard has completed balloting within ASTM Committee E07 and has also been through Department of Defense laboratory review. It should be published within the next year.

In several cases, we have developed new ideas for standards but have not been able to contact users with an immediate need within ASTM Committee E07 or organized users groups. In these cases, we have published reports of the concepts and invited participation in round robin evaluations. One concept was a hollow sphere design that seems to be particularly useful for systems that permit rotation of the parts being inspected. Another was a twisted strip image quality indicator design for characterizing a microfocus $x-$ ray tube beam. Here, the concept is simply that of a thin strip with a half twist. The twist allows the long dimension of the strip cross section to be perfectly oriented with the $x$-ray beam at some location, without careful orientation of the strip itself. We have provided samples of both concepts to potential users and are awaiting reports of their evaluations.

The rest of the world is also quite interested in implementing radioscopic inspection technology. International Institute of welding Commission $\mathrm{V}$ is developing a number of standards for this technique, which they will submit to the International standards organization as draft standards. NIST is serving as liaison 
between ASTM and IIW, so U.S. standards will be compatible with the rest of the world. During this next year, we will supply one of our $X-Y$ stage calibration boards for consideration as an international standard (ISO). To make American industry aware of these international activities, we have published summaries of the annual meetings for the NDE community.

\section{Charpy $\nabla$-notch Calibration}

The Charpy impact test is a small-scale laboratory and industrial fracture experiment that uses a pendulum-type drop hammer and a centimeter-size material specimen to measure the ductile or brittle behavior of steel. It is the most widely used standard for predicting the fracture behavior of steel because of its simplicity and low cost. We evaluate the results from the fracture of standardized specimens, results that are used to certify the accurate operation of these machines. We have performed these evaluation services for about 1000 machines, from around the world, during the past year.

Three specimen energy ranges (near 17, 98, and $200 \mathrm{~J}$ ) are now available. We are evaluating new materials, for more consistent values within the existing energy ranges.

We are also evaluating the effect of the striker design on the absorbed energy. While the ASTM standard specifies an 8-mm radius at the striker face, much of the rest of the world uses a striker face with a $2-\mathrm{mm}$ radius. The two striker designs provide similar data at low specimen energies, but can diverge by over $20 \%$ at energies above $200 \mathrm{~J}$. We are using our reference specimens to the to compare the two strikers. 


\section{CRYOGENIC MATERIALS}

L.I. Sparks, J.W. Bransford, R. Compos**, R. Deal**, E.S. Drexler, B.J.Filla, J.D. McColskey, R.P. Reed*, D.L. Rule, N.J. Simon, A.J. Slifka, D. R. Smith, R. I. Tobler, G. Velarde**, and R. P. Walsh

A broad scope of mechanical, physical, and metallurgical behaviors of solid materials are studied. The primary temperature range of interest is from the normal boiling point of helium, $4 \mathrm{~K}$, up to ambient temperatures. An exception occurs in the study of oxidation of metals where temperatures sufficient to ignite alloys are achieved. Goals of our research are: characterization of pure metals, structural alloys, polymers, ceramics, composites, thermalinsulating materials, and superconductors; development of test procedures and standards; and, collection and evaluation of extant material property data.

Four major programs were funded by other agencies and one by a private sector entity: (1) the Department of Energy continued to sponsor development of materials technology necessary to support the design of superconducting magnets for fusion-energy, power generating systems; (2) the Department of Defense sponsored a program to evaluate composite materials and their components for use in superconducting Magnetic Energy storage systems; (3) NASA continued to support apparatus development and materials research to obtain data for and understanding of oxidative processes in high pressure oxygen systems; (4) NASA continued to support tribological studies of material systems now in use and to expand the research to materials which may improve friction and wear characteristics; and Martin Marrietta supported research to determine the effect on thermal insulating properties of substituting environmentally acceptable hydrogenated chloroflorocarbon gases for currently used chloroflorocarbon gases.

our staff and facilities combine to provide a unique capability to study tensile, fracture, impact, shear, creep, fatigue, thermal conductivity, and thermal expansion at very-low temperatures. The results of our projects support specific tasks in design and in reliability assessments. Perhaps even more important is the use of our expertise and hard output by the general technical community.

\section{significant Accomplishments}

- The thermal and mechanical properties of eighteen neat resins were determined in the temperature range from 4 to $300 \mathrm{~K}$. The resins judged most promising for cryogenic composites were used to make uniaxial specimens which were similarly tested.

* Consultant to NIST

* * PREP Scholarship Program, University of Colorado 
- Composite tubes varying in diameter from 5 to $25 \mathrm{~cm}$ diameter and made from selected resins and glass fiber, were tested and modeled. This effort aids design and risk reduction in the proposed superconducting magnetic energy storage system.

- Short-crack, simulation tests were developed and applied to Incoloy 908, a candidate material for the superconductor sheath of the International Thermonuclear Experimental Reactor. These $4 \mathrm{~K}$ tests are economical and are considered crucial for conduit evaluation. These studies confirm that Incoloy 908 plate has a high fatigue threshold stress intensity factor at $4 \mathrm{~K}$.

Systematic testing of the tribological properties of stainless steel $440 \mathrm{C}$ as a function of load, velocity, and temperature have been completed. Surface and chemical analysis of the oxides produced in an oxygen environment are being done to aid in modeling and understanding the effects responsible for the observed wear modes. The research is continuing on diamondlike-carbon films and $\mathrm{Si}_{3} \mathrm{~N}_{4}$ materials. Initial tests suggest that the coefficient of friction can be reduced by an order of magnitude and the specific wear rate by two orders of magnitude.

\section{Tribology of Advanced Materials}

Present and future propulsion systems require advanced materials for bearing applications. The High Pressure Oxygen Turbopump (HPOTP) of the Space Shuttle Main Engine (SSME) currently uses AISI $440 \mathrm{C}$ martensitic stainless steel as bearing material, due primarily to its corrosion resistance. The bearings run in a liquid oxygen environment, essentially unlubricated, at a typical contact stress of $2.07 \mathrm{GPa}$. In addition, the bearings are subjected to high axial loads during start-up and shut-down. These combine to limit the life of the bearings to about 10 percent of the 7.5 hour design life. The high hardness and thermal conductivity of synthetic diamond make it an attractive material for use in unlubricated tribological systems. An advanced material system, possibly combining ceramic rolling elements with diamond-like-carbon (DLC) coated races, is needed to achieve the performance requirements of present and future propulsion systems.

An apparatus has been designed and built at NIST which allows tribological testing under the severe conditions that exist in the SSME. The schematic of the apparatus is shown in Figure 25 and its operating parameters are listed in Table 2. 
Table 2. Operating Parameters of the Tribometer.

\begin{tabular}{|l|l|}
\hline Axial load & 2 to $900 \mathrm{~kg}$ \\
\hline Torque & up to 45.2 newton-meter \\
\hline Temperature range & 800 to $1030 \mathrm{~K}$ \\
\hline rpm & 50 to 1800 \\
\hline Surface area & $6.45 \times 10^{-5} \mathrm{~m}^{2}\left(0.1 \mathrm{in}^{2}\right)$ \\
\hline Ball size (dia.) & $4.76 \times 10^{-3} \mathrm{~m}(3.16 \mathrm{in})$ \\
\hline Radius of contact path (cone) & $6.40 \times 10^{-3} \mathrm{~m}(0.252 \mathrm{in})$ \\
\hline Radius of contact path (ball) & $1.11 \times 10^{-3} \mathrm{~m}(0.44 \mathrm{in})$ \\
\hline Surface velocity (cone-on-cone) & 0.03 to $1.2 \mathrm{~m} / \mathrm{s}$ \\
\hline Surface velocity (ball-on-flat) & 0.06 to $2.0 \mathrm{~m} / \mathrm{s}$ \\
\hline Environment & inert gas or flowing oxygen \\
\hline
\end{tabular}




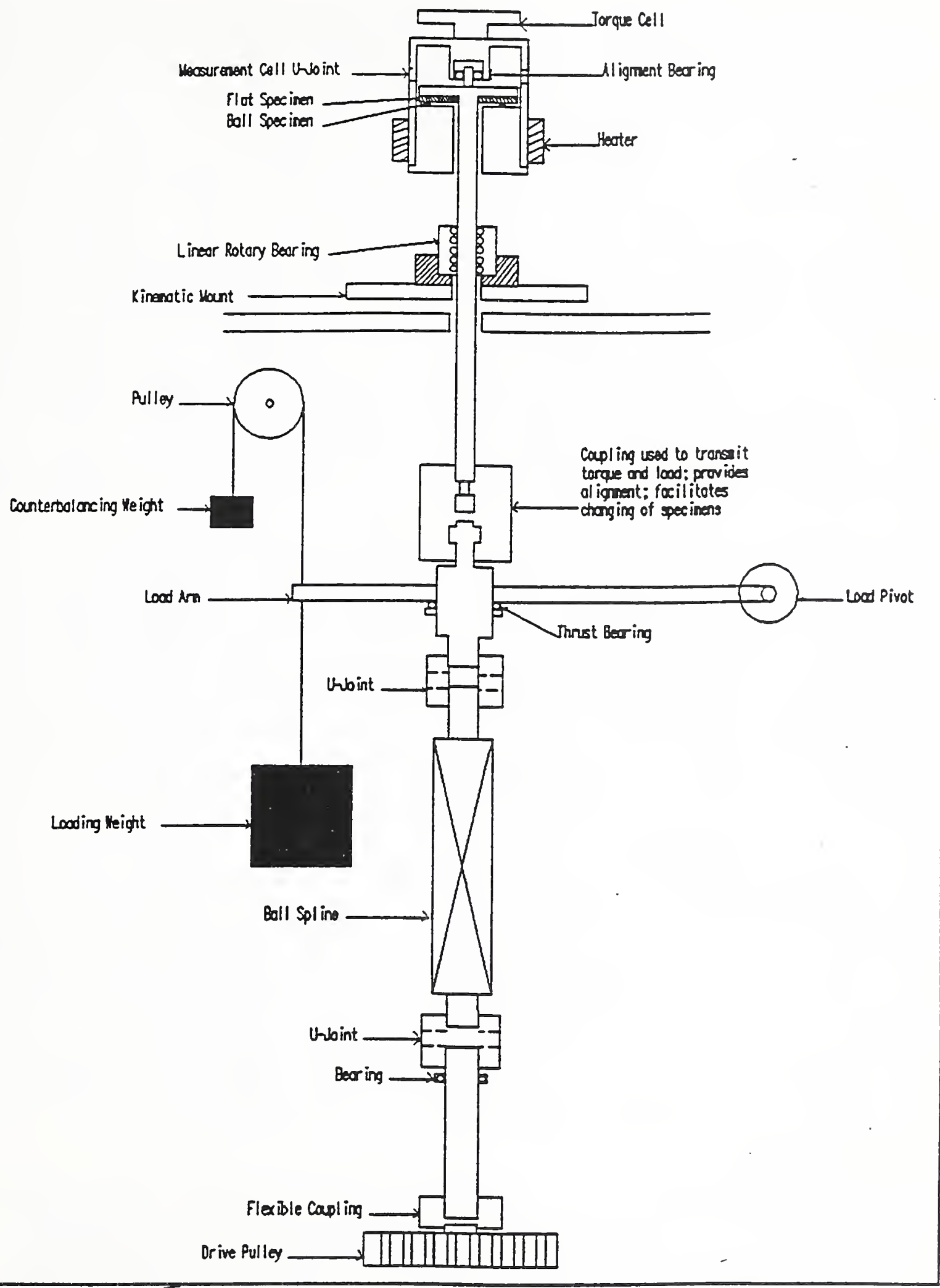

Figure 25. Schematic Diagram of the Tribometer. 
The near-term goal of the project was to quantitively determine the tribological behavior of the $440 \mathrm{C}$ material currently in use. The tests were completed this year and provide essential information which is being incorporated into the thermal model of the shuttle engine by the NASA sponsor. A summary of the findings for the $440 \mathrm{C}$ couple is given in Table 3.

Table 3. Tribological Data for $440 \mathrm{C} / 440 \mathrm{C}, \mathrm{Si}_{3} \mathrm{~N}_{3} / 440 \mathrm{C}$, and $440 \mathrm{C} / \mathrm{DLC}$ Couples.

\begin{tabular}{||c|c|c|c|c|c||}
\hline Couple & $\begin{array}{c}\text { Film } \\
\text { Thickmess } \\
(\mu \mathrm{m})\end{array}$ & $\begin{array}{c}\text { Hertzian } \\
\text { Contact } \\
\text { Stress } \\
(\mathrm{GPa})\end{array}$ & $\begin{array}{c}\text { Temperature } \\
\left({ }^{\circ} \mathrm{C}\right)\end{array}$ & $\begin{array}{c}\text { Coefficient } \\
\text { of Friction }\end{array}$ & $\begin{array}{c}\text { Wear } \\
\text { Rate } \\
\left(\mathrm{mm}^{3} / \mathrm{N} \cdot \mathrm{m}\right)\end{array}$ \\
\hline $440 \mathrm{C} / 440 \mathrm{C}$ & & 1.83 & $23 * *$ & 0.60 & $7.6 \times 10^{-6}$ \\
\hline $\mathrm{Si}_{3} \mathrm{~N}_{4} / 440 \mathrm{C}$ & & 1.83 & 86 & 0.56 & $2.5 \times 10^{-7}$ \\
\hline $440 \mathrm{C} / 440 \mathrm{C}$ & & 1.83 & -178 & 0.44 & $9.6 \times 10^{-6}$ \\
\hline $\mathrm{Si}_{3} \mathrm{~N}_{4} / 440 \mathrm{C}$ & & 1.83 & -159 & 0.56 & $6.8 \times 10^{-7}$ \\
\hline $440 \mathrm{C} / 440 \mathrm{C}$ & & 2.75 & 145 & 0.50 & $1.9 \times 10^{-6}$ \\
\hline $\mathrm{Si}_{3} \mathrm{~N}_{4} / 440 \mathrm{C}$ & & 2.75 & 151 & 0.57 & $2.3 \times 10^{-7}$ \\
\hline $440 \mathrm{C} / 440 \mathrm{C}$ & & 2.75 & -182 & 0.57 & $5.3 \times 10^{-6}$ \\
\hline $\mathrm{Si} \mathrm{N}_{4} / 440 \mathrm{C}$ & & 2.75 & -124 & 0.59 & $2.8 \times 10^{-7}$ \\
\hline $440 \mathrm{C} / \mathrm{DLC}$ & 1 & 1.83 & 31 & 0.03 & $<1.8 \times 10^{-8}$ \\
\hline $440 \mathrm{C} / \mathrm{DLC}$ & 1 & 1.83 & -183 & 0.12 & $2.8 \times 10^{-7}$ \\
\hline $440 \mathrm{C} / \mathrm{DLC}$ & 0.5 & 2.75 & 142 & 0.47 & $9.6 \times 10^{-6}$ \\
\hline $440 \mathrm{C} / \mathrm{DLC}$ & 1 & 2.75 & 47 & 0.16 & $1.8 \times 10^{-7}$ \\
\hline $440 \mathrm{C} / \mathrm{DLC}$ & 2 & 2.75 & 105 & 0.03 & $4.1 \times 10^{-6}$ \\
\hline $440 \mathrm{C} / \mathrm{DLC}$ & 0.5 & 2.75 & -66 & 0.54 & $5.0 \times 10^{-7}$ \\
\hline $440 \mathrm{C} / \mathrm{DLC}$ & 1 & 2.75 & -178 & 0.20 & $3.6 \times 10^{-9}$ \\
\hline $440 \mathrm{C} / \mathrm{DLC}$ & 2 & 2.75 & -152 & 0.43 & $1.1 \times 10^{-6}$ \\
\hline
\end{tabular}

A very low coefficient of friction can be achieved using DLC films in an oxygen environment. Table 3 shows data for eight tests of $440 \mathrm{C} / \mathrm{DLC}$ film couples. The coefficient of friction is the arithmetic mean coefficient of friction for sliding, and therefore the kinetic coefficient of fiction. The wear rate reported here is the average specific ball wear rate of the three $440 \mathrm{C}$ balls used 
for each test. The uncertainty of the coefficient of friction due to instrumentation is $15 \%$, and the uncertainty of the wear rate due to instrumentation is $0.5 \%$.

The data shows that the $1 \mu \mathrm{m}$ thick film is superior to both the thinner and the thicker films. This is possibly due to a balance that is achieved between load-carrying capacity, which would increase with increasing film thickness, and internal stress of the film, which also increases as film thickness increases. The coefficient of friction for the $1 \mu \mathrm{m}$ films is less than half of that of the films of other thicknesses that were studied. The wear rate of the $440 \mathrm{C}$ balls on the $1 \mu \mathrm{m}$ films is at least an order of magnitude less than that of other film thicknesses studied. These tests show that the frictional heating is significantly smaller for the $1 \mu \mathrm{m}$ film, which follows the coefficient of friction. The wear rate for $440 \mathrm{C}$ balls on the $1 \mu \mathrm{m}$ DLC film tested at room temperature and $2.75 \mathrm{GPa}$ stress is the wear rate for the entire test, run well into film breakdown. This film stayed intact for over $200 \mathrm{~m}$ sliding distance, at which time the wear rate was less than $5.33 \times 10^{9}$ $\mathrm{mm}^{3} / \mathrm{N} \cdot \mathrm{m}$.

Table 3 also shows data for $\mathrm{Si}_{3} \mathrm{~N}_{4}-\mathrm{On}-440 \mathrm{C}$. The $\mathrm{Si}_{3} \mathrm{~N}_{4}$ balls have an order of magnitude higher wear resistance than $440 \mathrm{C}$ balls, while the coefficient of friction for $\mathrm{Si}_{3} \mathrm{~N}_{4}$ is slightly higher than for 440C. Comparing these results with the results for $440 \mathrm{C}$ balls on DLC films shows that the $440 \mathrm{C} / \mathrm{DLC}$ film couple always has lower coefficients of friction that either $440 \mathrm{C}$ or $\mathrm{Si}_{3} \mathrm{~N}_{4}$ on $440 \mathrm{C}$. The coefficient of friction of $440 \mathrm{C} / 1 \mu \mathrm{m}$ DLC film couples is far superior to either $\mathrm{Si}_{3} \mathrm{~N}_{4}$ or $440 \mathrm{C}$ on $440 \mathrm{C}$. The wear rate of $440 \mathrm{C} / 1 \mu \mathrm{m}$ DLC is an order of magnitude lower than $\mathrm{Si}_{3} \mathrm{~N}_{4} / 440 \mathrm{C}$ couples, and two orders of magnitude lower that $440 \mathrm{C} / 440 \mathrm{C}$ couples.

\section{Mechanical and Thermal Characterization of composites}

In 1987 a program was initiated to demonstrate the feasibility of superconducting magnetic energy storage (SMES) and to consider the construction of an engineering test model (ETM). It was primarily sponsored by the strategic Defense Initiative office (SDIO), partially supported by the Electric Power Research Institute (EPRI), and managed by the Defense Nuclear Agency (DNA). The program objectives were to assess the feasibility of using SMES technology to provide electrical power for defense purposes (SDIO) and to provide grid stability and control and load leveling to benefit the electric-power utilities (EPRI).

Our research in support of SMES consisted of four principal tasks:

1. Various generic classes of resins that are suitable for either filament-winding or pultrusion manufacturing processes were tested at room and low temperatures. In all, eighteen 
different resins--including epoxy, cyanate-ester, vinyl-ester, and polyester systems--were studied.

2. Properties of composite plates with unidirectionally oriented E-glass fibers in both epoxy and cyanate-ester-resin matrices were determined at 295, 76, and $4 \mathrm{~K}$.

3. Compressive properties of tubular composite struts, ranging from $100 \mathrm{~mm}$ (4 in) to $250 \mathrm{~mm}(10 \mathrm{in})$ in diameter, were obtained at 295, 76, and $4 \mathrm{~K}$. Fiber lay-up, tube thickness and length, and resin system were varied in these experiments. Limited fatigue data were also obtained.

4. Analytic and failure analyses studies were conducted. These included the development of stress- and strain-controlled thermal-mechanical modeling for property prediction and quality control, the modeling of end fixtures, and analyses of failed tubes.

The summary report (approximately 650 pages) of this activity is now in editorial review to be published as a NISTIR. Specific properties, studied as a function of temperature are: tensile, compression, shear strengths and their moduli, thermal conductivity and contraction, effects of thermal cycling, and residual stress.

These characterizations were made on neat resins, uniaxial composites, and finally on composite tubes. Models, using observed results of component properties, were developed to address questions about the response of fiber-reinforced composite cylinders to loads, effects of end fittings, and failure analysis for composite tubes.

Table 4 and Figure 26 are typical of the data presented for compression tests on tubes and thermal conductivity of uniaxial composites respectively. 
Table 4. Compression Test Results for Composite Tube Number 5. TUBE NO. 5

MANUFACTURER:

LAY-UP :

WALL THICKNESS:

LENGTH :

RESIN :

FIBER :

PROCESS :

COMMENTS :

22 plies;

thickness: $18[ \pm 10]$ plies $x 0.51 \mathrm{~mm}(0.020 \mathrm{in}) / \mathrm{ply}=9.1 \mathrm{~mm}$ $(0.360$ in) $-90 \%$

4 [82] plies $x 0.025 \mathrm{~mm}(0.010 \mathrm{in}) / \mathrm{ply}=1 \mathrm{~mm}$ $(0.040$ in) $-10 \%$

- 2 internal hoop winds $\left(82^{\circ}\right)$

- Proprietary resin and cure schedule

$\left[82 / \pm 10_{3} / 82 / \pm 10_{3} / 82 / \pm 10_{3} / 82\right]$

$10.2 \mathrm{~mm}(0.40 \mathrm{in})$

$710 \mathrm{~mm}$ (28 in), $480 \mathrm{~mm}$ (19 in), $230 \mathrm{~mm}$ (9 in) DGEBA / DCH / ARA / ACL

E-glass, $1100 \mathrm{TEX}$ (450 yd/lb), continuous strand

filament winding

\begin{tabular}{|c|c|c|c|c|c|c|c|c|c|}
\hline \multirow{2}{*}{$\begin{array}{l}\text { Test } \\
\text { Temp } \\
(\mathrm{K})\end{array}$} & \multicolumn{3}{|c|}{$\begin{array}{c}\text { Tube Dimensions } \\
(\mathrm{mm})\end{array}$} & \multirow[t]{2}{*}{$\begin{array}{l}\text { Resin } \\
\text { System }\end{array}$} & \multicolumn{2}{|c|}{$\begin{array}{l}\text { Ultimate } \\
\text { Strength }\end{array}$} & \multirow{2}{*}{$\begin{array}{l}\text { Strain } \\
\text { to } \\
\text { Failure } \\
(8)\end{array}$} & \multirow[t]{2}{*}{$\begin{array}{c}\text { Poisson's } \\
\text { Ratio }\end{array}$} & \multirow{2}{*}{$\begin{array}{c}\text { Axial } \\
\text { Modulus }\end{array}$} \\
\hline & 1 & $t$ & I.D. & & $(\mathrm{MPa})$ & $(k s i)$ & & & \\
\hline \multirow[t]{5}{*}{295} & 710 & 10.2 & 102 & DGEBA/ & 681 & 98.8 & 1.59 & 0.36 & 42.0 \\
\hline & 710 & 10.2 & 102 & $\mathrm{DCH} /$ & 594 & 86.2 & 1.41 & 0.31 & 43.0 \\
\hline & 480 & 10.2 & 102 & ARA/ & 518 & 75.2 & 1.19 & $\ldots$ & 43.0 \\
\hline & 230 & 10.2 & 102 & ACL & 687 & 99.6 & 1.66 & -- & 41.5 \\
\hline & \multicolumn{3}{|c|}{$295-K$ average } & & 620 & 89.9 & 1.46 & 0.34 & 42.4 \\
\hline \multirow[t]{3}{*}{76} & 710 & 10.2 & 102 & & 907 & 131.5 & 2.08 & 0.31 & 46.8 \\
\hline & 710 & 10.2 & 102 & & 1190 & 172.5 & 3.30 & 0.28 & 42.8 \\
\hline & \multicolumn{3}{|c|}{$76-K$ average } & & 1048 & 152.0 & 2.69 & 0.30 & 44.8 \\
\hline \multirow[t]{3}{*}{4} & 710 & 10.2 & 102 & & 1154 & 167.4 & 2.63 & 0.30 & 48.2 \\
\hline & 710 & 10.2 & 102 & & 1069 & 155.0 & 2.37 & -- & 45.5 \\
\hline & & $-K$ ave & & & 1112 & 161.2 & 2.50 & 0.30 & 46.9 \\
\hline
\end{tabular}




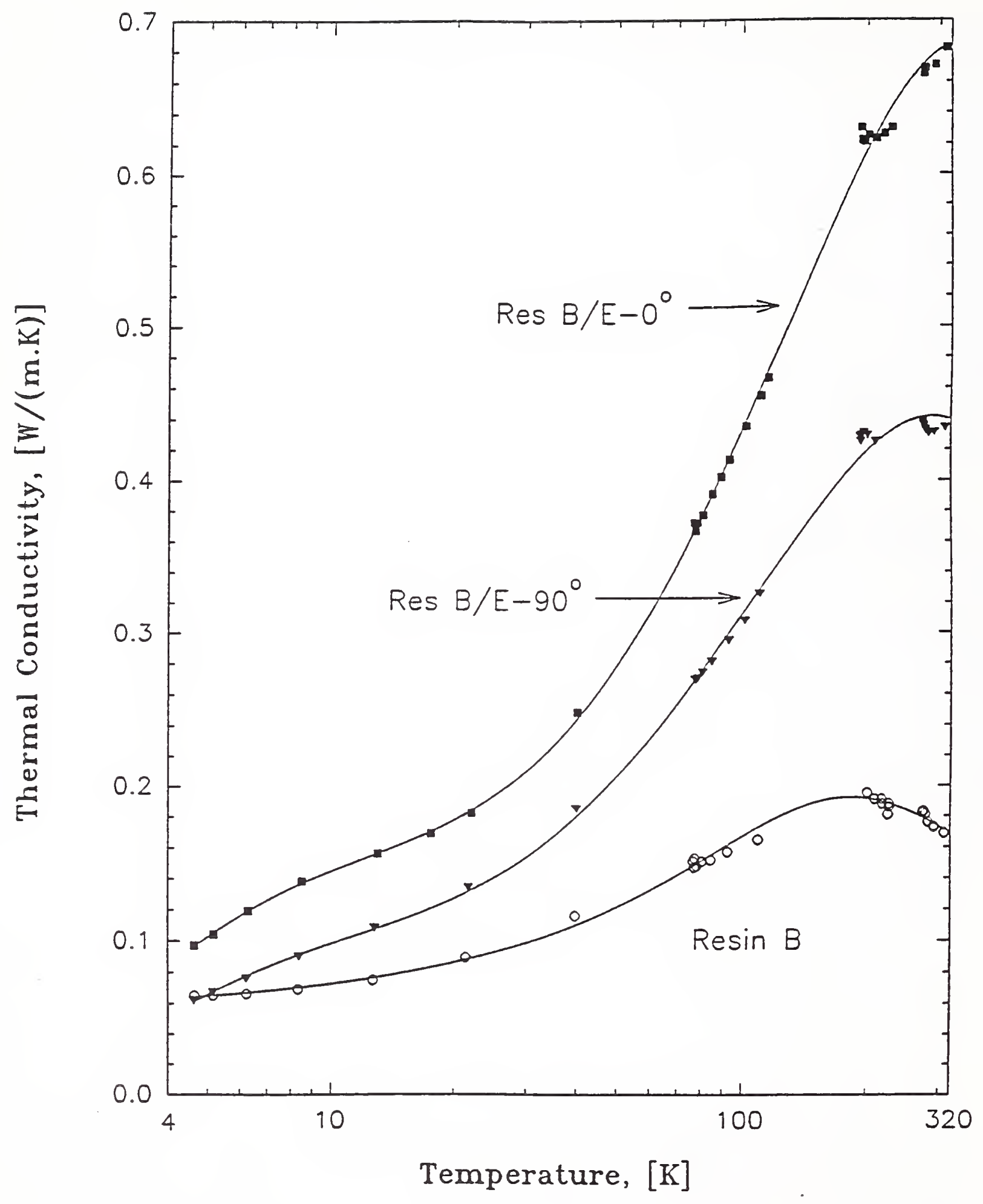

Figure 26. Thermal conductivity of the composite specimens. Experimental data are presented as discrete points. 


\section{DTA Analysis of the oxidation Characteristics of Alloys}

Traditionally the evaluation of materials for use in liquid and gaseous oxygen has been accomplished by tests that attempt to simulate various equipment failure modes. To some extent, these methods have met with success, particularly with nonmetallic materials. However, there often is some conflict in the "rank ordering" of materials. That is, one test will indicate that one material is better than other materials while a different test may indicate a different order or yield no information at all. For example $\mathrm{S} 44004$ when tested by frictional heating and ranked by the product of contact pressure, $\mathrm{P}$, times linear surface velocity, $v$, places this material at the bottom of a list of materials. However, when ranked by contact pressure times linear surface velocity times coefficient of friction, the material places close to the top of the list of materials. Mechanical impact tests in liquid and gaseous oxygen at pressures to $69 \mathrm{MPa}(10,000 \mathrm{psi})$ passes the material without qualifications. Additionally, the simulation test methods do not yield fundamental chemical reactivity information. Part of the difficulty is that equipment capable of yielding fundamental information could not operate at the required oxygen pressures. In an effort to overcome this equipment limitation, we have developed a high-pressure/hightemperature differential thermal analysis/thermo-gravimetric analysis (DTA/TGA) thermal analysis system, shown schematically in Figure 27. The system operating parameters are oxygen pressures from $0.1 \mathrm{kPa}$ ( 1 torr) to $34.5 \mathrm{MPa}(5000 \mathrm{psi}$ ) and at temperatures to $1973 \mathrm{~K}\left(3092^{\circ} \mathrm{F}\right)$. 


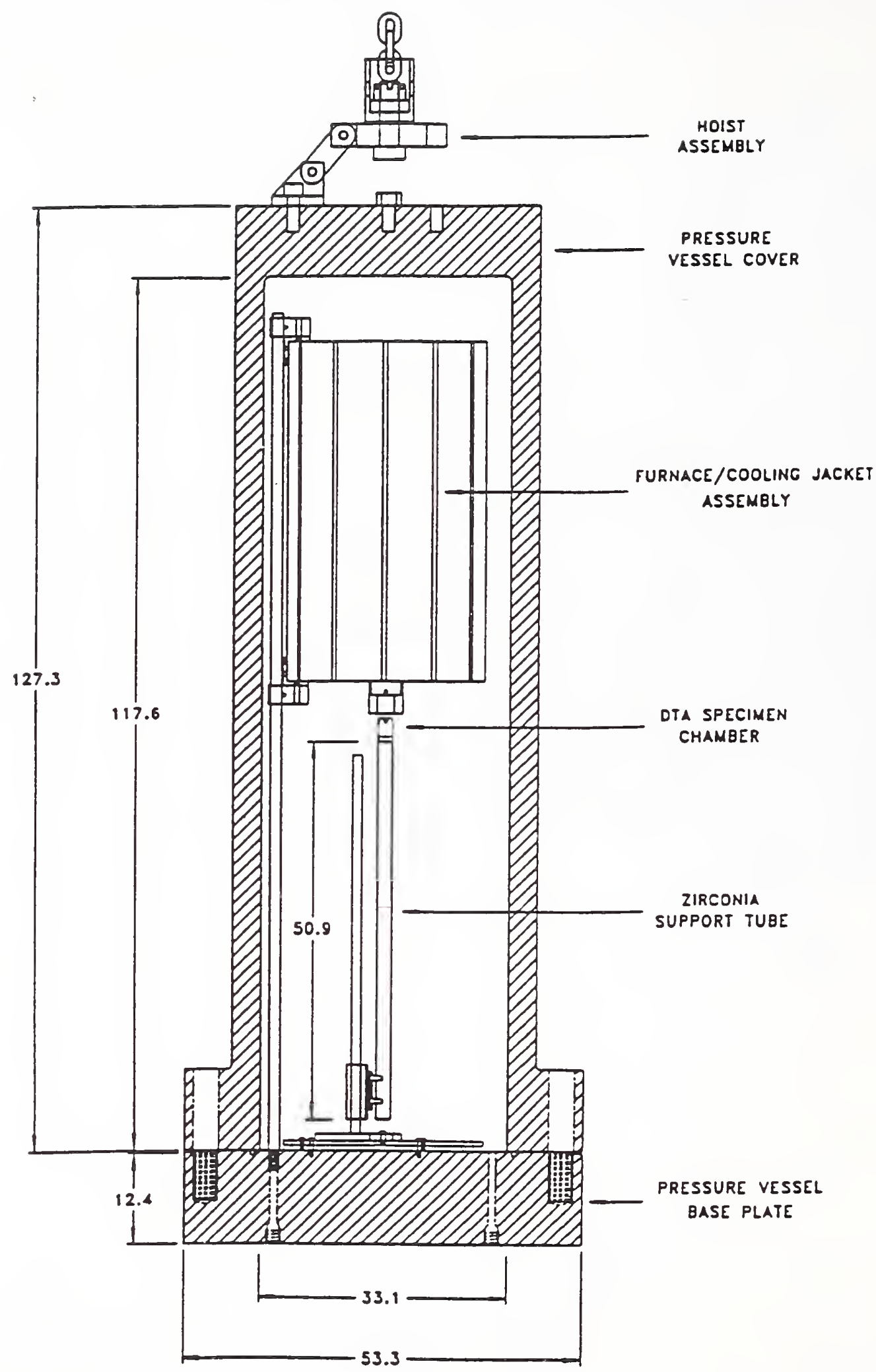

Figure 27. Schematic diagram of the high-pressure chamber, furnace assembly and DTA assembly. 
Alloys examined to date in this system include N04400, N06625, N07001, N07719, N07750, S4404, and S66286. A summary of the temperature at which destructive oxidation (nonprotective or timeindependent oxidation), $T_{d}$, begins is shown in Table 5 . Once destructive oxidation has begun, a material tends to selfheat to destruction. The terminology, destructive oxidation, must be qualified to distinguish it from ordinary surface oxidation. The onset of this destructive oxidation is the point at which the rate of heating due to exothermic oxidation exceeds the rate of heating due to furnace heating.

An example of the type of data obtained from the DTA is shown in Figure 28 for 544004 (S.S. 440C). This figure shows a helium baseline test and two oxygen tests at 0.689 and $1.724 \mathrm{MPa}$ ( 100 and $250 \mathrm{psi})$. The helium baseline test is featureless except for the endotherm at $1084 \mathrm{~K}$ which is due to the metallurgy of the material, possibly a carbide solutioning. The test at $0.689 \mathrm{MPa}$ shows the onset of an exotherm at $1016 \mathrm{~K}$. The test at $1.724 \mathrm{MPa}$ shows the onset of an exotherm 1018K. An additional test at $3.447 \mathrm{MPa}(500$ psi) gave the onset of an exotherm at $1023 \mathrm{~K}$. These exotherms are considered to be the onset of destructive oxidation.

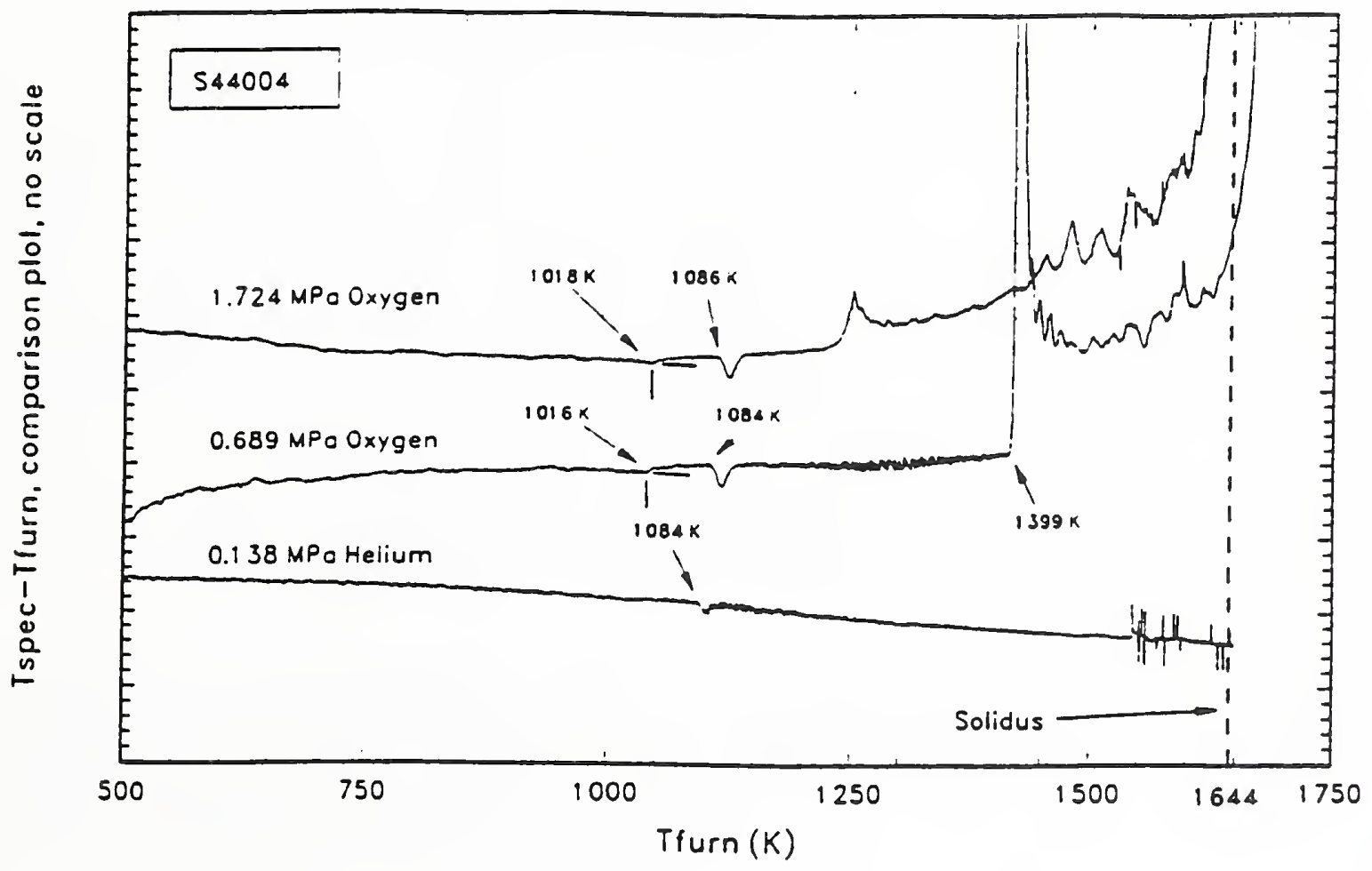

Figure 28. Examples of the helium baseline test and two oxygen tests at 0.689 and $1.724 \mathrm{MPa}$ for $\mathrm{S44004}$. 
Table 5. Onset Temperature for Destructive oxidation.

\begin{tabular}{|c|c|c|}
\hline Material & Pressure, MPa & $T_{\mathrm{d}, ~} \mathrm{~K}$ \\
\hline N04400 & 0.689 & $1283(1) \#$ \\
& 1.724 & $1276(1)$ \\
\hline N06625 & 0.689 & $1497(1)$ \\
& 1.724 & $1507(1)$ \\
\hline \multirow{2}{*}{ N07001 } & 0.689 & $1031(1)$ \\
& 1.724 & $1054(2)$ \\
\hline \multirow{2}{*}{ N07718 } & 0.689 & $>1533(1)$ \\
& 1.724 & $>1533(1)$ \\
\hline \multirow{2}{*}{ N07750 } & 0.689 & $978(1)$ \\
& 1.724 & $1055(1)$ \\
\hline \multirow{2}{*}{ S66286 } & 0.689 & $1016(1)$ \\
& 1.724 & $1019(2)$ \\
& 3.447 & $1023(1)$ \\
\hline
\end{tabular}

\# number of data points are given in parentheses

Cryogenic structural Alloy Measurements for Fusion Magnet systems

This year's effort contributed to the characterization of newly developed conduit sheath materials which contair the superconducting cable as well as liquid helium coolant at $4 \mathrm{~K}$. These materials have to be compatible with $\mathrm{Nb}_{3} \mathrm{Sn}$ thermal expansion and heat treatment at about $700^{\circ} \mathrm{C}$ and also withstand approximately 40,000 fatigue cycles. Since proposed conduit alloys, such as Incoloy 908, are in a developmental stage, it is critical to acquire a broader measurement base. In particular, short crack fatigue data and weld properties are needed. New mechanical tests are needed for conduits in view of special geometry (thin sections) and service conditions (high stress, high-cycle fatigue after sensitization heat treatments).

Accomplishments include the first intralaboratory comparison of three leading candidate materials which shows that Incoloy 908 may offer potential advantages compared to modified 316LN type alloys. Temperature dependence and sensitivity studies confirmed that Incoloy 908 plate has a relatively high fatigue threshold stress intensity factor at $4 \mathrm{~K}$, assuming material is properly processed. Short crack simulation tests were applied for the first time, and now are considered crucial for conduit evaluation at $4 \mathrm{~K}$. Compared to the traditional approach, the automated short crack simulation approach using new hardware and modified software greatly reduces 
testing time and fluid costs while producing conservative design data that are appropriate for conduit applications. Also, a series of surface flaw tests was planned and initiated jointly with MIT. The surface flaw specimen more closely simulates a type of flaw likely to be encountered in service, and (for the first time at 4 K) enables characterization of resistance to crack growth in a direction through the conduit wall.

A significant component in the development of the International Thermonuclear Experimental Reactor (ITER) is the U.S.-Japan cooperative program. This year associations with Japan included attendance at a joint international meeting in Berkeley, California. Two summary reports covering the Japanese approach to 4-K materials, their predictive maintenance strategy, and JIS prestandards research programs, as well as a current overview of the status of research on magnetic field effects resulted. As part of the U.S.-Japan exchange program, a NIST employee was granted a Ph.D. from Tohoku University. Several program areas have been identified which would complement ITER and the U.S.-Japan cooperative program: Design and Maintenance strategy Development, New Test Methodology Assessment, structural Alloy Characterization, Materials Evaluation Standards, and Magnetic Field Effects on Materials Behavior.

\section{Critical Data Evaluation and Compilation for Fusion Magnet systems}

our effort has focussed on the need to develop electrical insulation for the toroidal field (TF) magnets that will withstand the expected shear and compression stresses as well as the fast neutron fluence and gamma radiation load.

A test method has been developed with simulates the simultaneous shear and compression stresses which TF-magnet insulation will experience. The miniaturized specimens also allow measurement of the bond adhesion to the conductor sheath alloy and can be irradiated in the limited space of the Garching $4-\mathrm{K}$ reactor facility. An agreement has been reached with the NET (Next European Torus) team at the Max Planck Institute in Garching to irradiate these specimens. The U.S.-NIST test method provides for the measurement of the compressive load, which is undetermined for the specimens that NET developed for irradiation in the same facility. Four of them can be irradiated at once in the reactor capsule as compared to one NET specimen, permitting better statistics and faster screening. During the last year, we measured cryogenic shear/compression failure envelopes on a number of specimen types to support optimization of specimens to send to Garching for irradiation.

A comprehensive review of the literature on the irradiation of organic insulation was also carried out; this review includes over 260 full-page figures that illustrate data from 125 references and contains about 200 additional pages of text and tables. The chief 
conclusion of the review was that the current data base did not support ITER TF insulation requirements. The review therefore provided impetus to attain a higher fast neutron fluence in the cooperative irradiation program with NET at Garching. It also stimulated the private sector exploration of additional resin systems that may be more radiation-resistant. In addition, the review documented the lack of irradiation and testing data at the 4-K temperature in which the TF coils will operate and the lack of tests that simulate the operating stresses to which the insulation will be exposed. This manuscript has received NIST-editorial approval and a formal report entitled "A Review of Irradiation Effects on Organic-Matrix Insulation for Next Generation Fusion Devices" will be published. 
OUTPUTS

\author{
and
}

INTERACTIONS 


\section{SELECTED RECENT PUBLICATIONS*}

Balzar, D., Profile Fitting of X-ray Diffraction Lines and Fourier Analysis of Broadening, J. Appl. Crystallogr. 25 (1992) pp. 559570 .

Balzar, D.; Ledbetter, H., Residual Stresses in Aluminum-Mullite $(\alpha$-Alumina) Composites, in Advances in X-ray Analysis, Vol. 36, Plenum, New York, 1993, forthcoming.

Balzar, D.; Ledbetter, H., Microstrains and Domain Sizes in Bi-Cu-O Superconductors: An X-Ray Diffraction Peak-Broadening Study, $J$. Mater. Sci. Lett. 11 (1992) pp. 1419-1420.

Balzar, D.; Ledbetter, H., Voigt-Function Modeling in Fourier Analysis of Size- and Strain-Broadened X-Ray Diffraction Peaks, $J$. Appl. Crystallogr., forthcoming.

Balzar, D.; Ledbetter, H., Determination of Cyrstallite-size and Lattice-strain Parameters from X-ray Diffraction Line-Profile Analysis by Approximating both Size and strain Broadened Profiles with the Voigt Functions, Accuracy in Powder Diffraction II, Gaithersburg, Maryland, May 1992, p. 37.

Balzar, Di Ledbetter, H., Residual Stresses in Aluminum/Mullite $\alpha-$ Alumina) Composites, 41 st Annual Denver X-ray Conference, Colorado Springs, Colorado, August 1992, p. 114.

Balzar, D.; Ledbetter, H., Crystal structure and compressibility of 3:2 Mullite, American Mineralogist, submitted.

Balzar, D.; Ledbetter, H.; Roshko, A., X-ray Diffraction PeakBroadening Analysis of $(\mathrm{La}-\mathrm{M})_{2} \mathrm{CuO}_{4} \mathrm{High}-\mathrm{T}_{\mathrm{c}}$ Superconductors, Powder Diffr., forthcoming.

Balzar, D.; Ledbetter, H.; Roshko, A., Stacking Faults and Microstrain in $\mathrm{La}_{1.85} \mathrm{M}_{0.15} \mathrm{CuO}_{4}(\mathrm{M}=\mathrm{Ca}, \mathrm{Ba}, \mathrm{Sr})$ by Analyzing $\mathrm{X}$-ray Diffraction Line Broadening, Physica C, 185-189, 1991, pp. 871-872.

Bond, L.J.; Chiang, C.-H.; Fortunko, C.M.; McColskey, J.D., Absorption of Sound in Gases Between 10 and $25 \mathrm{MHz}$ : Argon, Proc., 1991 IEEE Ultrasonics Symposium, B.R. McAvoy, Ed., 1992, pp. 10691073 .

Bond, L.J.; Chiang, C.-H.; Fortunko, C.M., Absorption of Ultrasonic Waves in Air at High Frequencies (10-20 MHz), J. Acoust. Soc. Amer. 92 (4) Pt. 1, 1992, pp. 2006-2015.

* Papers that were published or accepted for publication by the Editorial Review Boards of NIST during fiscal year 1992. 
Bond, L.J., The Image of NDT, Intl. Advances in NDT, Vol. 17, Gordon and Breach Science Publishing, 1992, 16 pp.

Bond, L.J.; Zhu, H.; Albach, P.H., Experimental Examination of Mode-Conversion at Hemispherical Surface Indentations, Ultrasonics, 30 (5) pp. 301-310.

Bond, L.J.; Yang, J., Ultrasonic Techniques for Sizing Voids by Using Area Functions, IEEE Proc., Part A, 139, (2), 1992, pp. 4550 .

Bransford, J.W.; Filla, B.J., A High-Pressure DTA/TGA System for Materials oxidation studies, Proc., Advanced Earth-to-orbit Propulsion Tech. Conf., May 19-21, 1992, Huntsville, AL., pp. 4856.

Bransford, J.W.; Filla, B.J., DTA Analysis of Several Iron- and Nickel-Based Alloys, Proc., Advanced Earth-to-orbit Propulsion Tech. Conf., May 19-21, 1992, Huntsville, AL., pp. 57-67.

Bussiba, A.; Tobler, R.L.; Berger, J.R., Superconductor Conduits: Fatigue Crack Growth Rate and Near Threshold Behavior of Three Alloys, Adv. Cryo. Eng., Vol. 38A, 1992, pp. 167-174.

Carlson, N.M. ; Johnson, J.A.; Larsen, E.D.; Clark, A.V.; Fortunko, C.M.; Schaps, S.R., Ultrasonic Sensing of GMAW: Laser/EMAT Defect Detection system, Trans. Amer. Soc. for Metals, to be published in Recent Trends in Welding and Tech., TWR-92.

Cheng, Y. - W. , The Continuous-Cooling-Transformation Diagrams of a Nb-Treated SAE 1141 Steel, Proc., Intl. Conf. on Processing Microstructure and Properties of Microalloyed and other Modern High Strength Low Alloy Steels, The Iron and steel Society, Warrendale, PA, 1992, pp. 223-234.

Clark, A.V.; Schaps, S.R.; Fortunko, C.M., A Well-Shielded EMAT Subsystem for on-Line Ultrasonic Monitoring of GMA Welding Processes, Proc., IEEE 1991 Ultrasonics Symposium Proceedings, Vol. 1, December 8-11, 1991, B.R. McAvoy, editor, pp. 337-340.

Clark, A.V.; Fortunko, C.M.; Lozev, M.G.; Schaps, S.R.; Renken, M.C., Determination of Sheet steel Formability Using Wide Band Electromagnetic-Acoustic Transducers, J. Res. in NDE, in press.

Clark, A.V.; Berlinsky, Y., Effect of Liftoff on Accuracy of Phase Velocity Measurements Made with Electromagnetic Acoustic Transducers, to be published in Research in Nondestructive Evaluation. 
Clark, A.V.; Berlinsky, Y.; Izworski, N.; Cohen, Y.; Mitrakovic, D.V.; Schaps, S.R., Methods to Improve the Accuracy of on-Line Ultrasonic Measurements of steel Sheet Formability, to be published in J. Nondestruct. Eval.

Dally, J.W.; Read, D.T., Electron Beam Moire, Experimental Mechanics, forthcoming.

Datta, S.; Ledbetter, H.; Lei, M., Elastic Properties of UniaxialFiber Reinforced Composites; General Features, chapter in: Nondestructive Evaluation and Material Properties of Advanced Materials, New York: TMS, 1991, pp. 23-28.

Datta, S.; Ledbetter, H.; Taya, M., Elastic Constants of $\mathrm{SiC} / \mathrm{Al}_{2} \mathrm{O}_{3}$ Composites: Measurements and Modeling, to be submitted.

Drexler, E.S.; Simon, N.J.; Reed, R.P., Shear-Compressive Properties of a Vacuum-Impregnated Insulation system at $76 \mathrm{~K}$, Cryogenics, Vol. 32 (ICMC Supplement), 1992, pp. 22-25.

Fitting, D.W.; Fortunko, C.M., A Hemispherical Test Fixture for Measuring the Wavefields Generated in an Anisotropic Solid, Proc., 1991 IEEE Ultrasonics Symposium, IEEE Cat. \#91CH3079-1, 1992,

pp. $831-836$.

Foldeaki, M.; Ledbetter, H.; Paranthaman, M.; Duan, H.; Hermann, A., Asymmetry between Flux Penetration and Flux Expulsion in Tl2212 superconductors, Phys. Rev. Lett., submitted.

Foldeaki, M.; Ledbetter, H. , Orientation Dependence of Flux Pinning in a Layered $\mathrm{Bi}_{2} \mathrm{Sr}_{2} \mathrm{Ca}_{1} \mathrm{Cu}_{2} \mathrm{O}_{8}+10 \% \mathrm{Ag}$ Composite, Mat. Res. Soc. Symp. Proc. 25, 1992, pp. 701-706.

Foldeaki, M.; Ledbetter, H.; O'Handley, R.; Oti, J.; Yamamoto, T., Pinning Force and Time-Dependent Response in a Grain-oriented Yttrium 1:2:3 Superconductor, Mat. Res. Soc. Symp. Proc., forthcoming.

Foldeaki, M.; Ledbetter, H.; Uggowitzer, P., Magnetic Properties of Cr-Mn Austenitic Stainless Steels, J. Magn. Magn. Mater. 110, 1992, pp. 185-196.

Foldeaki, M.; Ledbetter, H., Magnetic-Susceptibility-Temperature Peaks in Fe-Cr-Ni Alloys, Phys. Stat. Sol. (a) 129, 1992, pp. 255262 .

Foldeaki, M.; Ledbetter, H., Magnetic susceptibility of $\mathrm{Pr}_{2} \mathrm{CuO}_{4}$ Monocrystals and Polycrystals, J. Appl. Phys. 70, 1991, pp. 57365738 . 
Foldeaki, M.; Ledbetter, H.; Hidaka, Y., Magnetic Studies of $\operatorname{Pr}_{2-\mathrm{x}} \mathrm{Ce}_{\mathrm{x}} \mathrm{Cu}_{4-\delta}$, Physica C 185-189, 1991, pp. 1127-1128.

Fortunko, C.M.; Petersen, G.L.; Chick, B.B.; Renken, M.C.; Preis, A.L., Absolute Measurements of Elastic-Wave Phase and Group Velocities in Lossy Materials, Rev. Sci. Instrum. 63 (6), June 1992 , pp. 3477-3486.

Fortunko, C.M.; Petersen, G.L.; Chick, B.B.; Renken, M.C., Preis, A.L., Absolute Measurements of Elastic-Wave Phase and Group Velocities in Lossy Materials, in Proc. 1991 Ultrasonics Symposium, B.R. MCAvoy, Ed., IEEE, New York, 1992, pp. 837-843.

Heyliger, P.; Jilani, A.; Ledbetter, H.; Leisure, R.; Wang, C.-Y., Elastic Constants of Isotropic Cylinders Using Resonant Ultrasound, J. Acoust. Soc. Amer., forthcoming.

Hwang, I.S.; Morra, M.M.; Ballinger, R.G.; Nakajima, H.; Tobler, R.L., Charpy Absorbed Energy and $J_{I c}$ as Measures of Cryogenic Fracture Toughness, ASTM J. Testing and Evaluation, Vol. 20, No. 4, July 1992, pp. 248-258.

Kluken, A.O.; McCowan, C.N.; Siewert, T.A., Effect of Inclusion Volume Fraction and Size Distribution on Cryogenic Toughness of Austenitic stainless steel Weld Metals, Microstructural Science (Proc., Intl. Metallographic Soc. meeting), forthcoming.

Kluken, A.O.; Siewert, T.A.; Smith, R., Effects of Copper, Nickel, and Boron on Mechanical Properties of Low-Alloy steel Weld Metals Deposited at High Heat Input, Welding Journal, in review.

Kotecki, D.J.; Siewert, T.A., WRC-1992 Constitution Diagram for Stainless Steel Weld Metals: A Modification of the WRC-1988 Diagram, Welding Journal 71, May 1992, p. 171-s.

Kuziak, R.M.; Cheng, Yi-Wen, Microstructural Evolution in Microalloyed Medium-Carbon Forging Steels during Thermomechanical Processing, Proc., Intl. Conf. on Processing, Microstructure and Properties of Microalloyed and other Modern High Strength Low Alloy Steels, The Iron and Steel Society, Warrendale, PA, 1992, pp. 5164 .

Ledbetter, H.; Lei, M.; Hermann, A.; Sheng, Z., Low-Temperature Elastic Constants of $\mathrm{Y}_{1} \mathrm{Ba}_{2} \mathrm{Cu}_{3} \mathrm{O}_{7}$, Physica $\mathrm{C}$, to be submitted.

Ledbetter, H.; Datta, S., Cast-Iron Elastic Constants: Effect of Graphite Aspect Ratio, Z. Metallk. 83, 1992, pp. 195-198. 
Ledbetter, H.; Fortunko, C., Dynamic Young Modulus of a CeramicAluminum Particle-Reinforced Composite: Measurement and Modeling, Proc., IEEE 1991 Ultrasonics Symposium, (IEEE, New York, 1991) B.R. MCAvoy, Ed., pp. 1065-1067.

Ledbetter, H., Dynamic-static Young Modulus: A Case study, Mater. Sci. Eng., to be submitted.

Ledbetter, H.; Datta, S. Elastic Properties of $\mathrm{Al}_{2} \mathrm{O}_{3} / \mathrm{Al}$ Composites: Measurements and Modeling in Damage and oxidation Protection in High-Temperature Composites, AD-volume 25-2 (ASME, New York, 1991), pp. 83-88.

Ledbetter, H.; Kim, S., Metal-Oxide Debye Temperatures and Elastic Constants: Estimation from Interionic Spacing, J. Phys. Chem. Solids, to be submitted.

Ledbetter, H., A Thermal-Expansion/Thermal-Expansivity Relationship, Intl. J. Thermophys., to be submitted.

Ledbetter, J.; Kim, S.; Roshko, A., Critical-Temperature/DebyeTemperature Correlation in $(\mathrm{La}-\mathrm{M})_{2} \mathrm{CuO}_{4}$ Superconductors, Physica $\mathrm{C}$ 190, 1991, pp. 129-130.

Ledbetter, $\mathrm{H}$. ; Lei, M., Monocrystal Elastic constants of Orthotropic $\mathrm{Y}_{1} \mathrm{Ba}_{2} \mathrm{Cu}_{3} \mathrm{O}_{7}$; An Estimate, J. Mater. Res. 6 , 1991, pp. 2253-2255.

Ledbetter, H.; Kim, S.; Togano, K., Elastic Properties of $\mathrm{Bi}_{2} \mathrm{Sr}_{2} \mathrm{Ca}_{1} \mathrm{Cu}_{2} \mathrm{O}_{8}$ and $\mathrm{Bi}_{2} \mathrm{Sr}_{1.5} \mathrm{Ca}_{1.5} \mathrm{Cu}_{2} \mathrm{O}_{8}$, Physica C 185-189, 1991,

pp. $935-936$.

Ledbetter, H.; Datta, S,; Kriz, R., Elastic Constants of $\gamma-\mathrm{Al}_{2} \mathrm{O}_{3}-$ $\mathrm{SiO}_{2}$ (Fiber)/PEEK Composite: Measurements, Modeling, and Low Temperatures, J. Appl. Phys., to be submitted.

Ledbetter, H., Atomic Frequency and Elastic Constants, Z. Metallk. 82, 1991, pp. 820-822.

Ledbetter, H.; Kim, S.; Roshko, A., Correlation between $\mathrm{T}_{C}$ and Elastic Constants of $(\mathrm{La}-\mathrm{M})_{2} \mathrm{CuO}_{4}, \mathrm{M}=\mathrm{Ca}, \mathrm{Ba}, \mathrm{Sr}, \mathrm{Z}$. Physik $\mathrm{B}$ : Condensed Matter, forthcoming.

Ledbetter, $\mathrm{H}$. Elastic constants of Polycrystalline $\mathrm{Y}_{1} \mathrm{Ba}_{2} \mathrm{Cu}_{3} \mathrm{O}_{\mathrm{x}}, \mathrm{J}$. Mater. Res., forthcoming.

Lei, M.; Ledbetter, H., Oxides and Oxide Superconductors: Elastic and Related Properties, NISTIR 3980, 1991. 
Lin, S.; Lei, M.; Ledbetter, H., Elastic Constants and Debye Temperature of $\mathrm{Y}_{1} \mathrm{Ba}_{2} \mathrm{Cu}_{3} \mathrm{O}_{\mathrm{x}}$ : Effect of oxygen Content, Mater. Lett., forthcoming.

Madigan, R.B.; Quinn, T.P.; Siewert, T.A., Sensing Droplet Detachment and Electrode Extension for Control of Gas Metal Arc Welding, Proc., 3rd Intl. Conf. on Trends in Welding Research, June 1-5, 1992, Gatlinburg, TN.

Masuda-Jindo, K.; Tewary, V.K.; Thomson, R., Theoretical study of Fracture of Brittle Materials: Atomistic Calculations, Materials Science and Engineering, Vol. A146, 1991, p. 273.

Masuda-Jindo, K.; Tewary, V.K.; Thomson, R., Atomic Theory of Fracture of Brittle Materials; Application to Covalent Semiconductors, J. Mater. Res., Vol., 6, 1991, p. 1553.

McCowan, C.N.; Tomer, A.; Drexler, J.W., Microstructure of UltraHigh Nitrogen steels, Microstructural Science, Vol. 19: Structural-Property Relationships and Correlations with the Environmental Degradation of Engineering Materials, D.A. Wheeler, G.W.E. Johnson, D.V. Miley, and M.B. Louthan, Sr., Eds., ASM International, Materials Park, OH, 1992, pp. 681-687.

Mornis, M.A.; Quinn, T.P.; Siewert, T.A.; steel, J.H.P., Sensing of Contact Tube Wear in Gas Metal Arc Welding, NISTIR 3996, September 1992 .

Murray, A.; Fortunko, C.M.; Mecklenburg, M.F.; Green, R.E., Jr., Analysis of Delaminations in Art objects Using Air-Coupled Ultrasound, Proc., Materials Research Soc. Symposium Spring 1992.

Murray, A.; Fortunko, C.M.; Mecklenburg, M.F.; Green R.E., Jr., Evaluation of Delaminations in Art objects Using Air-Coupled Ultrasound, in Materials Issues in Art and Archeology III, J.R. Druzik, G.S. Wheeler, and I. Firestone, Eds., Materials Research Soc., Proc., 267, Pittsburg, 1992, in press.

Murray, A.; Boltz, E.; Fortunko, C.M.; Mecklenburg, M.F.; Green, R.E., Jr., Air-Coupled Ultrasonic system for Nondestructive Evaluation of Wooden Panel Paintings, in Proc. 3rd Int'l. Conf. on Nondestructive Testing, Microanalytical Methods, and Environmental Evaluation for study and Conservation of Works of Art, Siena, 1992, in press.

Nakajima, H.; Yoshida, K.; Tsuji, H.; Tobler, R.L.; Hwang, I.; Morra, M.; Ballinger, R.G., The Charpy Impact Test as an Evaulation of $4 \mathrm{~K}$ Fracture Toughness, Adv. Cryo, Eng., Vol. 38A, 1992,

pp. 207-215. 
Paranthaman, M.; Foldeaki, M.; Balzar, D.; Ledbetter, H. ; Nelson, A.; Hermann, A., Enhanced Flux Pinning via Selective Chemical Substitution in Bulk superconducting Tl-2212, Phys. Rev., to be submitted.

Petersen, G.L.; Chick, B.B.; Fortunko, A Versatile Ultrasonic Measurement system for Flaw Detection and Material Property Characterization in Composite Materials, in Proc. 5th International Symposium on Nondestructive Characterization of Materials, $T$. Kishi, T. Saito, C. Ruud, and R. Green, Jr., Eds., Iketani Science and Technology Foundation, Tokyo, 1992, pp. 847-856.

Purtscher, P.T.; Quantifying the Embrittlement due to sensitization in an Austenitic stainless steel, scripta Metallurgica et Materialia, Vol. 26, 1992, pp. 343-346.

Purtscher, P.T.; Austin, M.; Kim, S.; Rule, D., Aluminum-Lithium Alloys: Surface-Cracked Tension Fracture Tests and Physical and Thermal Properties at Cryogenic Temperatures, NISTIR 3986, March 1992 .

Purtscher, P.T.; Sanders, J.A.; Matlock, D.K.; Krauss, G., Ductile Fracture and Tempered Martensite Embrittlement of 4140 steel, Proc., Iron \& Steel Soc. Conf., Oct. 1992.

Purtscher, P.T.; Cheng, Y. - W., structure-Property Relationships in Microalloyed Ferrite-Pearlite steels Phase 1: Literature Review, Research Plan, and Initial Results, NISTIR 3992, to be published.

Purtscher, P.T.; Cheng, Y.-W., Microstructure and Tensile Properties of Microalloyed SAE 1141 Forgings, to be published in the Proc. of the 34 th Mechanical Working and steel Processing Conf., Oct. 24-26, 1992, Montreal, Canada.

Purtscher, P.T.; Mccolskey, J.D.; Drexler, E.S., Aluminum-Lithium Alloys: Evaluation of Fracture Toughness by Two Test standards, ASTM E813 and E1304, accepted for publication in ASTM STP 1172, American Society for Testing and Materials, Philadelphia, PA.

Purtscher, P.T.; Drexler, E.S.; Through-Thickness Mechanical Properties of High-strength Aluminum Alloy Plates for Cyrogenic Applications, Proc., Light-weight Alloys for Aerospace Applications II, W. Lee and N.J. Kim, Eds., The Minerals, Metals, and Materials Society, Warrendale, PA, 1991, pp. 65-75.

Quinn, T.P., Dynamic Model of Electrode Extension for Gas Metal Arc Welding, Proc., 3rd Int. Conf. on Trends in Welding Res., June 1-5, 1992, Gatlinburg, TN, and Granjon Paper Competition, Intl. Inst. Welding.

Quinn, T.P.; Madigan, R.B.; Siewert, T.A., An Electrode Extension Model for Gas Metal Arc Welding, submitted to Welding Journal. 
Read, D.T.; Dally, J.W., A New Method for Measuring the Constitutive Properties of Thin Films, J. Mater. Res., forthcoming.

Read, D.T.; Dally, J.W., E-Beam Moire study of Fracture of a GFRP Composite, J. Appl. Mech., forthcoming.

Read, D.T.; Dally, J.W., Fatigue Behavior of Aluminum Thin Film under Cyclic Axial Stress, J. Electronic Packaging, forthcoming.

Read, D.T., In-Situ Measurements of Strength and Ductility of Thin Films, Joint ASME-JSME Symposium on Electronic Packaging, April 1992 .

Read, D.T.; Dally, J.W.; Szanto, M., Scanning Moire at High Magnification Using Optical Methods, Experimental Mechanics, forthcoming.

Read, D.T.; Lucey, G.K., Automated Finite Element Mesh Generation for SMT Solder Joints, J. Electronic Packaging, Volume 113, June, 1991, pp. 178-185.

Read, D.T.; Pfuff, M., Potential Drop in the Center-Cracked Panel with Asymmetric Crack Extention, Int., J. Fracture, Vol. 48, No. 3, 1991, pp. 219-229.

Reed, R.P.; McCowan, C.N.; Simon, N.J.; McColskey, J.D., Deformation and Fracture Characteristics of Al-Li Alloys in LOX Mechanical-Impact Tests, Adv. Cryo. Eng. -Mater., Vol. 38A, F.R. Fickett and R.P. Reed, Eds., 1992, pp. 19-28.

Schramm, R.E.; Clark, A.V.; McGuire, T.J.; Filla, B.J.; Mitrakovic, D.V.; Purtscher, P.T., Noncontact Ultrasonic Inspection of Train Rails for Stress, Proc. Intl. Conf. on Rail Quality and Maintenance for Modern Railway Operations, June 24-26, 1992, Delft, The Netherlands.

Schramm, R.E.; Clark, A.V., Jr.; McGuire, T.J., Ultrasonic Measurement of Residual Stress in Railroad wheel Rims, Proc., 10th Intl. Wheelset Congress, Sept. 27-Oct. 1, 1992, Sydney, Australia, The Institution of Engineers, Australia, 11 National circuit, Barton, ACT, National Conference Publication No. 92/10, pp. 151155 .

Shepherd, D.A.; Siewert, T.A., Precision and Bias in Charpy V-Notch Testing (ASTM Standard Test Method E-23), ASTM Research Report, American Society for Testing Materials, Philadelphia, 1992.

Shiloh, K.; Bond, L.J.; and Som, A.K., Detection Limits for Single Small Flaws and Groups of Flaws When Using Focused Ultrasonic Transducers, Ultrasonics, in press. 
Siewert, T.A.; McCowan, C.N.; Polansky, D.; Jones, T.S., Quantitative Evaluation of Distributed Pores in Reference Radiographs, welding Journal, forthcoming.

Siewert, T.A., Status Report: AWS Standards for Identifying Arc Welds (A9.1) and Recording Weld Data (A9.2), Proc., AWS Conf. on Computerization of Welding Data, in press.

Siewert, T.A.; Madigan, R.B.; Quinn, T.; Mornis, M.A., Through-theArc sensing for Real-Time Measurement of Gas Metal Arc Weld Quality, Proc., AWS Conf. on Computerizations of Welding Data, Miami, Florida, 1992.

Siewert, T.A.; Madigan, R.B.; Quinn, T.P.; Mornis, M.A., Throughthe-Arc Sensing for Control of GMAW, Proc., 1992 ASM Conf. on Trends in Welding Research, Gatlinburg, TN.

Siewert, T.A.; McCowan, C.N., Welding for Cryogenic Service, Chapter in ASM Metals Handbook, 10th Ed., forthcoming.

Siewert, T.A.; Austin, M.W.; Lucey, G.K.; Plott, M.J., Evaluation and Qualification standards for an X-ray Laminography system, Materials Evaluation, 50, September 1992, p. 1027.

Siewert, T.A., Report on 1991 Actions by International institute of Welding, materials Evaluation, 50, March 1992, p. 422.

Siewert, T.A.; Austin, M.W., An X-ray Image Quality Indicator Designed for Easy Alignment, Materials Evaluation, 50, September 1992 , p. 1069.

Siewert, T.A.; McCowan, C.N., Joining of Austenitic Stainless Steels for Cryogenic Applications, Advances in Cryogenic Engineering - Materials, 38, Plenum Press, NY, 1992, p. 109.

Siewert, T.A.; Fitting, D.W.; Austin, M.W., A Rotationally symmetric Image Quality Indicator for Digital X-Ray Imaging Systems, Materials Evaluation, 50, March 1992, p. 360.

Siewert, T.A.; McCowan, C.N.; Olson, D.L., Ferrite number prediction for stainless steel welds, Key Engineering Materials, Vols. 69 \& 70, Trans. Tech. Publications, Switzerland, 1992, p. 149 .

Siewert, T.A.; MCCowan, C.N., Development of an SMA Electrode to Match Type 316LN Base Metal Cryogenic Properties, Cryogenics, 31, sept. 1991, p. 775.

Siewert, T.A., standard Formats for Welding property Data, Proceedings of Computerization of welding Information-III, Ypsilanti, MI, September 12-14, 1990, American Welding Society, Miami, FL., 1992. 
Simon, N.J.; Drexler, E.S.; Reed, R.P., Properties of Copper and Copper Alloys at Cryogenic Temperatures, NIST MN 177, 1992, 850 pp.

Simon, N.J.; Reed, R.P.; Walsh, R.P., Compression and Shear Tests on Vacuum-Impregnated Composites at Cryogenic Temperatures, Adv. Cryo. Eng. (Mater.), Vol. 38, 1992, pp. 363-370.

Simon, N.J.; Reed, R.P., Temperature Increases in Aluminum Alloys During Mechanical-Impact Tests for oxygen compatibility, Flammability and Sensitivity of Materials in oxygen Enriched Atmospheres: Vol, 5, ASTM STP 1111, J.M. Stoltzfus and K. McIlroy, Eds., Amer. Soc. for Testing and Mater., Phil., 1991, pp. 367-380.

Simon, N.J.; McColskey, J.D.; Reed, R.P.; Garcia-Salcendo, C.M., Reaction Sensitivities of Al-Li Alloys and Alloy 2219 in Mechanical-Impact Tests, Flammability and Sensitivity of Materials in Oxygen-Enriched Atmospheres: Vol. 5, ASTM STP 1111. Joel M. Stoltzfus and K. McIlroy, Eds., Amer. Soc. for Testing and Mater., Phil., 1991, pp. 193-215.

Simon, N.J.; Drexler, E.S.; Reed, R.P., Review of Cryogenic Mechanical and Thermal Properties of Al-Li Alloys and Alloy 2219, NISTIR 3972, 1991, 191 pp.

Slifka, A.J.; Compos, R.; Wei, R.; Wilbur, P.; Chaudhuri, D.K., Tribological Behavior of $440 \mathrm{C} / \mathrm{Diamond}-\mathrm{Like-Carbon}$ Film Couples, Adv. Earth-to-Orbit Propulsion Tech. Conf., NASA/MSFC, Huntsville, AL, May 19-21, 1992, NASA Conference Publication 3174, Vol. II, 1992 , pp. 398-403.

Slifka, A.J.; Morgan, T.J.; Compos, R.; Chaudhuri, D.K., Wear Mechanism Maps of $400 \mathrm{C}$ Martensitic stainless steel, Proc., Wear of Materials Conf., April 13-17, 1992, San Francisco, CA.

Slifka, A.J.; Siegwarth, J.D.; Chaudhuri, D.K.; Compos, R., A Tribometer for Measurements in Hostile Environments, submitted to The Journal of Tribology.

Szanto, M.; Dally, J.W.; Read, D.T., A Grid-Moire Hybrid Method for Measuring Strain and Displacement, opt. Eng., forthcoming.

Szanto, M.; Read, D.T., Application of the J-Integral to StressStrain Concentrations, Engineering Fracture Mechanics, Vol. 43 , No. 3, pp. 401-415.

Tewary, V.K., A Model for Phonons and Rotational Excitations in Solid $\mathrm{C}_{60}$, Phys. Rev. Lett., submitted. 
Tewary, V.K.; Thomson, R., Interfacial cracks in Composite Materials, "Materials Modeling - From Theory to Technology", C.A. English, J.R. Matthews, and A.M. Stoneham, Eds., Institute of Physics, Bristol, U.K., 1992, p. 167.

Tewary, V.K.; Kriz, R.D., Green's Function Method for Calculation of stress Fields in Composite Materials, "Local Mechanics Concepts for Composite Materials systems," J.N. Reddy and K.L. Reifsnider. Eds., Publisher Springer-Verlag (Berlin), 1992, p. 341.

Tewary, V.K.; Fortunko, C.M., A Computationally Efficient Representation for Elastic Wave Propagation in Anisotropic Solids, J. Acoust. Soc. Amer., Vol. 91 (4) Pt. 1, April 1992, pp. 18881896.

Tewary, V.K., Elastic Green's Function for a Bimaterial Composite Solid Containing a Free Surface Normal to the Interface, J. Mater. Res., Vol 6, 1991, p. 2592.

Tewary, V.K., Green's Function for Generalized Hilbert Problem for Cracks and Free Surfaces in Composite Materials, J. Mater. Res., Vol. 6, 1991, p. 2585 .

Tewary, V.K.; Kriz, R.D., Generalized Plane strain Analysis of a Bimaterial Composite containing a Free surface Normal to the Interface, J. Mater. Res., Vol 6, 1991, p. 2609.

Tewary, V.K.; Kriz, R.D., stress Distribution in a Bimaterial Composite Containing a Free Surface, Modern Theory of Anisotropic Elasticity and Applications, J.J. Wu, T.C.T. Ting, and D.M. Barnett, Eds., Publisher SIAM, Philadelphia, 1991, p. 74 .

Tewary, V.K. and Thomson, R.M., Lattic Statics of Interfaces and Interfacial Cracks in Bimaterial solids, J. Mater. Res., Vol. 7, 1992 , p. 1018 .

Thomson, R.; Zhou, S.J.; Carlsson, A.E.; Tewary, V.K., Lattice Imperfections studied by use of Lattice Green's Function, Physical Review, forthcoming.

Tobler, R.L.; Ma, L.M.; Reed, R.P., Mechanical Properties and Warm Prestress of Ultra-Low Carbon steel at $4 \mathrm{~K}$, Proc., Intl. Industrial symp. on the super Collider, in supercollider III, Plenum Press, New York, 1992, pp. 139-146.

Tobler, R.L., ; Bussiba, A.; Guzzo, J.F.; Hwang, I.S., Charpy Specimen Tests at 4 K, Adv. Cryo. Eng., Vol. 38A, 1992, pp. 217224.

Tobler, R.L.; Berger, J.R.; Bussiba, A., Long-Crack Fatigue Thresholds and Short Crack Simulation at Liquid Helium Temperature, Adv. Cryo. Eng., Vol. 38A, 1992, pp. 159-166. 
Walsh, R.P.; Reed, R.P.; McColskey, J.D.; Tupper, M.; Johnson, E., Large scale Tests of composite support struts for superconducting Magnetic Energy Storage Rings, Adv. Cryogenic Engineering Materials, Vol. 38A, 1992, pp. 421-428.

Weller, M.; Ledbetter, H., Temperature-Dependent Young Modulus of an $\mathrm{SiC}_{\mathrm{w}} / \mathrm{Al}_{2} \mathrm{O}_{3}$ Composite, J. Mater. Sci., to be submitted.

Zhu, H,; Bond, L.J.; Albach, P.H., Experimental Investigation of Rayleigh wave Generation at surface Pit with Compression wave Incidence, Ultrasonics International '91, France, ButterworthHeinemann (Guildford), 1992, pp. 239-242. 


\section{SELECTED TECHNICAL AND PROFESSIONAL COMMITTEE LEADERSHIP}

American Society for Testing and Materials

C16.30: Thermal Measurements of Thermal Insulation Materials

D.R. Smith, Task Group Chairman

E24 : Fracture Testing of Metals

D.T. Read

J.D. McColskey

E28.07: Impact Testing

C.N. McCowan, Chairman

E28.10.02:Temperature Effects

R.L. Tobler, Task Group Leader

G04 : Compatibility and Sensitivity of Materials in oxygen Enriched Atmospheres

J.W. Bransford

American Welding Society

Board of Directors

T.A. Siewert, Director at Large

Welding Journal

H.I. McHenry, Reviewer

T.A. Siewert, Key Reviewer

Computerization of Welding Information Committee

T.A. Siewert, Vice Chairman

International Institute of Welding

Commission $V$ on Nondestructive Evaluation

T.A. Siewert, U.S. Delegate

study Group 212 on Arc Physics

T.A. Siewert, U.S. Delegate

Metallurgical society

Metallurgical Transactions

H. Ledbetter

Welding Research Council

Materials and Welding Procedures subcommittee

T.A. Siewert

University Research Committee

T.A. Siewert 


\section{AWARDS}

Materials Reliability Division staff received the following awards in FY 1992:

\section{Bronze Medals}

Thomas siewert

For developing a materials research program that contributes to the quality, reliability, and safety of welded structures (1991).

David Read

for developing a fracture mechanics approach to assess the reliability of electronic packages (1991).

\section{Safety Award}

Daniel Vigliotti For leadership of the safety program in the Materials Reliability Division (1991).

\section{Measurement Service Award}

Dominique Shepherd For successful implementation of the Thomas siewert Daniel Vigliotti certification program for charpy impact test machines (1991). 
A. Van Clark, Jr.

Christopher M. Fortunko

Timothy P. Quinn

Thomas A. Siewert

Thomas A. Siewert Mark w. Austin

Vinod K. Tewary

Ralph L. Tobler
Received an Award of Merit from the Federal Laboratory Consortium for Technology Transfer for his collaboration with Iowa State University on ultrasonic measurement of sheet steel formability.

Appointed Fellow by Courtesy in the Department of Materials Science and Engineering at the Johns Hopkins University.

Received the Hetenyi Award from the Society for Experimental Mechanics for the outstanding Paper in the Journal of Experimental Mechanics.

Received a Certificate of Appreciation from the American Sociery for Testing Materials, Committee E28, for his contributions to impact testing standards.

Received the first place award from the American Welding Society for their poster presentation "Monitoring Solder Joint Quality in Circuit Boards."

Received the Pride of India Award from the Bochasanwasi Swaminarayan Sanstha for contributions in the field of computational materials science.

Received a doctoral degree from Tohoku University in Japan for his research and dissertation entitled "Fracture Mechanics at Liquid Helium Temperatures: Property Measurements and Prestandards Research." 


\section{INDUSTRIAL AND ACADEMIC INTERACTIONS}

\section{Industrial Interactions}

AC Rochester

The Structural Materials Group extended its CRDA with the ACR Division of General Motors. ACR is adapting our welding arc sensor technology for application on their production lines.

Alcoa

P.T. Purtscher collaborates with Alcoa to evaluate the metallurgical and mechanical properties of Al-Li alloys.

Battelle Columbus Laboratories

H. Ledbetter collaborates with E. Collings on Ti-Al alloy elastic constants.

Bechtel

The Structural Materials Group is conducting large-scale tests on composite materials for use in the superconducting magnetic energy storage system.

Chrysler corporation

Yi-Wen cheng is working with Chrysler Motors Corporation to develop the metallurgical data needed for the direct forging of microalloyed bar steels.

Comalco

$\mathrm{H}$. Ledbetter collaborates with $\mathrm{K}$. Xia on the elastic constants of $\mathrm{Al}_{2} \mathrm{O}_{3}-\mathrm{mullite} / \mathrm{Al}$.

Composite Technology Development, Inc.

N.J. Simon and others in the structural Materials Group are developing new test methods and screening radiation-resistant insulation for superconducting magnets. D. Rule is measuring thermal conductivities of materials supplied by CTD, Inc. The interaction has been formalized in a CRDA.

Ford Motor Company

A.V. clark is working with Ford on the simulation of ultrasonic measurement of formability in a continuous annealing line. 
General Atomics

The Structural Materials Group is conducting large-scale tests on composite materials for use in the superconducting magnetic energy storage system.

General Electric

T.A. Siewert is working with the Aircraft Engines Department of General Electric and the Army Materials Technology Laboratory to develop a military standard for radioscopic inspection.

Hercules

D.W. Fitting and C.M. Fortunko are working with Hercules on ultrasonic techniques for nondestructive evaluation of composites.

Hewlett Packard

R.P. Walsh and J.W. Dally (IPA) used experimental mechanic techniques to assist $H P$ engineers in the solution of a materials reliability problem.

Hitachi (Japan)

H. Ledbetter collaborates with H. Tsuiki on elastic constants of $\mathrm{Bi}-\mathrm{O}$ monocrystal superconductors.

H. Ledbetter collatorates with S.-P. Matsuda on elastic constants of $\mathrm{Tl}-\mathrm{O}$ superconductors.

International Copper Association, Ltd.

N.J. Simon and E.S. Drexler cooperated with ICA to develop the database for copper and produced a monograph describing the cryogenic properties in 1992. ICA will produce a computerized version of the database.

Kobe steel, Itd.

R.I. Tobler is collaborating with M. Shimada in studies of mechanical test variables affecting the measurement of fracture mechanics parameters for steels at liquid helium temperature.

Lockheed

C. M. Fortunko is working with Lockheed to develop a new standard test block to calibrate transducers used to inspect composite materials. 
The Structural Materials Group is working with Lockheed on the analysis of failed composite support struts for SMES.

Luckens steel

Yi-Wen Cheng and Harry McHenry are working with Lukens Steel to qualify thermomechanically processed steels for use in Naval shipbuilding.

Martin Marietta

The structural Materials Group is generating and compiling mechanical property data on a new Al-Li alloy.

D.R. Smith measured the thermal conductivity of CFC-free insulating materials intended for cryogenic fuels tanks.

Materials Research and Engineering

The structural Materials Group transfers measurement technology to this company for evaluating materials at cryogenic temperatures.

NTT

H. Ledbetter collaborates with $Y$. Hidaka on oxidesuperconductor elastic constants, monocrystal and polycrystal.

H. Ledbetter collatorates with $\mathrm{K}$. Kinoshita on La-Osuperconductor elastic constants.

Omega Marine International

J.D. McColskey participates on the Joint Industrial Program to evaluate the prospects of using aramid rope as mooring line for deepwater, offshore oil well platforms.

Oregon Steel Mills

R.L. Tobler collaborated with $K$. Manton to conduct and evaluate round-robin tensile tests on linepipe steel according to ASTM standards.

Precision Acoustic Devices (PAD), Inc.

C. M. Fortunko is collaborating with PAD in the development of an air-coupled ultrasonic instrument for the nondestructive evaluation of composite materials. 
Reynolds Metals

The Structural Materials Group is collaborating with Reynolds to evaluate the metallurgical and mechanical properties of Al-Li alloys.

\section{Academic Interactions}

Atominstitut der Osterreichen Universitaten, Vienna

N.J. Simon cooperates with H.W. Weber in studies of the properties of irraidated composites and activation of structural alloys for fusion reactors.

Brigham Young University

H. Ledbetter collaborates with B. Adams on elasticconstants/texture relationships.

Colorado School of Mines

T.A. Siewert is an Adjunct Professor of Metallurgy.

T.A. Siewert is working with S. Liu in the study of droplet transfer in the welding arc.

A.V. Clark collaborates with D. Matlock on texture and formability research using ultrasonics.

Y.W. Cheng works with C. Van Tyne and G. Krauss on the thermomechanical processing of steel.

P.T. Purtscher works with Drs. G. Krauss and D. Matlock on the characterization of the mechanical properties of austenitic stainless steels.

Colorado State University

H. Ledbetter collaborates wtih P. Heyliger (Civil Engineering) in studying the natural resonances of regular-shape solids.

H. Ledbetter collaborates with R. Leisure (Physics) on ultrasound resonance spectroscopy.

A. Slifka collaborates with $R$. Wei and $P$. Wilbur on the preparation and evaluation of DLC films. 
Davidson college

H. Ledbetter collaborates with L. Cain (Physics) on austenitic-steel elastic constants.

Indian Institute of Technology (Madras)

H. Ledbetter collaborates with R. Rao (Physics) on higherorder elastic constants.

Institute of Metal Research (Shenyang, China)

H. Ledbetter collaborates with Y. Li in studying austeniticsteel elastic constants.

Institute of Metallurgy, ETH (Zurich)

H. Ledbetter collaborates with P. Uggowitzer in studying austenitic-steel elastic constants and magnetic properties.

Iowa State University: Center for Advanced NDE, Ames Laboratories A.V. Clark collaborates with R.B. Thompson on texture and formability using ultrasonics.

C.M. Fortunko serves as a NIST representative to the center for Nondestructive Evaluation.

Johns Hopkins University

C.M. Fortunko collaborates with R.E. Green on the nondestructive characterization of materials.

Konan University (Kobe, Japan)

H. Ledbetter collaborates with N. Nakanishi (Chemistry) on oxide elastic constants.

Massachusetts Institute of Technology

R.L. Tobler collaborates with I.S. Hwang of the Materials Sciences Department in the evaluation of nickel-base superconductor sheath alloys for applications at $4 \mathrm{~K}$.

Max-Planck-Institut für Metallforschung (Stuttgart, Germany)

H. Ledbetter collaborates with M. Weller to study the internal friction and dielectric constants of various materials. 
Ohio State University

Vinod Tewary of Ohio state is a guest scientist working with C.M. Fortunko on modelling wave propagation in composite materials

Osaka University

H. Ledbetter collaborates with Y. Tsunoda (Physics) to study $\mathrm{Cu}(\mathrm{Fe})$ elastic constants.

A.V. Clark works with H. Fukuoka and M. Hirao on the development of ultrasonic measurement techniques for determining residual stress and texture.

Princeton University

D.L. Rule measured the thermal conductivity of Be-Cu alloys for the Princeton Plasma Physics Laboratory.

Stanford University

A.V. Clark and S.R. Schaps collaborate with B.A. Auld on capacitive array research.

C. M. Fortunko is collaborating with Professor B.T. Kuri-Yakub on the development of air-coupled ultrasonic transducers.

J.D. Mccolskey collaborates with G. Springer in the development of optimum lay-up angles for maximizing the compressive axial strengths of E-glass-epoxy composite support tubes.

Technischen Universitat, Munich

N.J. Simon and others of the Structural Materials Group cooperate with $\mathrm{H}$. Gerstenberg to develop in-situ 4-K shearcompression tests for superconducting magnet insulation after irradiation at the Munich Research Reactor.

Tennessee State University

A. Slifka collaborates with D.K. Chaudhuri on the tribological behavior of ion-implanted and ion-deposited materials.

Tohoku University

H. Ledbetter collaborates with Y. Shindo (Materials Processing Department) on waves in composites. 
R.L. Tobler interacts with Dr. H. Takahashi of the Research Institute for Fracture Technology to document fracture mechanics test procedures for structural alloys at $4 \mathrm{~K}$.

Tsinghua University (Beijing, China)

H. Ledbetter continues studies with $Y$. He (Physics) on oxide superconductor elastic constants.

University of Arkansas

H. Ledbetter collaborates with Z. Sheng (Physics) on oxidesuperconductor elastic constants.

University of Belgrade

D. Mitraković was a guest researcher at NIST in the Nondestructive Evaluation Group, working on instrumentation for inspecting railroad wheels.

Unviersity of California

H. Ledbetter collaborates with R. Fisher in studying oxidesuperconductor specific heats.

University of Colorado

H. Ledbetter is an Adjunct Professor in the Department of Mechanical Engineering and member of the graduate faculty.

H. Ledbetter collaborates with $S$. Datta (Mechanical Engineering) on problems of waves in composites.

H. Ledbetter collaborates with M. Foldeaki (Physics) on magnetic properties of alloys and oxide superconductors.

H. Ledbetter collaborates with Professor A. Hermann (Physics) on oxide-superconductor elastjc constants.

D.T. Read interacts with R. May (Electrical Engineering) on use of CU's electronic microfabrication facilities.

C.M. McCowan interacts with J. Drexler (Geology) on the use of CU's microanalytical facilities.

University of Geneva

H. Ledbetter continues studies with B. Seeber on the elastic constants of Chevrel-phase superconductors. 
University of Hawaii

H. Ledbetter collaborates with M. Manghnani (Geophysics) to study pressure dependence of elastic constants of oxide superconductors.

University of Illinois (Urbana)

H. Ledbetter collaborates with W. Kriven (Materials Science) on ceramic elastic constants.

University of Maryland

Professor J.W. Dally works with D.T. Read on high resolution experimental mechanics and thin film testing.

University of Michigan

D.W. Fitting collaborates with researchers at the University of Michigan on the development of silicon-based acoustical arrays.

University of South Carolina

H. Ledbetter collaborates with R. Edge (Physics) on elastic and magnetic properties of $\mathrm{Fe}-\mathrm{Cr}-\mathrm{Ni}$ alluys.

H. Ledbetter collaborates with T. Datta (Physics) on magnetic properties: steels and superconductors.

University of stuttgart (Germany)

H. Ledbetter collaborates with B. Gairola (Institute for Theoretical and Applied Physics) on graphite-fiber elastic constants.

H. Ledbetter collaborates with E. Kröner (Institute for Theoretical and Applied Physics) on monocrystal-polycrystal elastic constants.

University of Tsukuba (Japan)

H. Ledbetter collaborates with T. Suzuki (Applied Physics) on elastic constants and phase transitions.

H. Ledbetter collaborates with K. Otsuka (Materials Science) on the elastic constants of the monocrystal shape-memory alloy $\mathrm{Cu}-\mathrm{Al}-\mathrm{Ni}$.

H. Ledbetter collaborates with $M$. Saito (Engineering Mechanics) on elastic constants of technical solids. 
H. Ledbetter collaborates with M. Uwe (Materials Science) on elastic properties of barium-bismuthate superconductors.

Univeristy of Washington

H. Ledbetter collaborates with M. Taya (Mechanical Engineering) on composite-material elastic constants.

Unviersity of Zagreb

H. Ledbetter collaborates with D. Balzar (Metallurgy) on defect properties of oxide superconductors.

Virginia Polytechnic Institute and state University

J.D. McColskey collaborates with M. Hyer in analysis of structural composite support tubes for superconducting magnetic energy storage rings. 


\section{APPENDIX}


MATERIALS RELIABILITY DIV.

H.I. McHenry, Chief

C.M. Fortunko, Deputy Chief

K. S. Sherlock

Administrative officer
H. M. Quartemont Division Secretary
.05 Materials Characterization

C.M. Fortunko

D.T. Lewis-Sec'y .

J.R. Berger

E.S. Boltz

D.W. Fitting

M.A. Hamstad

S.A. Kim

H.M. Ledbetter

I.H. Lin

D.T. Read

R.L. Santoyo

Guest Researchers

D. Balzar

L.J. Bond

J.W. Dally

M Foldeaki

o. Lee

M. Mohapatra

M. Szanto

V.K. Tewary

Students

M.C. Renken
Y-W. Cheng

P.T. Purtscher

S.R. Schaps

R.E. Schramm

Guest Researchers

M. Lozev

Students

D.M. Serna

\section{.07 structural Materials T.A. Siewert}

V.E. CiaranelloSec'y.

M.W. Austin

R.B. Madigan

C.N. McCowan

T.P. Quinn

D.A. Shepherd

D.P. Vigliotti

S. Yukawa

Guest Researchers

A. Kluken
.07 Structural Materials

L.L. Sparks

P.K. Wright-Sec'y.

J.W. Bransford

E.S. Drexler

W.P. Dube

B.J. Filla

J.D. McColskey

D.L. Rule

N.J. Simon

A.J. Slifka

D.R. Smith

R.L. Tobler

R.P. Walsh

Contractor

R.P. Reed

Students

D.M. Mason 


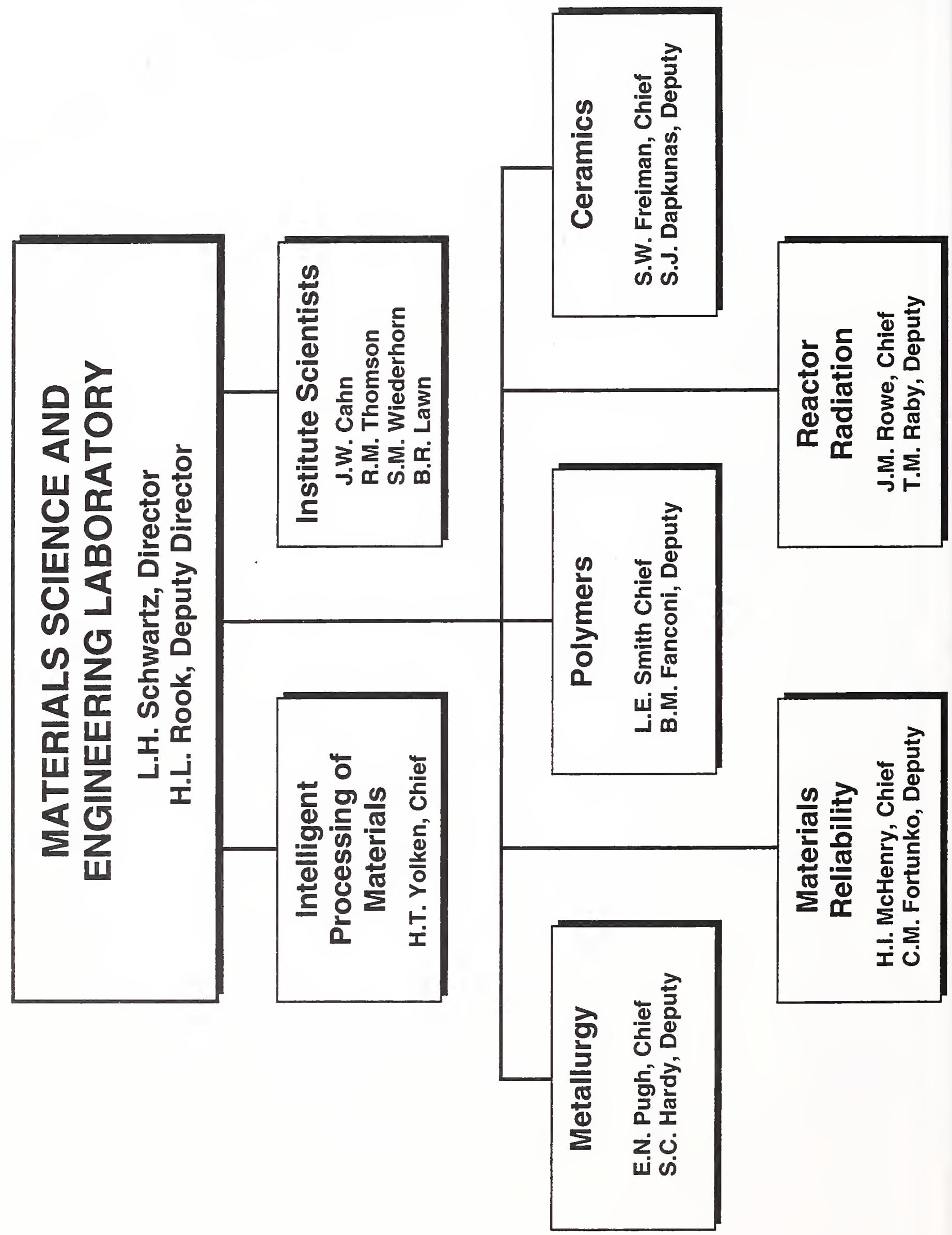




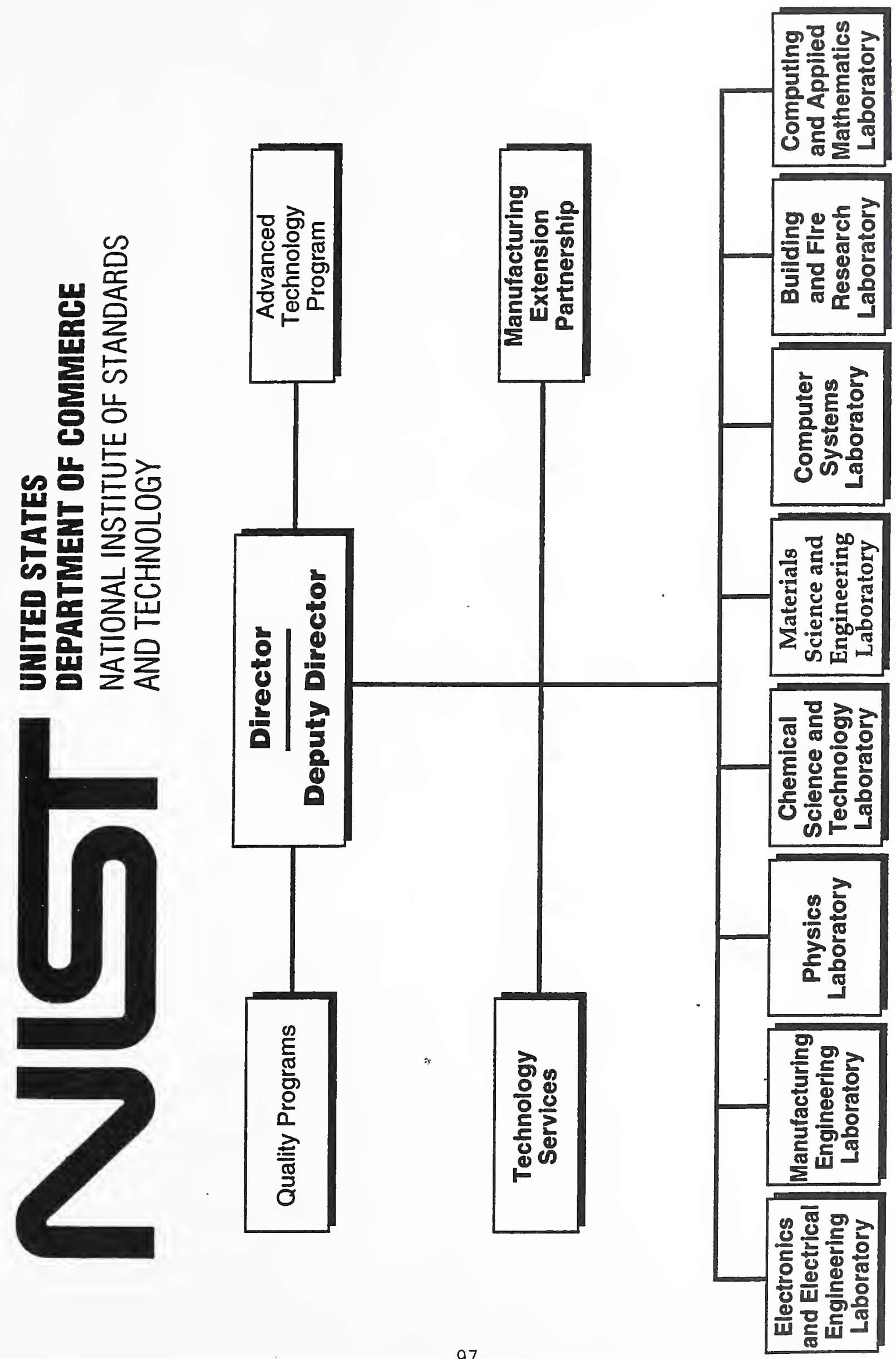



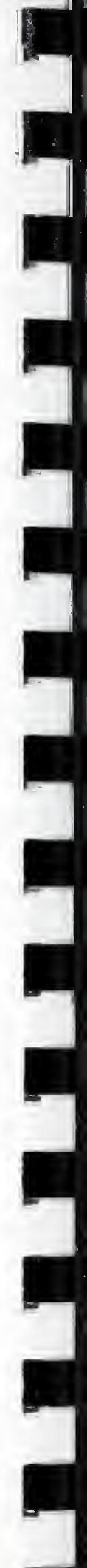

